\title{
Decoupling of Iron and Phosphate in the Global Ocean
}

by

\author{
Payal Parekh
}

B.S., University of Michigan, 1995

Submitted in partial fulfillment of the requirements for the degree of

Doctor of Philosophy

at the
MASSACHUSETTS INSTITUTE OF TECHNOLOGY
and the

WOODS HOLE OCEANOGRAPHIC INSTITUTION

June 2003

(C) Massachusetts Institute of Technology 2003. All rights reserved.

Author

Joint Program in Oceanography/Applied Ocean Science and Engineering May 2, 2003

Certified by

John C. Marshall Professor

Thesis Supervisor

Certified by

Edward A. Boyle

Professor

Thesis Supervisor

Accepted by ...

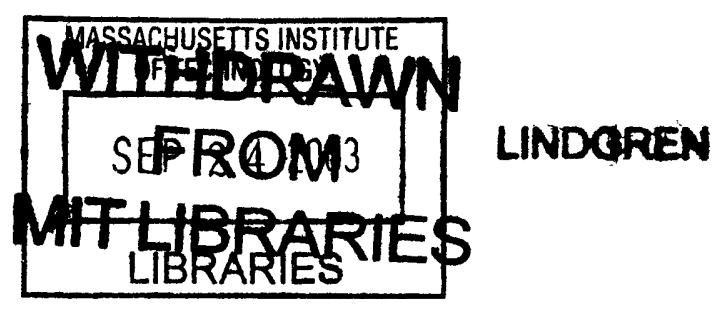


$+;$ 


\title{
Decoupling of Iron and Phosphate \\ in the Global Ocean
}

by

\author{
Payal Parekh
}

Submitted to the Joint Program in Oceanography/Applied Ocean Science and

Engineering

on May 2, 2003, in partial fulfillment of the

requirements for the degree of

Doctor of Philosophy

\begin{abstract}
Iron $(\mathrm{Fe})$ is an essential micronutrient for marine phytoplankton often limiting phytoplankton growth due to its low concentration in the ocean and thus playing a role in modulating the ocean's biological pump. In order to understand controls on global Fe distribution, the decoupling between $\mathrm{Fe}$ and $\mathrm{PO}_{4}$ and the sensitivity of surface nutrient concentrations to changes in aeolian iron supply, I use a hierarchy of ocean circulation and biogeochemistry models.

I formulate a mechanistic model of iron cycling which includes scavenging onto sinking particles and complexation with an organic ligand. The iron cycle is coupled to a model of the phosphorus cycle. The aeolian source of iron is prescribed. This system is examined in the context of a highly idealized box model. With appropriate choice of parameter values, the model can be brought into consistency with the relatively sparse ocean observations of iron in the oceans.

I implement this biogeochemical scheme in a coarse resolution ocean general circulation model, guided by the box model sensitivity studies. This model is also able to reproduce the broad regional patterns of iron and phosphorus. In particular, the high macro-nutrient concentrations of the Southern Oceans result from iron limitation in the model.

I define a tracer, $\mathrm{Fe}^{*}$ that quantifies the degree to which a water mass is iron limited. Surface waters in high nutrient, low chlorophyll regions have negative $\mathrm{Fe}^{*}$ values, indicating Fe limitation, because aeolian surface dust flux is not sufficient to compensate for the lack of iron in upwelled waters.

The oceanic residence time of $\mathrm{Fe}$ is $\sim 285$ years in the model, confirming that transport plays an important role in controlling deep water $\left[\mathrm{Fe}_{T}\right]$. Globally, upwelling accounts for $40 \%$ of 'new' iron reaching the euphotic zone.

Due to the potential ability of iron to change the efficiency of the carbon pump
\end{abstract}


in the remote Southern Ocean, I study Southern Ocean surface $\mathrm{PO}_{4}$ response to increased aeolian dust flux. My box model results suggest that a global ten fold increase in dust flux can support a $\mathrm{PO}_{4}$ drawdown of $\sim 0.25 \mu \mathrm{M}$, while the GCM results suggest a $\mathrm{PO}_{4}$ drawdown of $0.5 \mu \mathrm{M}$.

Thesis Supervisor: John C. Marshall Title: Professor

Thesis Supervisor: Edward A. Boyle

Title: Professor 


\section{Acknowledgments}

"The ocean is a place of paradoxes."

Rachel Carson

My path toward a doctoral degree can hardly be considered direct. There were many dead ends; finding the 'right' question to focus on was an arduous task. At various times I followed roads that led me far astray from my research and during my third year even decided to leave, only to be convinced to continue by John Marshall. At various times, I felt as if I were hitting my head against a wall and the end to the thesis would never be in sight. Then suddenly, the work started coming together and research became easier and fun. That is when I knew my life as an apprentice (aka doctoral student) was coming to an end. Now six years later, after working on two different projects with two different advisors, I am able to reflect on my time as a student. Additionally, as any doctoral student learns, a Ph.D. is due to the collaborative effort of many different people.

Having entered MIT with a background in sedimentary field geology and geochemistry, I never envisioned that I would write a modeling thesis. I would like to thank David Glover for developing and teaching the 'Modeling, Data Analysis and Numerical Techniques for Geochemistry' course at WHOI. It has been the best class I took during my graduate career and introduced me to biogeochemical modeling, a field that I did not even know existed prior to taking this course. I appreciate Dave's assistance with research during the early years of my $\mathrm{Ph} . \mathrm{D}$. work, his positive attitude and friendly demeanor.

I owe a big thanks to my advisor 'Papa John' Marshall for encouraging me to continue when I wanted to quit. He believed in my abilities when I did not myself. Although my thesis work is far from John's area of expertise, he fully supported my work. In fact, I think John and I have had more political discussions than oceanographic discussions! Despite our very different outlooks on the world, we found a way 
to respect each other's opinions. I will miss our crazy conversations on the 15th floor of the Green building.

I thank Ed Boyle for offering to be my co-advisor, so I could stay in the chemical oceanography program. Ed has been very patient with all of my questions regarding analytical techniques for measuring iron. He has also made his unpublished data available to me for model comparison.

Working with Mick Follows, my unofficial advisor, has been sheer joy. His unassuming manner is to be admired. Even when my research was not going well, he always ended our meetings on a positive note, leaving me with a few words of encouragement. After hashing out ideas on the whiteboard in Mick's office, I always left excited about exploring a new idea.

Jim Moffett and Mike Bacon, my committee members from WHOI, have provided meaningful insights at critical junctures. I appreciate their interest in my work and willingness to travel to MIT for committee meetings.

Although Tina Voelker was not on my committee, she provided me with many helpful comments during the early stages of my thesis. She also shared her insights on being a woman in science and the importance of balancing life and work. I thank her for being such a great mentor and role model.

Some of the most interesting conversations about ocean biogeochemistry occurred in the company of Taka Ito and Stephanie Dutkiewicz. I thank them for their insights, enthusiasm and friendship. I hope to collaborate with them for many years to come.

My dear friend, Constantine Giannitsis was a great teacher of numerical methods. He helped me to make sense of finite-difference modeling and various ODE solving schemes. But more importantly, he always made me take a break to smell the roses. I sorely miss the deep conversations I shared with him during lunch on the Green Dot about love, philosophy, politics and life.

Never having written a computer program until my second year at MIT, FORTRAN was a menace at times. I had the good fortune of improving my programming 
abilities due to Jean Mimi Champin's assistance. I appreciate his endless patience and willingness to help me debug portions of the MITGCM code last summer. In addition to FORTRAN and convincing me that $v i$ is indeed the superior editor, Jean Mimi has also introduced me to the great beers of the world. I will fondly remember the political actions we participated in together, as well as the crazy bicycle rides.

David Ferreira and Martin Losch were kind enough to share with me their encyclopedic knowledge of Matlab. Despite my endless questions, they continued to hang out with me. Their assistance greatly improved the figures in the thesis. Similarly, Patrick Heimbach has been very helpful whenever I have had problems with LaTeX. I also thank him for giving me his ear when I was depressed or confused about life. He holds a special place in my heart.

I thank Chris Hill and Alistair Adcroft for developing the MITGCM and teaching me how to run my model on parallel computers. Chris always encouraged me when the going was tough. I thank Alistair for his sweet smile, good chocolate and amusing personality.

Bridget Bergquist has been a wonderful classmate. I appreciate her willingness to explain to me the iron measurement papers that I did not understand, and provide useful critiques of my sometimes outlandish ideas about iron cycling in the ocean. I also thank her for her laid back attitude, sweet smile and Midwestern friendliness.

MIT can be a very tough and lonely place. Fortunately, though, the comradery among students in the Green Building is exemplary. I thank my fellow graduate students for working to improve graduate student life for all students in the department and for looking out for one another.

The support staff at WHOI have been extremely helpful with big and small tasks. I thank Joanna Ireland, Julia Westwater, Stacey Brudno Drange, and Marsha Gomes. I thank Rose for caring and always greeting me with a smiling face during those late nights in Clark. Vasco was always offering to give me a ride home during the cold winter nights. I thank him for introducing me to Cape Verdean culture through his 
poetry, writings and paintings.

Equally at MIT, there are many people in the Green Building that I owe a big thanks to: Linda Meinke and Charmaine King for assisting me with printing problems; Diana Spiegel for UNIX assistance; Lisa McFarren, Helen Dietrich and Chuck Bowser for helping me navigate through the bureaucratic maze of MIT; Greg Shomo from Techsquare for his general computer assistance, interesting conversations about art and linguistics and his friendship; Bud Brown for help with some of the figures in the thesis, sharing with me his handyman skills and telling me cool hanggliding stories; and Carol Sprague and Vicki McKenna for making sure I got my stipend! I thank Carol also for supporting my activist causes.

Due to my amazing ability to procrastinate, I often ended up working until very late at night to meet a deadline. This provided me the opportunity to form a friendship with Tony Palotta - a very special man. I thank him for caring about my well being. I will miss his sweet face and interesting stories.

I am fortunate enough to have made many friends within the department: I thank the lunch and hiking crew for much needed diversions; Susie Carter, Michael Horowitz, and Jess Atkins for the amusing conversations back in the E34 days; Lihini Aluwihare for helping me in the early days at WHOI; Bill Lyons for epic training runs along the Charles River and becoming a friend that I adore; Nili Harnik for her sweet nature; Albert Fischer for being such a good friend when times were tough for me; Fernanda Hoefel for her calmness; Helen Hill and Mary Elliff for being supportive women in the department; the Italian mafia and Patrick Miller down in Woods Hole for their love; Jim Thomson for his positive outlook on life (and being my Woods Hole messenger!); Ariane Verdy for her idealism; and my officemate with the sweet French accent, Fanny Monteiro for her good nature.

I would like to give a special thanks to Joel Sloman for his daily visits. He has introduced me to the world of art and poetry and often fed me when I was too busy to cook. His ability to remain young and wise at the same time is amazing. I have 
learned a lot about love and life from him.

There were numerous people the last few months that took care of me while I was busy writing away: Fernanda, Nico Biassoni, Anke Hildebrandt, Anne O' Brien, Jen Banister, Jaspal Singh and Hardip Mann, Jen Jacobs and Pedro, Samudra and Lalita Vijay and their son Ghoulam. I thank them for feeding me, giving me a place to stay, and, in general, their friendship. I must also thank Bayard Wenzel for helping me to get a wireless connection at my home and meeting me at new and exotic restaurants around the city.

I would like to give a very big thanks to Oren Weinrib and Alex Rae. They both graciously agreed to help with proofreading and editing the thesis. I thank Alex for always being there for me. Oren must be thanked for many things including introducing me to performance art, sharing with me his Naked Manifesto, engaging me in thought-provoking conversations about politics, love, and life and making sure I always had fun. Both of them have showed me that there is much to learn outside the walls of academia.

Nitin Sawhney and Sunaina Maira have been inspirational activists and academics for me. I admire their ability to combine their quest for social justice and research into one. I will miss the late conversations with Nitin over beer about making academia more responsive to society's needs. I thank Sunaina for always inviting me to really cool political art events around the city.

There were times when MIT has been rough, but there were many communities within MIT and around the Boston area that gave me refuge. I thank my many friends at MIT for giving me the opportunity to get to know you. I fondly remember late night coffee and tea with my architecture buddies, cooking with Ann and Ray for hall feeds in East Campus, all-night costume parties with the Media Lab stars and organizing demonstrations and popular education events with those inclined to fight politically for a more socially just campus.

I also had the good fortune of working with Association for India's Development 
(AID) to provide support to grassroots organizations in India. I made many friends through AID and I thank them for allowing me to stay involved with my homeland from so many miles away. The fighting spirit of the folks in the Narmada Valley and the survivors of Bhopal are truly inspirational.

Many members of the South Asian Center have been my family away from home. I thank them for taking care of me and allowing me to be in touch with issues immigrants from my corner of the world face in this country. I also thank them for organizing many cultural and artistic events that showcase the diversity of the Indian subcontinent.

I am eternally grateful for meeting the larger global justice community in the Boston area. Working with these wonderful people helped me find a way to stay human and put my radical ideas into action. Organizing demonstrations and teachins and taking part in civil disobedience gave me hope that a small group of people can change the world. I count many of you among my closest friends in Boston. Although many of you had no idea what I did at that crazy technical school in Cambridge, you were all very supportive of the radical geek!

I thank my Freedom Rising friends, especially David Solnit for letting me be an honorary member of your affinity group. Building puppets for various demonstrations and hanging out with you in many different cities always made for a nice reprieve from research.

Many friends have introduced me to the arts, from poetry to sculpture to avantegarde performance art to protest art, from Indian classical music to electronic music. I thank you for widening my horizons and giving me a glimpse into how those that use the right side of their brains think.

Last in this list, but first in my heart is my family. Their love and support cannot be expressed in words. I thank my parents, Meena and Prithvish, for just letting me be myself and accepting me as I am. I thank my sweet sister, Aarti, for listening when times were rough. My Foi always checked up on me and has always been so 
proud of me. I thank my relatives in India for supporting my academic goals and accepting that my visits back to India were short. I would especially like to thank $\mathrm{Ba}$ and Nani for their strength and for passing some of it on to me. I dedicate this thesis to them.

It was a long road and very difficult at times, but now that I have reached the goal, it seemed worth it. 


\section{Contents}

1 Introduction $\quad 23$

1.1 Biogeochemistry of Iron in the Oceans . . . . . . . . . 26

1.2 Prior Modeling Studies . . . . . . . . . . . . . . . . 32

1.3 Increased Aeolian Supply . . . . . . . . . . . . . . . 34

1.4 Summary . . . . . . . . . . . . . . . . . 35

2 Explorations of Biogeochemical Iron Cycling using a Multi-box Model 37

2.1 Global Ocean Biogeochemistry Model . . . . . . . . . . . 38

2.1.1 Representation of Macro-nutrient Cycling . . . . . . . . 39

2.1 .2 Iron Cycling . . . . . . . . . . . . . . . 40

2.2 Model Results . . . . . . . . . . . . . . . . . . . . 42

2.2.1 Case I: Net Scavenging Model . . . . . . . . . . . . 43

2.2.2 Case II: Scavenging-Desorption Model . . . . . . . . . 45

2.2.3 Case III: Complexation . . . . . . . . . . . . . 48

2.3 Discussion . . . . . . . . . . . . . . . . 54

3 Sensitivity of Surface Phosphate to Aeolian Iron Source and Up$\begin{array}{ll}\text { welling Strength } & 57\end{array}$

3.1 Results: Increased Aeolian Flux Simulations . . . . . . . . . . . 59

3.1.1 Increased Dust Flux: Southern Ocean . . . . . . . . . . . 59

3.1.2 Increased Dust Flux: Globally . . . . . . . . . . 60 
4 Global Iron Cycling: Simulations Using an Ocean General Circulation Model $\quad 65$

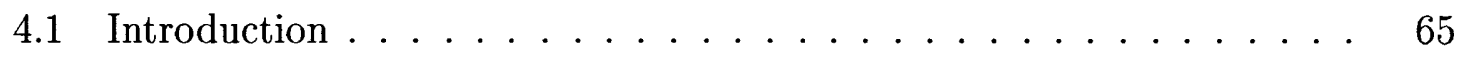

4.2 Physical Model . . . . . . . . . . . . . . . . 66

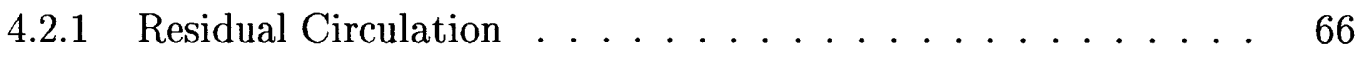

4.2.2 Temperature and Salinity Sections $\ldots \ldots \ldots \ldots$

4.3 Biogeochemical Component . . . . . . . . . . . . . . . 69

4.3.1 Aeolian Flux Forcing Field . . . . . . . . . . . . . . . 72

4.3.2 Iron Parameterization $\ldots \ldots \ldots \ldots \ldots \ldots$

4.4 Results . . . . . . . . . . . . . . . . 76

4.4 .1 Net Scavenging Results . . . . . . . . . . . . . 76

4.4 .2 Scavenging-Desorption Results . . . . . . . . . . . . 80

4.4 .3 Complexation Results $\ldots \ldots \ldots \ldots$

4.5 Summary $\ldots \ldots \ldots \ldots \ldots \ldots \ldots \ldots \ldots$

5 Regional and Global Iron Distributions $\quad 89$

5.1 A Tracer of Iron Limitation: $\mathrm{Fe}^{*} \ldots \ldots \ldots \ldots$

5.2 Iron Residence Time $\ldots \ldots \ldots \ldots$. . . . . . . . . 93

5.3 Importance of upwelled iron to the euphotic zone $\ldots \ldots \ldots \ldots 94$

5.4 Temporal and Vertical Variations: Comparisons to Data . . . . . . 95

5.5 Sensitivity to Aeolian Forcing . . . . . . . . . . . . . . . 102

5.6 Sensitivity to Variable Fe:C Uptake Ratio _ . . . . . . . . . . . 108

5.7 Chapter Summary . . . . . . . . . . . . . . . . . 111

6 GCM simulation: Southern Ocean Phosphate Sensitivity to Increased Aeolian Dust Flux $\quad 115$

6.1 Aeolian Forcing Field . . . . . . . . . . . . . . . . . 116

6.2 Global Distributions . . . . . . . . . . . . . . . . . 116

6.2 .1 Phosphate . . . . . . . . . . . . . . . 116 


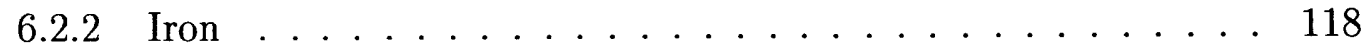

6.3 Southern Ocean Results . . . . . . . . . . . . . . . . 118

6.3.1 Comparison of 'modern' and 'paleo' surface phosphate distribution . . . . . . . . . . . . . . . 121

$6.3 .2 \mathrm{Fe}^{*} \ldots \ldots \ldots \ldots \ldots \ldots \ldots \ldots$

6.3.3 Local Source of Iron to the Southern Ocean . . . . . . . . 124

6.4 Comment . . . . . . . . . . . . . . . . . . . . . . 124

7 Conclusions $\quad 125$

7.1 Next Steps . . . . . . . . . . . . . . . . . . . . . . . 127

7.1.1 Research Recommendations from a Modeling Perspective . . . 127

7.1 .2 On-going Work . . . . . . . . . . . . . . 128

7.2 Final Comments . . . . . . . . . . . . . . . . 131 


\section{List of Figures}

1-1 Observed surface $\mathrm{PO}_{4}$ and chlorophyll a $\ldots \ldots \ldots \ldots \ldots$

1-2 Average yearly Fe aeolian flux ( $\mathrm{mg} \mathrm{Fe} \mathrm{m}^{-2} \mathrm{yr}^{-1}$, Gao et al., 2001) . . 26

1-3 Vertical profile of $\mathrm{Fe}$ in the Pacific and the Atlantic . . . . . . 28

1-4 Observed Fe at surface, $1000 \mathrm{~m}$ and below $2000 \mathrm{~m} \ldots \ldots \ldots \ldots$

$1-5$ Schematic diagram of iron cycling . . . . . . . . . . . 31

2-1 Box model schematic . . . . . . . . . . . . . . . . . . 39

2-2 Sensitivity of deep Fe to scavenging rates . . . . . . . . . . . 44

2-3 Schematic diagram of scavenging-desorption model $\ldots \ldots \ldots$

2-4 Sensitivity of deep Fe to scavenging-desorption rate constants $\ldots 47$

$2-5$ Schematic diagram of complexation . . . . . . . . . . . . 49

2-6 Sensitivity of Fe to scavenging rate and $K_{F e^{\prime} L} \ldots \ldots \ldots \ldots \ldots$

2-7 Sensitivity of $\mathrm{L}^{\prime}$ to scavenging rate and $K_{F e^{\prime} L} \ldots \ldots \ldots \ldots \ldots \ldots$

2-8 Sensitivity of $\mathrm{Fe}$ to scavenging rate and $K_{F e^{\prime} L}$ for $\mathrm{L}_{T}=4 \mathrm{nM} \quad \ldots \ldots \quad 54$

2-9 Sensitivity of $\mathrm{L}^{\prime}$ to scavenging rate and $K_{F e^{\prime} L}$ for $\mathrm{L}_{T}=4 \mathrm{nM} \ldots \ldots$

3-1 Surface S. Ocean $\mathrm{PO}_{4}$ sensitivity to S. Ocean only dust increase $\ldots 60$

3-2 Surface S. Ocean $\mathrm{PO}_{4}$ sensitivity to global dust increase . . . . . . . 61

3-3 Percent Iron in surface Southern Ocean derived from dust $\ldots \ldots 63$

3-4 S. Ocean deep Fe response to dust increase and upwelling strength . . 63

4-1 Global residual mean of the model $\ldots \ldots \ldots \ldots$

$4-2 \quad$ Vertical velocity of model at $50 \mathrm{~m} \ldots \ldots \ldots \ldots$ 
4-3 Comparison of observed and model temperature . . . . . . . . . 69

4-4 Comparison of observed and model salinity . . . . . . . . . . . 70

4-5 Aeolian flux field used to force the model . . . . . . . . . . . . 73

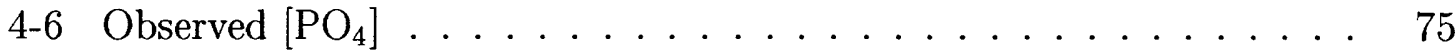

4-7 Modeled $\left[\mathrm{PO}_{4}\right]$ for net scavenging case $\ldots \ldots \ldots \ldots$

4-8 Modeled $\left[\mathrm{Fe}_{T}\right]$ for net scavenging case . . . . . . . . . . . . . 79

4-9 Modeled $\left[\mathrm{PO}_{4}\right]$ for complexation case . . . . . . . . . . . . 82

4-10 Modeled $\left[\mathrm{Fe}_{T}\right]$ for the complexation case $\ldots \ldots \ldots$. . . . . . . 83

$4-11$ Fraction FeL . . . . . . . . . . . . . . . . 85

4-12 Modeled surface $\mathrm{PO}_{4}$ distribution (Archer and Johnson, 2000) . . . . 87

4-13 Modeled $\mathrm{Fe}_{T}$ distribution (Archer and Johnson, 2000) . . . . . . 88

5-1 Zonally averaged section of $\mathrm{Fe}^{*}$ in the Atlantic basin . . . . . . . 91

5-2 Zonally averaged section of $\mathrm{Fe}^{*}$ in the Indo-Pacific basin . . . . . . . 92

5-3 Zonally averaged section of $\mathrm{Fe}^{*}$ in the Southern Ocean basin . . . . . 92

5-4 Comparison of modeled and observed Fe profiles at BATS . . . . . 95

5-5 Comparison of modeled and observed Fe profiles at Station ALOHA . 96

5-6 Comparison of modeled and observed Fe profiles in the N. Pacific . . 97

5-7 Comparison of modeled and observed Fe profiles in the eq. Pacific . . 98

5-8 Comparison of modeled and observed Fe profiles in the S. Ocean . . . 98

5-9 Comparison of modeled and observed surface Fe in the W. Atlantic . 100

5-10 Monthly modeled surface $\left[\mathrm{Fe}_{T}\right]$ at $10^{\circ} \mathrm{N}, 45^{\circ} \mathrm{W} \ldots \ldots 101$

5 -11 Monthly modeled dust flux at $10^{\circ} \mathrm{N}, 45^{\circ} \mathrm{W} \ldots \ldots . . \ldots 102$

5-12 Comparison of observed and modeled monthly surface $\left[\mathrm{Fe}_{T}\right]$ at Station

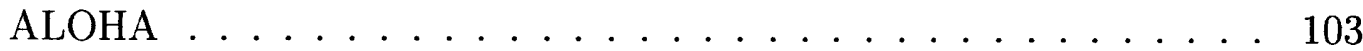

5-13 Modeled monthly dust flux at Station ALOHA . . . . . . . . . . . . 104

5-14 Seasonal dust deposition (Mahowald et al., 2003) . . . . . . . . . 105

5-15 Modeled $\left[\mathrm{PO}_{4}\right]$ response to Mahowald et al. (2003) dust forcing . . . 107

5-16 [Modeled $\left[\mathrm{Fe}_{T}\right]$ response to Mahowald et al. (2003) dust forcing . . . 109 
5-17 Variance in intracellular Fe:C ratio (Sunda and Huntsman, 1995) . . 110

5-18 Modeled $\left[\mathrm{PO}_{4}\right]$ response to variable Fe:P ratio $\ldots \ldots \ldots \ldots$

5-19 Modeled $\left[\mathrm{Fe}_{T}\right]$ response to variable Fe:P ratio $\ldots \ldots \ldots$

6-1 Aeolian flux forcing used for the increased dust flux simulation (Mahowald et al., 1999) . . . . . . . . . . . . . . 117

6-2 Modeled $\left[\mathrm{PO}_{4}\right]$ for 'paleo' case . . . . . . . . . . . . . . . . 119

6-3 Modeled $\left[\mathrm{Fe}_{T}\right]$ for 'paleo' case . . . . . . . . . . . . . 120

6-4 Comparison of surface $\left[\mathrm{PO}_{4}\right]$ in $\mathrm{S}$. Ocean between 'paleo' and 'modern' case ............................ 122

6-5 Zonally averaged $\mathrm{Fe}^{*}$ in the $\mathrm{S}$. Ocean for the 'paleo' case . . . . . . 123

7-1 Schematic diagram of ecosystem model . . . . . . . . . . 128

7-2 Comparison of modeled and observed chlorophyll . . . . . . . . 130 


\section{List of Tables}

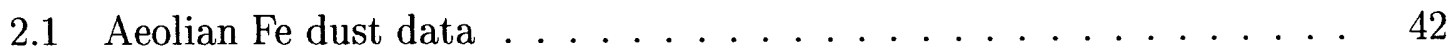

2.2 Model Parameters . . . . . . . . . . . . . . . . . . . 43 


\section{Chapter 1}

\section{Introduction}

Iron $(\mathrm{Fe})$ is known to be an essential micronutrient for marine phytoplankton capable of limiting phytoplankton growth due to its low concentration (Coale et al., 1996; Martin et al., 1994; Price et al., 1994). Ocean regions with such low Fe concentrations are typically characterized by high surface concentrations of macronutrients, but low chlorophyll (referred to as HNLC regions). The Southern Ocean, northern North Pacific and equatorial Pacific are classified as HNLC regions (Figure 1-1). Fertilization experiments have shown primary productivity in these regions responds to Fe additions (Martin et al.,1994; Coale et al., 1996; Boyd et al., 2000). At their outset in the North Atlantic, the deep waters are replete in iron relative to $\mathrm{PO}_{4}$. However, due to the different biogeochemistry and decoupling of $\mathrm{PO}_{4}$ and $\mathrm{Fe}$ in the deep ocean, when the waters upwell again (e.g. in the Southern Ocean and the northern North Pacific), they are depleted in Fe relative to phosphorus. Unless the external aeolian supply is sufficient to offset the deficit, iron is limiting.

Evidence from ice cores (Petit et al., 1999) and sediments (Rea, 1994), in addition to suggestions from numerical models (Mahowald et al., 1999), indicate an increased global aeolian dust supply of 2-5 times during the Last Glacial Maximum (LGM) and an increase as high as 20 times at high latitudes. An increased dust flux might have increased nutrient utilization (Francois et al., 1997; Kumar et al., 1995) and 

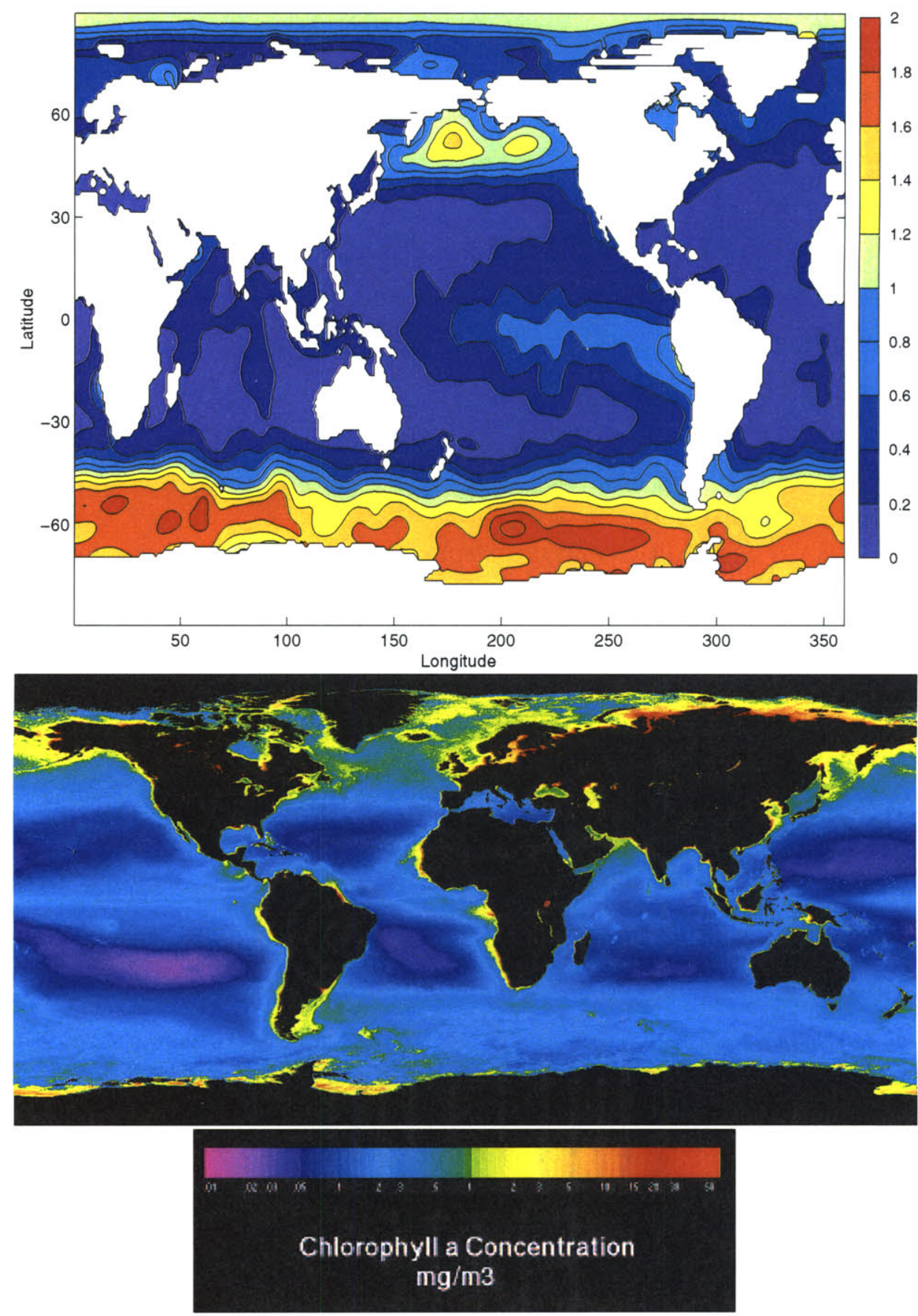

Figure 1-1: Top panel displays the surface $\mathrm{PO}_{4}$ from Conkright et al. (1994) in $\mu \mathrm{M}$. The bottom panel displays the yearly averaged chlorophyll $a$ concentration $\left(\mathrm{mg} / \mathrm{m}^{3}\right)$ as sensed by SeaWiFs (Figure courtesy of NASA). 
subsequent drawdown of $\mathrm{pCO}_{2}$ in the Southern Ocean during the LGM. However, this hypothesis is yet to be clearly supported. While the field experiments have clearly shown an increase in primary production following iron fertilization in the HNLC regions (Martin et al.,1994; Coale et al., 1996; Boyd et al., 2000) there is, as yet, no clear evidence of a change in export production which would be necessary for modulation of the biological pump of carbon.

While iron may play a significant role in regulating primary productivity and biological drawdown of $\mathrm{CO}_{2}$, the processes controlling its distribution in the global ocean are poorly understood. Yet, companies have formed (Lam and Chisholm, 2002) with the aim of fertilizing the ocean with iron to mitigate rising $\mathrm{CO}_{2}$ levels in the atmosphere due to fossil fuel burning.

Much of the emphasis of iron modeling studies have focused on the cycling of Fe within the ecosystem in the upper ocean (Armstrong, 1999; Christian et al., 2002; Leonard et al., 1999; Moore et al., 2002). These models must impose the upwelled iron reaching the euphotic zone. Only two studies have focused on modeling the large scale distribution and maintenance of Fe in the deep waters (Archer and Johnson, 2000; Lefévre and Watson, 1999), the source for upwelled iron. By building on these previous deep water iron studies, incorporating new understanding and field data, this thesis focuses on understanding what controls the oceanic distribution and supply of iron to the euphotic zone and the effect increased dust flux has on nutrient drawdown in the high latitudes. I test various parameterizations of iron cycling based on its biogeochemical properties within the context of a simple six-box model and a physically more sophisticated three-dimensional coarse resolution ocean general circulation model. I find that the binding of Fe to an organic ligand is able to counteract the loss of Fe due to scavenging. The dominance of scavenging over transport at detph leads to the decoupling between $\mathrm{Fe}$ and $\mathrm{PO}_{4}$ in the deep ocean. 


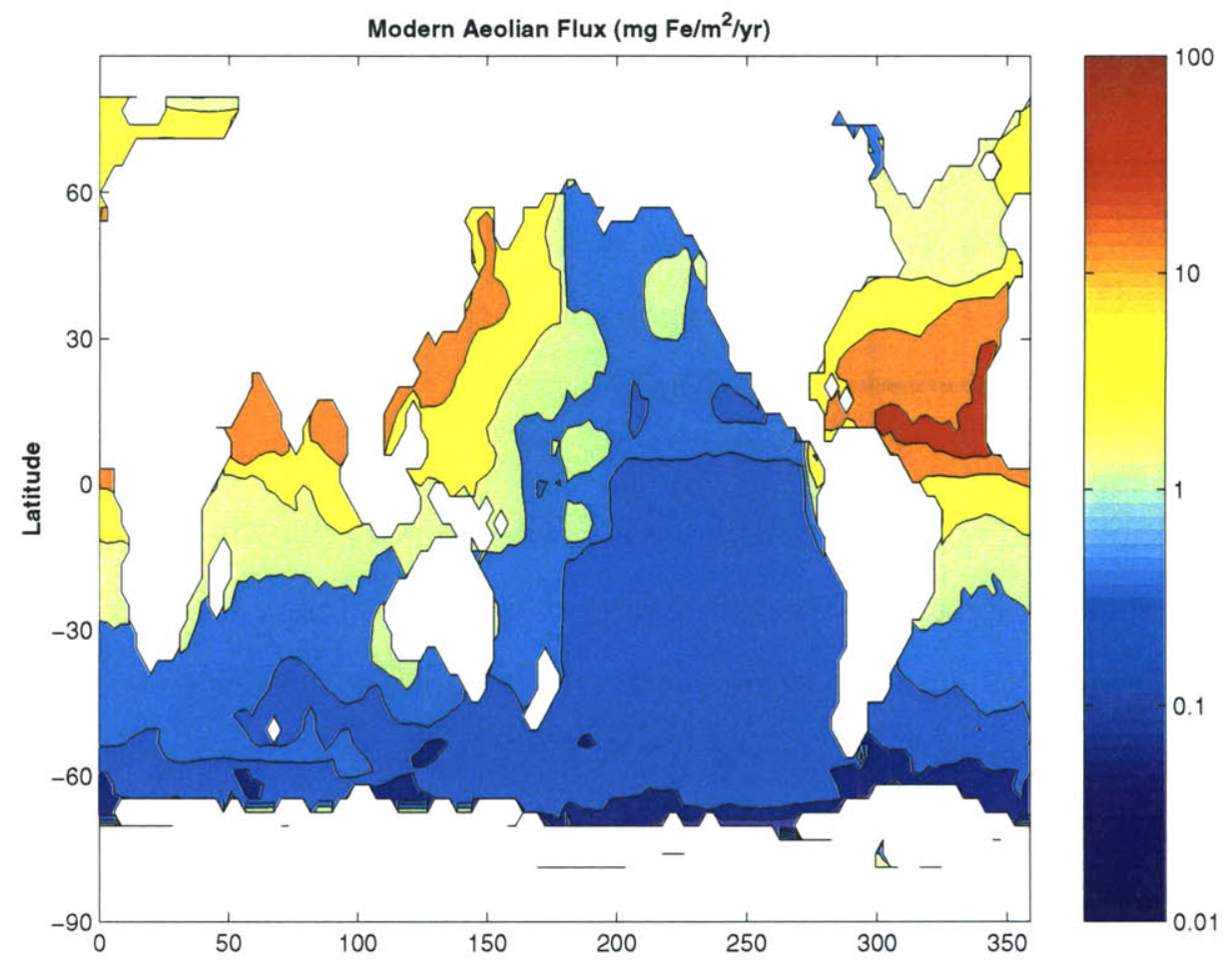

Figure 1-2: Average yearly Fe flux extrapolated from in situ marine boundary layer measurements by Gao et al.(2001).

\subsection{Biogeochemistry of Iron in the Oceans}

Like other metals, such as lead and aluminum, iron has an episodic aeolian source to the surface ocean. Global estimates of annual atmospheric iron deposition range between 14-32 x $10^{12}$ g Fe (Duce and Tindale, 1991; Tegen and Fung, 1995; Mahowald et al., 1999; Gao et al., 2001) with deposition strongest in the North Atlantic and Indian Oceans (Figure 1-2). Dust deposition is lowest in the South Pacific and Southern Ocean.

Assessing the bioavailability and solubility of aeolian-derived Fe is a major research focus. The extent of dissolution in seawater appears to depend on the aerosol source, degree of atmospheric processing, residence time of aerosol Fe in the euphotic zone, particulate load present in surface waters, and the chemical reactions aeolian-derived Fe is subjected to in surface waters (Jickells and Spokes, 2001). Recent studies suggest 
the solubility of Fe in dust may be below $5 \%$ (Jickells and Spokes, 2001; Spokes and Jickells, 1996).

Other recent evidence indicates that Fe is found in both the soluble $(<0.02 \mu \mathrm{m})$ and colloidal size classes (0.02-0.4 $\mu \mathrm{m}$ ) (Wu et al., 2001). Previously, due to analytical difficulties, investigators were unable to distinguish between these two forms of Fe. Colloidal iron particles may be less bioavailable than soluble iron (Hudson and Morel, 1990; Wells et al., 1983) and could aggregate into larger particles that sink out of the water column (Honeyman and Santschi, 1989). Since most of the available Fe measurements were not able to distinguish between soluble and colloidal Fe, I do not consider the role of colloids. Rather, in this thesis, 'dissolved' Fe refers to Fe that has passed through a $0.4 \mu \mathrm{m}$ filter. As we learn more about the nature of Fe-colloids in the ocean, I hope to incorporate this knowledge in the future.

Iron is removed from the water column by scavenging onto sinking particles. Direct quantitative estimates of scavenging rates of Fe have not yet been made, though Bruland et al. (1994) indirectly estimate a residence time for Fe with respect to scavenging between 70-140 years in the water column. Thorium (Th) is a metal that has similar abiological properties to Fe. Bacon and Anderson (1982) calculate an oceanic scavenging rate for Th and also suggest that scavenged Th is released back to the water column. They describe the latter process as a first order reaction proportional to the particulate Th concentration, estimating redissolution rates of 1.33-6.30 $\mathrm{yr}^{-1}$. Since Fe and Th have similar metallic properties, it seems reasonable to speculate that scavenged $\mathrm{Fe}$ on particles may also be subject to redissolution.

The vertical profile of iron reflects its role in the biological cycle and atmospheric source. Its vertical profile falls into two categories based on the depth of the mixed layer, rate of biological productivity and dust flux. Regions with deep mixed layers, high productivity and/or weak dust flux are characterized by depleted $\left[\mathrm{Fe}_{T}\right]$ at the surface that increases with depth (Figure 1-3A). In regions with stratified mixed layers, low biological productivity, and strong dust flux, iron builds up near the 

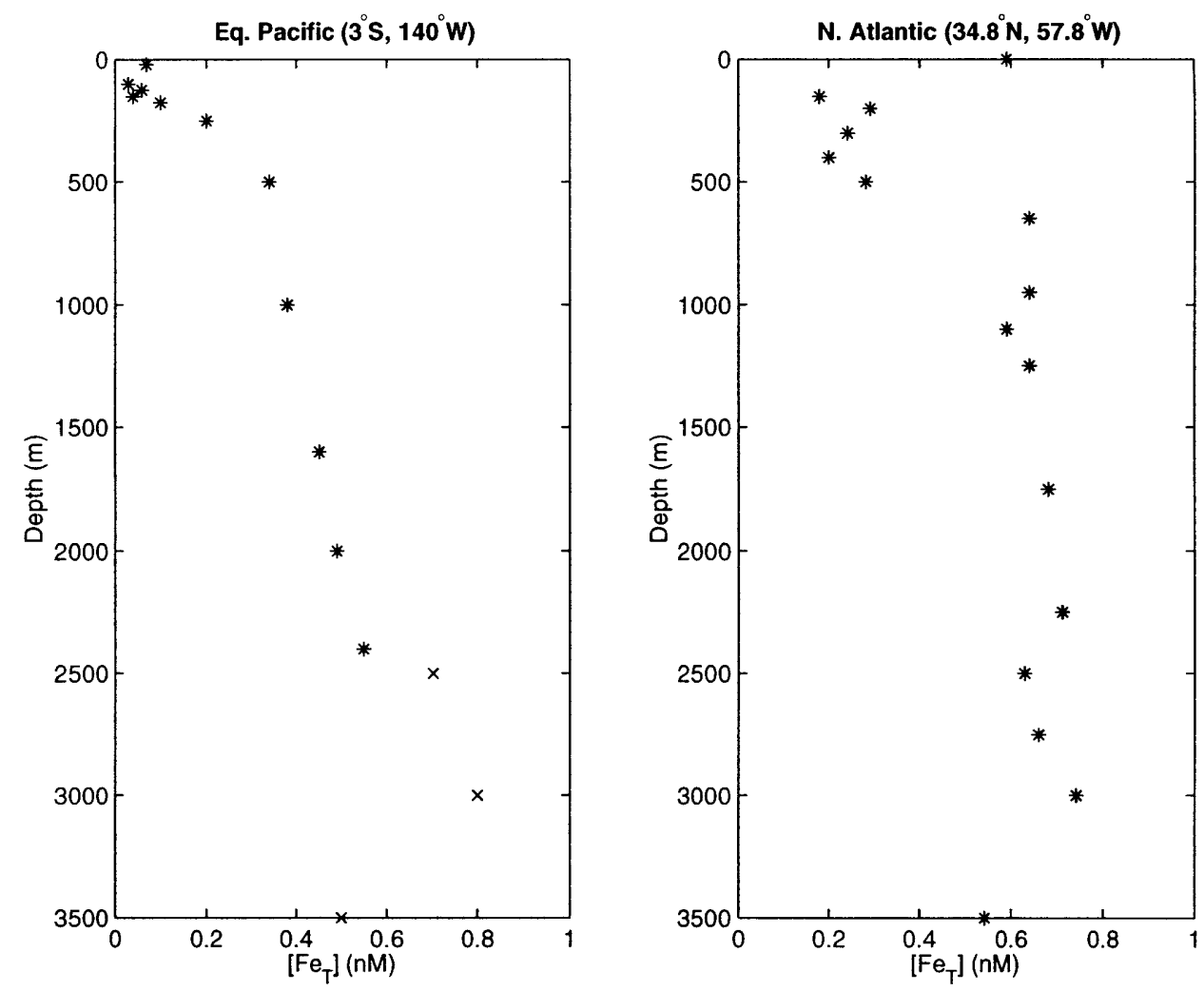

Figure 1-3: Vertical profile in the A) Equatorial Pacific at $3^{\circ} \mathrm{S}, 140^{\circ} \mathrm{W}$ (Johnson et al., 1997) and B) western North Atlantic at $34.8^{\circ} \mathrm{N}, 57.8^{\circ} \mathrm{W}$ (Wu et al., 2001).

surface, has a minimum near the base of the mixed layer and then increases with depth (Figure 1-3B). In Figure 1-4A, I present a compilation of surface $\left[\mathrm{Fe}_{T}\right]$ from published and unpublished measurements courtesy of E. Boyle. In high dust flux regions, such as the North Atlantic, surface $\left[\mathrm{Fe}_{T}\right]$ can be elevated. Due to the analytical difficulty of measuring iron, the deep water iron distribution is currently poorly resolved, but it is clear that large scale, deep water Fe gradients do not mirror those of nitrate and phosphate. Rather concentrations, at $\sim 1000 \mathrm{~m}$, are highest in the Atlantic ( 0.6-0.8 $\mathrm{nM}$ ), intermediate in the Indo-Pacific basin (0.4-0.7 $\mathrm{nM})$, and lowest in the Southern Ocean (0.2-0.3 nM) (Figure 1-4B). For depths greater than 2500m, few measurements exist (Figure 1-4C), but suggest highest $\left[\mathrm{Fe}_{T}\right]$ in the Atlantic basin and lower $\left[\mathrm{Fe}_{T}\right]$ in the Southern Ocean and Pacific basin.

Field studies suggest that $99 \%$ of dissolved iron (i.e. that which passes through 

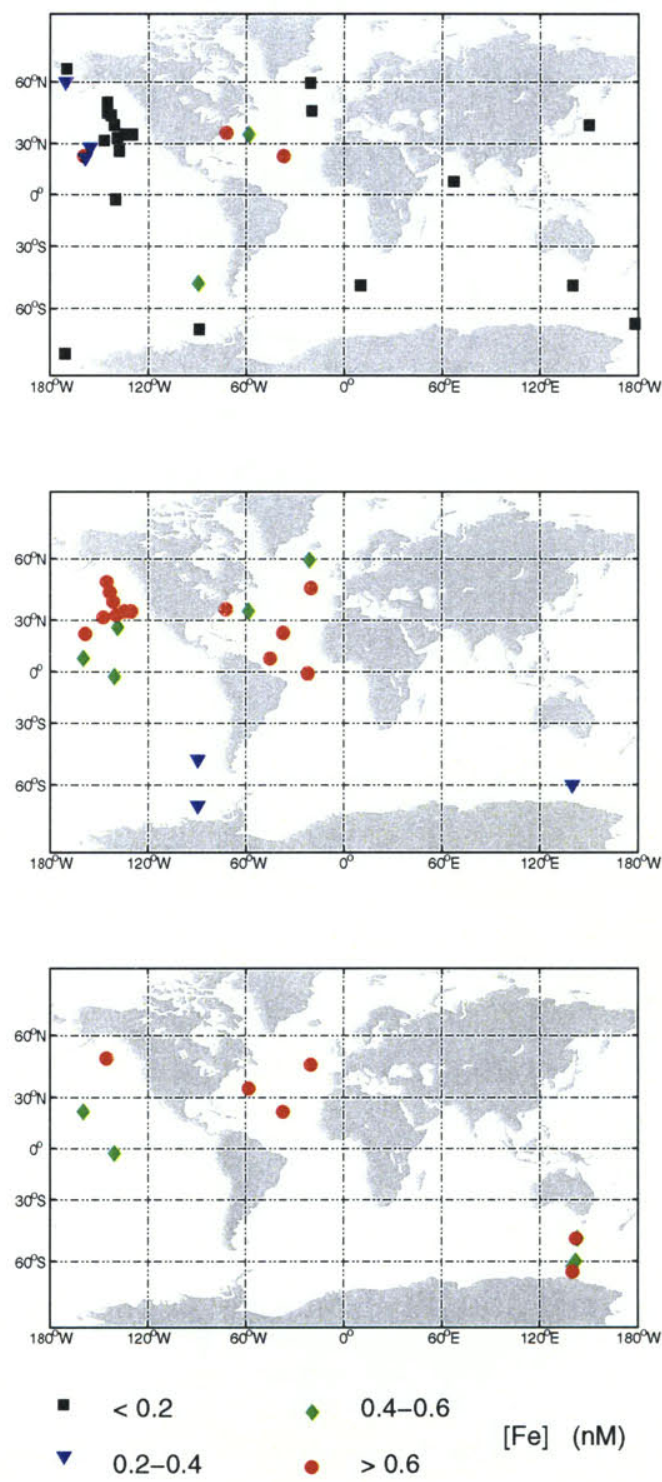

Figure 1-4: $[\mathrm{Fe}](<0.4 \mu \mathrm{m})$ at the surface (top panel), at 1000-2000m (middle panel) and depths $>2000 \mathrm{~m}$ (bottom panel). Data sources: Boyle (unpublished); de Baar et al.,1999; de Jong et al., 1998; Johnson et al., 1997 and references therein; Measures and Vink, 2001; Nishioka et al.,2001; Obata et al., 1993; Powell and Donat, 2001; Rue and Bruland, 1995; Sedwick et al., 2000; Sohrin et al., 2000; Takeda et al., 1995; Wu and Luther, 1994; Wu et al., 2001 
a $0.4 \mu \mathrm{m}$ filter) is bound to organic ligands throughout the world's oceans (Gledhill and van den Berg, 1994; Rue and Bruland, 1995; van den Berg, 1995; Wu and Luther, 1995; Rue and Bruland, 1997; Gledhill et al., 1998; Nolting et al., 1998; Witter and Luther, 1998; Witter et al., 2000; Boye et al., 2001; Powell and Donat, 2001). The reaction between $\mathrm{Fe}^{\prime}$ and an Fe-binding organic ligand $\left(\mathrm{L}^{\prime}\right)$, a molecule with potential binding sites, is:

$$
F e^{\prime}+L^{\prime} \rightleftharpoons F e L
$$

where $L^{\prime}$ is the Fe-binding organic ligand. The thermodynamic equilibrium can be expressed as:

$$
K_{F e L}=[F e L] /\left[F e^{\prime}\right]\left[L^{\prime}\right]
$$

The source(s), $\operatorname{sink}(\mathrm{s})$ and chemical characterization of the ligand is not well known. Estimates of the concentration of ligand range between $0.5-6 \mathrm{nM}$ and most studies suggest only one class of active organic ligand, but two studies (Rue and Bruland, 1997; Nolting et al., 1998) have inferred two ligand classes in the North Pacific and the Pacific sector of the Southern Ocean. Vertical ligand profiles appear nutrient-like with ligand concentration below $1000 \mathrm{~m}$ remaining relatively constant.

The estimated conditional stability constant of the ligand $(\mathrm{s})\left(\mathrm{K}_{\mathrm{FeL}}\right)$ ranges between $10^{9.8} \mathrm{M}^{-1}$ and $10^{14.3} \mathrm{M}^{-1}$ without any clear regional pattern. Conditional stability constants are estimated using competitive ligand exchange adsorptive cathodic stripping voltammetry (CLE-ACSV). A known concentration of a well characterized and purified synthetic ligand is added to a series of field samples containing natural ligands and a range of added metal. Once the synthetic ligand has equilibrated, ACSV is used to measure the concentration of the metal complexed to the added ligand as a function of total metal in solution.

Traditionally, only the free metal is considered to be bioavailable (Anderson and 


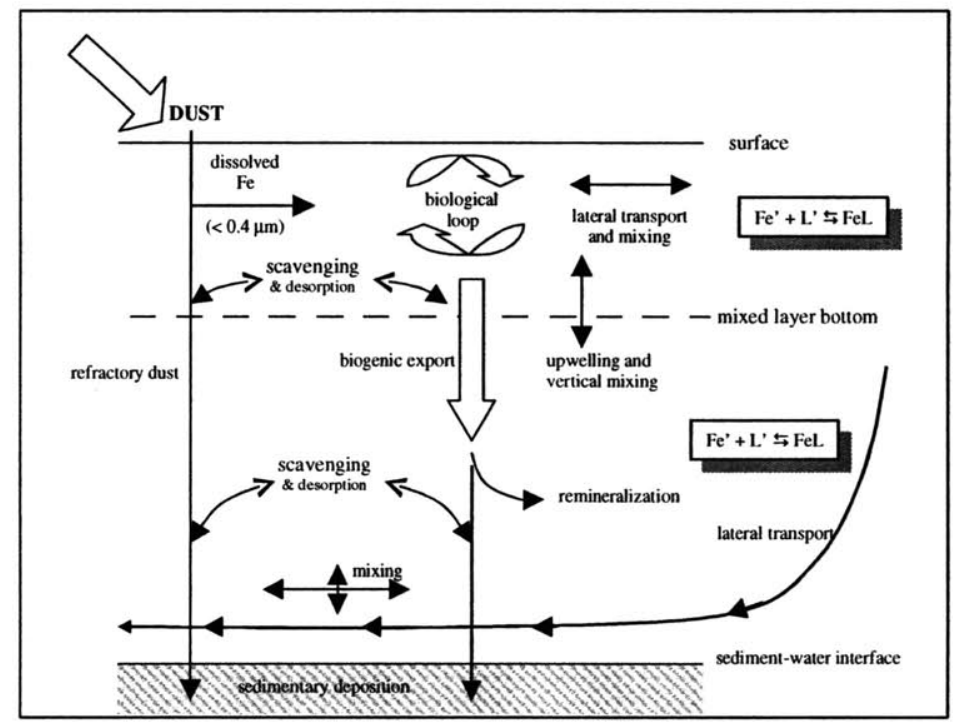

Figure 1-5: Schematic diagram of iron cycling in the global ocean. Figure courtesy of Bridget Bergquist.

Morel, 1978). Since essentially the total Fe pool is complexed, the complexed Fe may actually be bioavailable. Furthermore, extracting iron-binding compounds from seawater and characterizing certain functional groups within the compound, Macrellis et al. (2001) found that functional groups known to be present in marine and terrestrial siderophores are present in the marine environment. This suggests that the ligands are produced biologically by phytoplankton to aid in the uptake of Fe from seawater.

The various processes that iron is subjected to, which my model aims to mechanistically describe, are summarized in a schematic diagram (Figure 2-1) and will be described in more detail later. 


\subsection{Prior Modeling Studies}

Bruland et al. (1994) and Boyle (1997) suggested that the variable aeolian input into each ocean basin coupled with the biological processes of uptake/regeneration and the metallic property of scavenging could explain the profile of $\mathrm{Fe}$ in the world's oceans. Johnson et al. (1997) suggest that iron's complexation to an organic ligand must be controlling the deep water distribution.

Lefévre and Watson (1999) and Archer and Johnson (2000) developed models to examine possible controls on deep water Fe gradients. Lefévre and Watson (1999) use a ten box representation of the ocean adapted from the PANDORA model (Broecker and Peng, 1986, 1987), parameterizing scavenging of iron onto particles, as well as its biological consumption, remineralization and aeolian deposition. With a scavenging rate of $0.005 \mathrm{yr}^{-1}$ and solubility of the aeolian iron supply of $2 \%$, their model was able to reproduce the broad features of the deep water iron gradients, although the model yielded higher absolute concentrations in the deep Atlantic $(1.6 \mathrm{nM})$ than observed. Lefévre and Watson (1999) also introduced a parameterization of complexation and scavenging, which assumed an effective solubility of iron $\left(\mathrm{Fe}_{s o l}\right)$ to represent the iron complexed by a ligand, having a uniform oceanic concentration of $0.6 n M$. Iron loss was parameterized as a damping toward the effective solubility, $-k *\left([F e]-F e_{s o l}\right)$, with a timescale of $1 / k=100$ years, assuming that only iron which exceeds the effective solubility (i.e. is not bound to the ligand) can be scavenged from the water column. Implicitly, complexation to the ligand is assumed to be very rapid. In this model, deep water concentrations in the Antarctic and the Indo-Pacific were approximately $0.6 \mathrm{nM}$, and the deep Atlantic is somewhat higher with a concentration of $0.92 n M$. The concentrations are higher than currently observed in the Atlantic and Indo-Pacific. However, at the time of that study, this model seemed more consistent with the available evidence, which was interpreted to show that the deep water iron concentration was uniform in all basins. There were fewer measurements and none from the Southern Ocean at that time. 
Archer and Johnson (2000), using a three-dimensional global circulation and biogeochemistry model examined three parameterizations of iron cycling: (A) scavenging only, (B) complexation with one ligand and (C) complexation with two (strong and weak) ligands. In the first case, using a slow scavenging rate $\left(1.6^{*} 10^{-3} \mathrm{yr}^{-1}\right)$, the deep water distribution reflects that of a typical nutrient. In the second case, representing complexation with a very strong ligand $\left(\mathrm{K}=1.2^{*} 10^{13}\right)$ of uniform concentration $(0.6$ $\mathrm{nM}$ ) results in a uniform deep water Fe distribution, consistent with the observations and their interpretation at the time. In the third case, Archer and Johnson (2000) apply the profile of two iron-binding ligands, a strong ligand $\left(\mathrm{K}=1.2^{*} 10^{13} \mathrm{M}^{-1}\right)$ in the upper 500 meters with a maximum concentration of $0.5 \mathrm{nM}$ and a weaker ligand $\left(\mathrm{K}=3^{*} 10^{11} \mathrm{M}^{-1}\right)$ with concentrations ranging between 1.5-2.5 $\mathrm{nM}$ from the surface to depth, as measured by Rue and Bruland (1995) in the North Pacific. This model simulation results in roughly uniform deep water $[\mathrm{Fe}]$ in the Atlantic and Pacific basins. In this scenario, excess iron at the surface not utilized biologically was removed from the system,contributed to an unidentified process.

In the light of new data, the first goal of this thesis is to adapt and constrain parameterizations of iron cycling in the deep ocean. I test three parameterizations of iron cycling: (A) net scavenging onto particles, (B) explicit representation of scavenging and desorption to and from particles, and (C) scavenging and complexation by a single ligand with an imposed total concentration. Here, I test these parameterizations within the context of a computationally economical, but highly idealized, six-box model and a more sophisticated three-dimensional ocean general circulation model (GCM) to consider which of these parameterizations most successfully captures the observed system as present observations show. 


\subsection{Increased Aeolian Supply}

There is particular interest in the role of iron and aeolian dust supply in the modulation of the surface nutrient concentration of the Southern Ocean and the ocean's biological pumps of carbon (Martin, 1990). Evidence from ice cores (Petit et al., 1999) and suggestions from numerical models (Mahowald et al., 1999) indicates an increased aeolian supply of iron throughout the oceans during periods of glaciation. Numerical ocean models have been used to explore the implications for the carbon cycle by examining the response to imposed surface nutrient drawdown (e.g. Sarmiento and Orr, 1991). Watson et al. (2000) used a simplified ocean biogeochemistry model with explicit representation of iron cycling, forced with glacial-interglacial cycles in Southern Ocean iron deposition derived from ice core dust records. Their study suggests that a significant fraction of the observed glacial-interglacial change in atmospheric $\mathrm{CO}_{2}$ may be accounted for in this way. Deep water iron cycling is represented in that model as a particulate scavenging process. In contrast, Lefévre and Watson (1999) found it necessary to increase dust flux globally by a factor of 10 in order to drawdown modeled $\mathrm{pCO}_{2}$ by $50 \mu \mathrm{atm}$. Archer and Johnson (2000) examined the response of surface phosphate loading to increased aeolian dust supply in their global, threedimensional model in which deep ocean iron cycling is represented as a combination of complexation to organic ligands and scavenging by particles. The authors suggest that a significant drawdown of the surface macronutrients might be achieved with high ligand concentrations.

The nature of the parameterization of iron, as well as the distribution of and amount of dust flux increase, appears to affect the sensitivity of $\mathrm{pCO}_{2}$ drawdown and surface $\mathrm{PO}_{4}$ drawdown in the Southern Ocean, but varying results are drawn from a diverse suite of models and experiments. The second goal of this thesis is, therefore, to examine these issues through a set of sensitivity experiments in a common framework using the idealized six-box model. Further, I explore the response of surface $\mathrm{PO}_{4}$ in the HNLC regions to increased dust flux in the three-dimenensional GCM. 


\subsection{Summary}

It is clear that iron plays an important role in controlling the efficiency of the biological pump and the ultimate drawdown of $\mathrm{CO}_{2}$ by the ocean. Yet, there are many open questions regarding our understanding of the marine iron cycle and how to represent it in ocean models. This thesis develops an iron biogeochemistry model that draws on previously published models (Archer and Johnson, 2000; Lefévre and Watson, 1999), but incorporates knowledge from more recent observations and experimental evidence. I incorporate my iron biogeochemical model into a simple multi-dimensional box model and an ocean three-dimensional general circulation model, to test our understanding of controls on deep water iron distribution. Furthermore, I test the effect that increased dust flux has on surface $\mathrm{PO}_{4}$ drawdown in the Southern Ocean to place constraints on the role iron may play in glacial-interglacial cycles.

In Chapter 2, three parameterizations of iron cycling are presented: a net scavenging case, scavenging-desorption case and complexation-scavenging case. Embedded into a simple six-box model, each parameterization is able to reproduce the observed deep water gradients. Results of sensitivity studies to various rate constants and parameterizations are discussed.

The sensitivity of the three iron parameterizations to increased dust flux, as the earth likely experienced during the Last Glacial Maximum (LGM), are presented in Chapter 3. While each of the parameterizations are able to reproduce, in a broad sense, the modern observed deep water [Fe], their response to increased dust flux varies significantly.

I add the iron biogeochemical parameterizations to an ocean general circulation model in Chapter 4. While all three parameterizations successfully reproduced observed deep water iron gradients in the box model simulations, the ocean general circulation model, with a more sophisticated representation of physics, identifies some differences. Only the complexation case is able to easily capture the observed Fe distribution. 
Since the complexation case is the most mechanistic of the three parameterizations and is best able to reproduce modern global iron distributions, I examine the results from this parameterization in greater depth in Chapter 5. I compare modeled profiles to observations and find good agreement, except at the surface in high flux regions such as the North Atlantic. I calculate the global ocean residence time for Fe of $\sim 285$ years, indicating that transport must play a key role in controlling Fe distributions. I also find that globally, upwelling accounts for $40 \%$ of 'new iron' reaching the euphotic zone. Lastly, I define a tracer, $\mathrm{Fe}^{*}$, that indicates the degree to which a water mass is iron limited.

In Chapter 6, I examine the response of surface $\mathrm{PO}_{4}$ in $\mathrm{HNLC}$ regions to estimated LGM dust fluxes (Mahowald et al., 1999) using the ocean general circulation model. While surface $\mathrm{PO}_{4}$ is depleted considerably, there is still excess $\mathrm{PO}_{4}$ at the surface, despite a 2.5 -fold global increase in dust flux over modern day estimates.

I summarize the major findings of the thesis in Chapter 7. Additionally, I recommend areas of further study that would be helpful from a modeling perspective, as well as highlight additional research questions this thesis has brought to light. 


\section{Chapter 2}

\section{Explorations of Biogeochemical Iron Cycling using a Multi-box Model}

New data from the Pacific and Southern Oceans (de Baar et al., 1999; Powell and Donat, 2001; Sohrin et al., 2000; Wu et al., 2001; Boyle et al., in prep.) show the distribution of dissolved iron in the deep ocean differs significantly from the uniformity that previous models, such as those of Lefévre and Watson (1999) and Archer and Johnson (2000) sought to reproduce and understand. Concentrations now appear to be lowest in the Southern Ocean and highest in the Atlantic basin, with a range of values in the Pacific. These models and parameterizations need to be revisited in the light of the new data.

In addition, recent measurements indicate a range in the strength of the conditional stability constant and the presence of a significant amount of free ligand. The Lefévre and Watson (1999) model does not account for these observations. Archer and Johnson's (2000) model adds a weaker ligand in their two ligand scenario, but still has a strong ligand at the surface, which requires the bioavailability of Fe reaching the high latitudes to be reduced relative to the rest of the model-domain to keep 
surface $\left[\mathrm{PO}_{4}\right]$ high in the high latitude surface waters.

Here I aim to build on these previous studies and use more recent data to adapt and constrain the parameterizations of iron cycling in the deep oceans. I will also explore the implications for our understanding of the global nutrient and carbon cycle. In order to allow significant exploration of parameter space, I use a computationally economical, though highly idealized, six-box model of ocean biogeochemistry similar to that of Lefévre and Watson (1999) and Broecker and Peng $(1986,1987)$. I test three parameterizations of iron cycling with the model: (I) net scavenging onto particles (II) explicit representation of scavenging and desorption to and from particles, and (III) scavenging and complexation. I will show that, provided appropriate parameter values are chosen, each of these parameterizations can reproduce the broad characteristics of the presently observed deep ocean dissolved $(<0.4 \mu \mathrm{m})$ iron distribution. However, only the third case concurrently reproduces the observed deep water gradients and the speciation of iron and ligand.

In the following sections I will outline the structure and mechanics of the six-box ocean biogeochemistry model and discuss model results and sensitivities for each of the three iron parameterizations outlined above.

\subsection{Global Ocean Biogeochemistry Model}

I use a six box model (Figure 2-1) similar in construction to Broecker and Peng's $(1986,1987)$ Pandora Model, representing the surface and deep waters of the Atlantic, Antarctic, and Indo-Pacific basins. Each basin is divided into two layers, a 100 meter surface layer where biological uptake of nutrients occurs, and a deep layer. Broecker and Peng (1987) tuned volume transports to optimize the modeled ${ }^{14} \mathrm{C}$ distribution. I recognize that such highly idealized models have limitations, particularly for quantitative assessments (Broecker et al., 1999; Archer et al., 2000; Follows et al., 2002) but they do provide a useful framework in which to develop clear, qualitative 


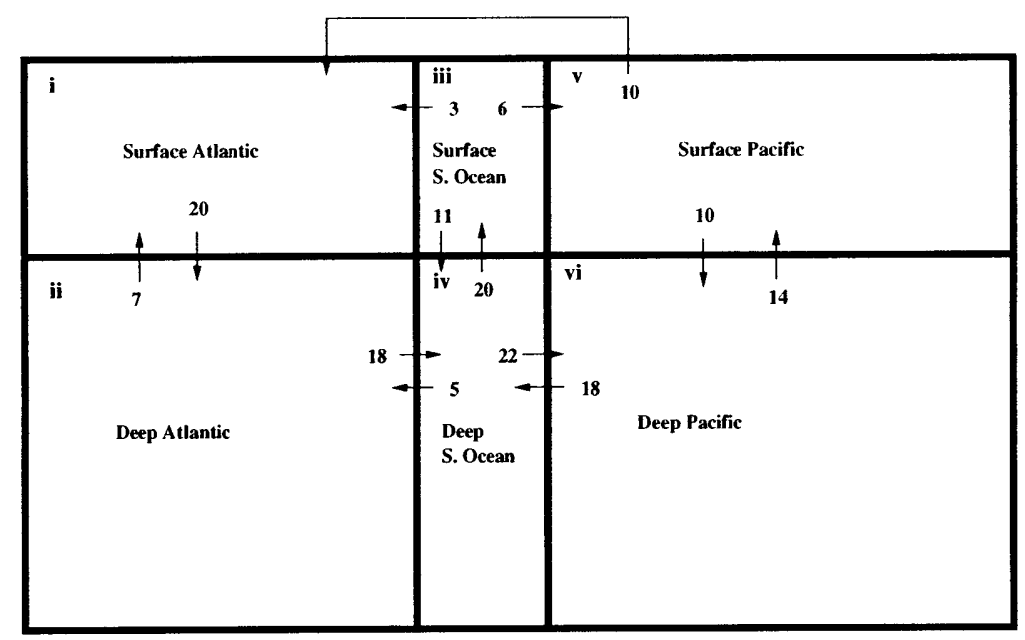

Figure 2-1: Schematic Diagram of box model adapted from Broecker and Peng (1986, 1987). The arrows represent volume transport (Sv).

understanding and preliminary sensitivity studies of unconstrained rates of various processes.

\subsubsection{Representation of Macro-nutrient Cycling}

The tracers explicitly carried in my model are phosphate $\left(\mathrm{PO}_{4}\right)$, dissolved organic phosphorus (DOP), total dissolved iron $\left(\mathrm{Fe}_{T}\right)$, and particulate inorganic iron $\left(\mathrm{Fe}_{P}\right)$. Biological uptake and regeneration are indexed to phosphorus. I illustrate the mechanics of the model's phosphorus cycle with the prognostic equations for phosphate $\left(\mathrm{PO}_{4}\right)$ and dissolved organic phosphate (DOP) for the surface and deep Atlantic (boxes $i$ and $i i$ in Figure 2-1). For the surface:

$$
\begin{aligned}
\frac{d P O_{4}^{i}}{d t} & =-u \cdot \nabla P O_{4}^{i}-\Gamma+\lambda D O P^{i} \\
\frac{d D O P^{i}}{d t} & =-u \cdot \nabla D O P^{i}+\Gamma f_{D O P^{i}}-\lambda D O P^{i} \\
\Gamma & =\mu P O_{4}^{i} \frac{F e_{T}^{i}}{F e_{T}^{i}+K_{s}}
\end{aligned}
$$


Superscript numerals indicate the relevant model reservoir. The first term on the right of (1) indicates transport by the model's circulation, the second represents biological export, and the third term the remineralization of DOP. Biological uptake and export are limited by light, phosphate and iron (2.3). In conditions where Fe and light are replete, $\mathrm{I}$ assume surface $\mathrm{PO}_{4}$ to be the limiting nutrient which is exported with a characteristic timescale, $1 / \mu$, of about 1 month. Iron limitation is represented by Michaelis-Menten kinetics. The half saturation constant $\left(\mathrm{K}_{s}\right)$ is globally uniform but is adjusted, within the range of measured values (Price et al., 1994; Fitzwater et al., 1996), to optimize the modeled surface $\left[\mathrm{PO}_{4}\right]$ and $\left[\mathrm{Fe}_{T}\right]$ distributions. For the deep:

$$
\begin{aligned}
\frac{d P O_{4}^{i i}}{d t} & =-u \cdot \nabla P O_{4}^{i i}+\Gamma^{i}\left(1-f_{D O P^{i}}\right)+\lambda D O P^{i i} \\
\frac{d D O P^{i i}}{d t} & =-u \cdot \nabla D O P^{i i}-\lambda D O P^{i i}
\end{aligned}
$$

In (2.4), the first term on the right represents transport, the second the remineralization of sinking particulate matter, and the third the remineralization of DOP.

Two-thirds of the exported nutrient $\left(f_{D O P}\right)$ enters the surface dissolved organic phosphorus (DOP) pool, while one-third is rapidly exported as particulate $\mathrm{P}$ to the deep $\mathrm{PO}_{4}$ pool (Yamanaka and Tajika, 1997). The imposed timescale for remineralization of DOP, $(1 / \lambda)$, is 6 months.

\subsubsection{Iron Cycling}

The aeolian source of iron is prescribed, while the loss of iron due to scavenging and iron's role in the biological cycle are modeled explicitly. Total dissolved iron $\left(\mathrm{Fe}_{T}\right)$, and particulate inorganic iron $\left(\mathrm{Fe}_{P}\right)$ are prognostic tracers of the model. The following equations below describe the iron cycle for the surface and deep Atlantic (boxes $i$ and ii in Figure 2-1). The equations for the other basins are similar. For the 
surface:

$$
\begin{aligned}
& \frac{d F e_{T}^{i}}{d t}=\alpha F_{i n}-u \cdot \nabla F e_{T}^{i}-\Gamma R_{F e}+\lambda D O P^{i} R_{F e}+J_{F e}^{i} \\
& \frac{d F e_{P}^{i}}{d t}=-J_{F e}^{i}-W s \frac{\partial}{\partial z} F e_{P}^{i}
\end{aligned}
$$

The first term on the right in (2.6) represents the aeolian source, the second term ocean transport of total iron, the third term biological utilization. Remineralization of DOM is represented by the fourth term on the right multiplied by the Redfield ratio $\left(\mathrm{R}_{F e}\right)$ between $\mathrm{PO}_{4}$ and $\mathrm{Fe}$. The fifth term, $J_{F e}^{i}$, represents the interactions with particles or ligands, which differ between each of the three parameterizations and will be described in more detail below.

Aeolian deposition $\left(\mathrm{F}_{\text {in }}\right)$ is the source of iron to the model ocean. Iron deposition data from Gao et al.(2001), Duce and Tindale (1991) and Jickells and Spokes (2001) were used to estimate the source to the surface waters of each basin. Table 2.1 summarizes the various datasets and the values used. The solubility of Fe aerosols $(\alpha)$ in seawater is not well known, although recent studies suggest it may be below $5 \%$ (Jickells and Spokes, 2001; Spokes and Jickells, 1996). Based on results of parameter space exploration, we use $\alpha=0.01$ for the models discussed here.

Iron is biologically utilized in proportion to $\mathrm{PO}_{4}$ with a fixed $\mathrm{Fe}: \mathrm{C}$ ratio $\left(\mathrm{R}_{F e}\right)$ and a C:P Redfield ratio of 16:1. Sunda and Huntsman (1995) have published estimates for the $\mathrm{Fe}: \mathrm{C}$ ratio that indicate marine phytoplankton decrease their cellular iron requirement to optimize growth in Fe-stressed environments, but I have not represented this variability here, as a clear relationship has not been established. The Fe:C ratio is globally adjusted to optimize surface $\left[\mathrm{PO}_{4}\right]$ and $\left[\mathrm{Fe}_{T}\right]$.

Evidence from Th isotopes indicates that the mean sinking rate of fine particles is between 500 and 1,000 myr $^{-1}$ (Cochran et al., 1993). In order to very crudely account for the different sinking rates of large and small particles, we have assumed that $10 \%$ 


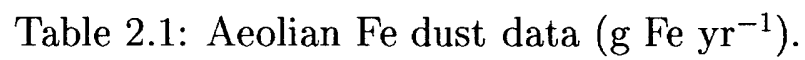

\begin{tabular}{lllll} 
Basin & Gao & Duce/Tindale & Jickells/Spokes & Model values \\
\hline Atlantic & 7.73 & 8.54 & 6.46 & 6.46 \\
Southern Ocean & 0.071 & - & - & 0.071 \\
Indo-Pacific & 5.71 & 23.5 & 10.17 & 10.17
\end{tabular}

Data sets: Duce and Tindale, 1991; Gao et al., 2001; and Jickells and Spokes, 2001.

of particles are large with a sinking rate of $20,000 \mathrm{myr}^{-1}$ and $90 \%$ are small particles with a sinking rate of $1,000 \mathrm{myr}^{-1}$, yielding an average sinking rate $\left(\mathrm{W}_{s}\right)$ of 2,900 $\mathrm{myr}^{-1}$.

The deep equations for iron are:

$$
\begin{aligned}
\frac{d F e_{T}^{i i}}{d t} & =-u \cdot \nabla F e_{T}^{i i}+\Gamma R_{F e}\left(1-f_{D O P}\right)+\lambda D O P^{i i} R_{F e} \\
& +J_{F e}^{i i} \\
\frac{d F e_{P}^{i i}}{d t} & =-J_{F e}^{i i}-W s \frac{\partial}{\partial z} F e_{P}
\end{aligned}
$$

I examine three different parameterizations for the geochemical processes: (I) net scavenging (II) scavenging and desorption, and (III) scavenging and complexation. In case I and II, I do not differentiate between complexed and free iron and assume that the total iron pool is subjected to all geochemical processes. In case III, I explicitly model complexation and differentiate between free iron and complexed iron.

\subsection{Model Results}

While I will focus on the iron distribution in this discussion, the phosphate distribution, which is explicitly controlled by iron limitation here, also provides a consistency check on the model. For solutions in which iron distribution is reasonable, the phosphate distributions are in good agreement with observations. Surface $\left[\mathrm{PO}_{4}\right]$ is 
Table 2.2: Model Parameters

\begin{tabular}{lll} 
Symbol & Definition & Value \\
\hline $\mathrm{R}_{F e}$ & Fe:P ratio & adjustable parameter \\
$\mathrm{f}_{D O P}$ & fraction of DOP & 0.67 \\
$\mathrm{~h}$ & Depth of surface box & $100 \mathrm{~m}$ \\
$\mathrm{H}$ & Depth of deep box & $3900 \mathrm{~m}$ \\
$\mathrm{~F}_{i n}$ & Aeolian Deposition rate & see Table 1 \\
$\alpha$ & Fe dust solubility & $1 \%$ \\
$\mu$ & Biological uptake rate & 1 month \\
& -1 \\
$\lambda$ & Remineralization rate & $0.5 \mathrm{yr}^{-1}$ \\
$\mathrm{k}_{s c}$ & Scavenging rate & variable \\
$\mathrm{k}_{b}$ & Backscavenging rate & variable \\
$\mathrm{W}_{s}$ & Particle sinking velocity & 2,900 myr \\
$\mathrm{K}_{s}$ & Iron half saturation constant & adjustable parameter \\
$\mathrm{K}_{F e L}$ & Ligand conditional stability constant & variable
\end{tabular}

elevated in the Southern Ocean box, depleted in the Atlantic box and intermediate in the Indo-Pacific box. Deep $\left[\mathrm{PO}_{4}\right]$ increases from the Atlantic to the Indo-Pacific.

\subsubsection{Case I: Net Scavenging Model}

Boyle (1997) suggested that the deep water distribution of iron may be modeled using simple parameterizations of aeolian deposition, biological uptake and remineralization of organic matter, and a representation of net scavenging to particles. Such a model is highly idealized, and does not attempt to explicitly represent the details of the biogeochemical processes, but it could be the simplest viable prognostic model for iron in the ocean. It has only one adjustable parameter and does not attempt to describe poorly understood details of the biogeochemical processes.

Here, I examine whether this parameterization can reproduce the broad basin to basin and surface to deep ocean observed gradients of dissolved iron. In this formulation $\mathrm{Fe}_{T}$ is scavenged and utilized biologically. This parameterization is conceptually similar to the no-ligand model of Lefévre and Watson (1999). I impose the regional variations in aeolian supply and examine the sensitivity of the dissolved iron distribution to the net scavenging rate. In this case the loss of iron is modeled simply 


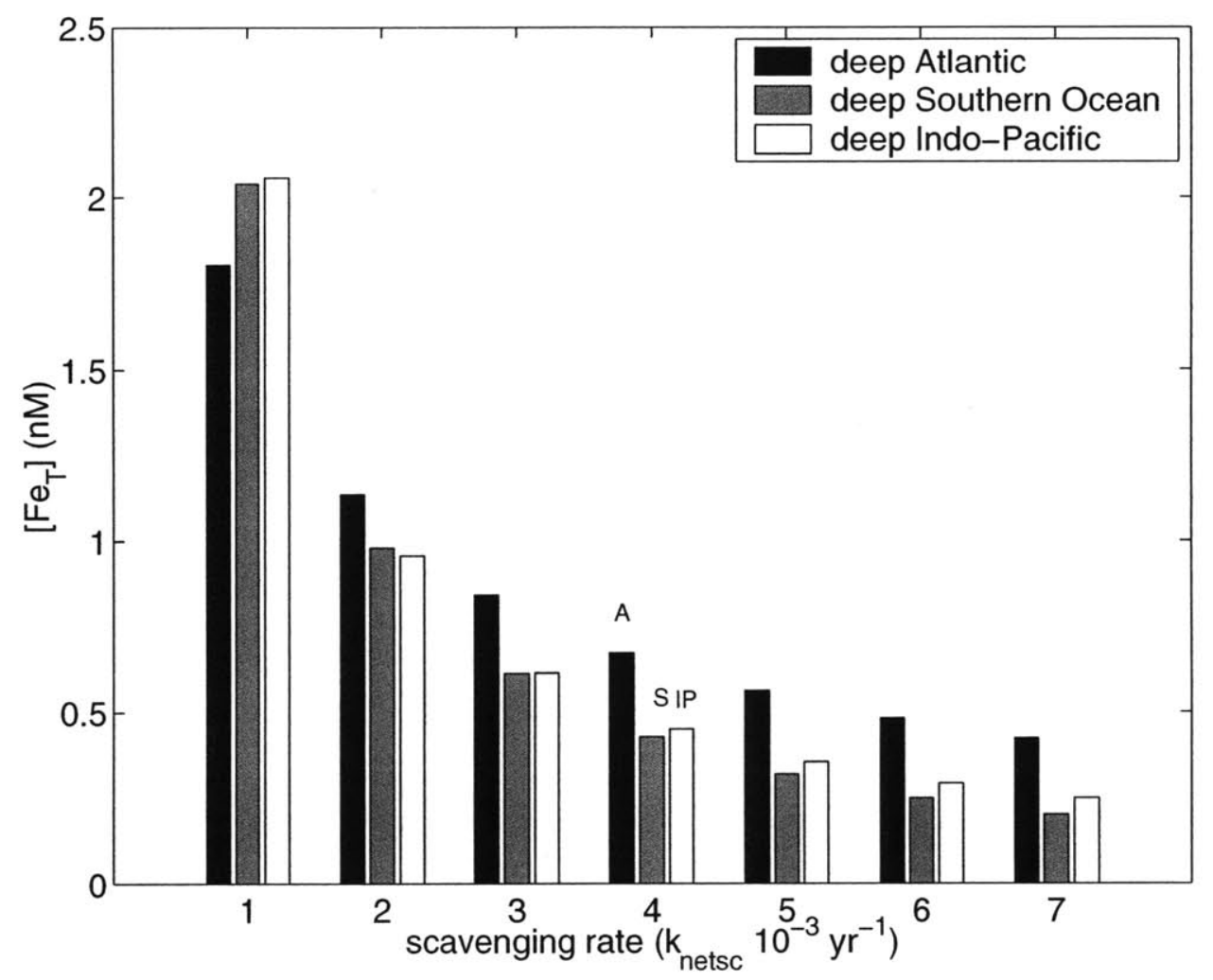

Figure 2-2: Sensitivity of deep $\left[\mathrm{Fe}_{T}\right]$ to scavenging rates. For slow scavenging rates, $\left(k_{\text {netsc }}<.001\right)$, the $\mathrm{Fe}_{T}$ distribution is nutrient-like. For intermediate scavenging rates, $.004<k_{\text {netsc }}<.006$, the observed gradients are reproduced. For $\mathrm{k}_{\text {netsc }}>.006$, the sense of gradient is reproduced, although mean concentrations are lower than observed.

as a first-order scavenging process, limited by the dissolved free Fe concentration. Scavenged iron is transfered to the particulate pool, $F e_{p}$, with rate constant $-k_{n e t s c}$, and is stripped from the water column as the particles sink. For the net scavenging (and scavenging-desorption) case Fe:C is $25 \mu \mathrm{mol}: 1 \mathrm{~mol}$. Here, then

$$
J_{F e}=-k_{n e t s c} F e_{T} .
$$

Figure 2-2 shows the deep ocean, dissolved iron concentrations in each of the three modeled regions (Atlantic basin, Southern Ocean, Pacific basin) as a function of the net scavenging rate. Each cluster of three bars represents the solution of the model at a particular value of scavenging rate. The relative lengths of the three bars 
reflect the basin to basin gradients of deep iron in each solution. In the case of a slow net-scavenging rate $\left(k_{n e t s c}=0.001 \mathrm{yr}^{-1}\right)$, the deep water distribution is that of a typical nutrient with the deep Indo-Pacific iron concentration greater than the deep Southern Ocean which is greater than the deep Atlantic. The result is unsurprising, but the gradients are not as observed. For stronger scavenging, $k_{n e t s c}>.004 \mathrm{yr}^{-1}$, the observed deep water Fe gradients (Atl>Indo-Pacific $>$ Southern Ocean) are reproduced. However, when $k_{n e t s c}>.006 \mathrm{yr}^{-1}$, though the inter-basin gradients remain of the correct sign, the mean ocean deep water $\left[\mathrm{Fe}_{T}\right]$ becomes much too low.

This simple model, representing the basin variations of the aeolian supply and a uniform, net scavenging rate can reproduce the unique deep water iron signature provided that $0.004 \mathrm{yr}^{-1}<k_{s c}<0.006 \mathrm{yr}^{-1}$. This is consistent with the previous study of Lefévre and Watson (1999).

\subsubsection{Case II: Scavenging-Desorption Model}

While the highly simplified model of Case I can reproduce the broad, basin-to-basin gradients of the dissolved iron distribution, it does not resolve the biogeochemical processes at work. In Cases II and III, I introduce more detailed parameterizations which attempt to represent processes known to be, or likely to be, at work in the ocean. I ask if these more detailed models can reproduce the observations and, if so, what constraints can be placed on system parameters by the observations?

Thorium is produced in the ocean by radio-decay and is subsequently scavenged out of the water column by sinking particles. Bacon and Anderson (1982), using oceanic observations of thorium isotopes, have estimated a scavenging rate between $0.2-1.28 \mathrm{yr}^{-1}$. This is much faster than the net scavenging rate for iron implied in our model (case I), but does not represent the net scavenging rate for Th. Bacon and Anderson (1982) suggest that scavenged Th is also desorbed from particles, i.e. released back to the water column, and also infer from data a rate at which this occurs. Since Fe and Th have similar metallic properties, I consider it likely that iron 


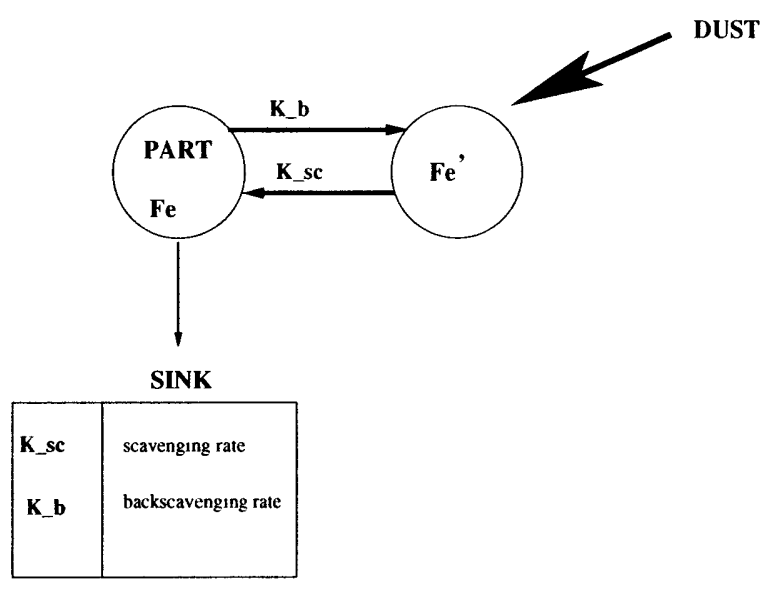

Figure 2-3: Schematic description of the scavenging and desorption model. Desorption is treated as a first order process dependent on the particulate iron concentration and transfers particulate Fe to the dissolved pool. Scavenging is modeled as a first order process dependent on the dissolved Fe concentration. Scavenged iron can be lost from the ocean, ultimately balancing the aeolian sink.

may experience a similar dynamic interplay of scavenging and desorption to and from particles.

To address this possibility in case II, I parameterize the interactions of iron with particles in the deep water as a cycle of rapid scavenging and desorption, which may result in a slow, net scavenging consistent with the observed distribution and Case I above (Figure 2-3). In this case

$$
J_{F e}=-k_{s c} F e_{T}+k_{b} F e_{P}
$$

Here $-k_{s c}$ is the scavenging rate. Scavenging is proportional to the availability of dissolved iron; $k_{b}$ is the desorption rate, and desorption is proportional to particulate iron. Figure 2-4 shows the deep water, dissolved iron concentration in each of the model regions as a function of scavenging rates ranging between 0.1-1 $\mathrm{yr}^{-1}$ and desorption rates between $20-100 \mathrm{yr}^{-1}$. When the ratio of desorption/scavenging $\sim 150-170$, this model is able to broadly reproduce the observed global deep water Fe gradients and concentrations (dashed contours). 
A.

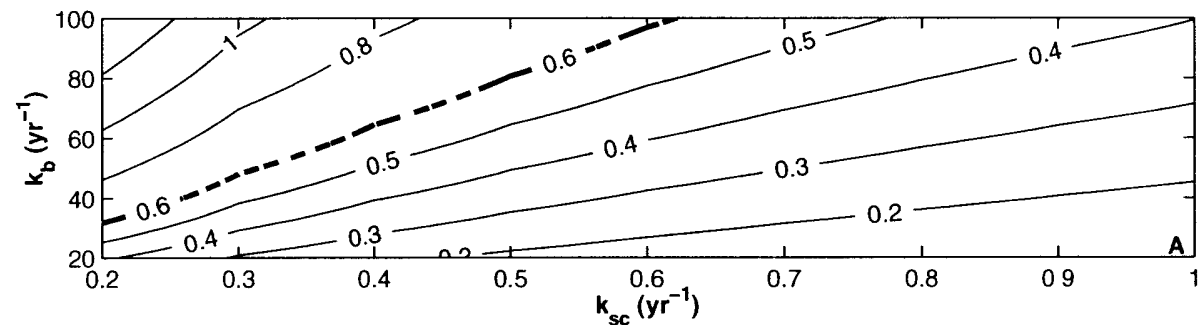

B.

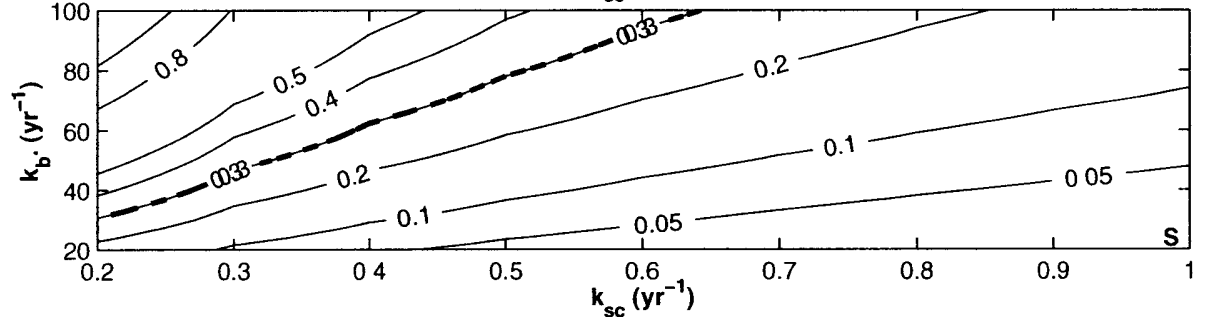

c.

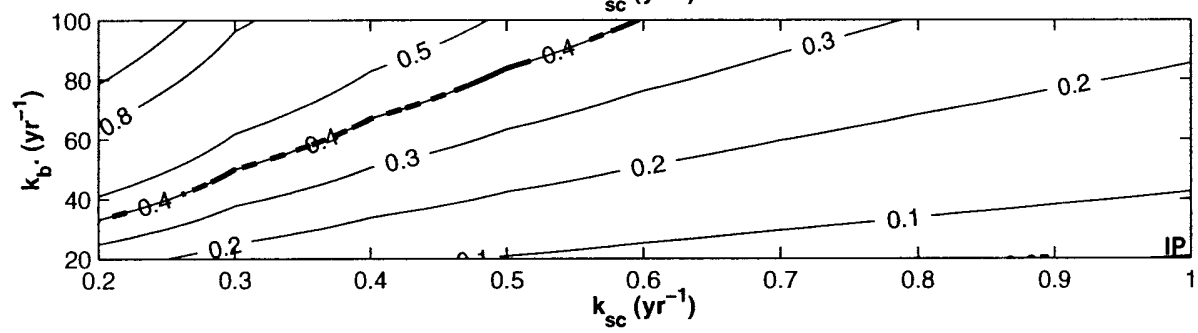

Figure 2-4: Scavenging-desorption model: Sensitivity of deep $\left[\mathrm{Fe}_{T}\right]$ (nM) to scavenging-desorption rate constants. [ $\left[\mathrm{Fe}_{T}\right]$ as a function of scavenging $\left(k_{s c}, \mathrm{yr}^{-1}\right)$ and desorption $\left(k_{b}, \mathrm{yr}^{-1}\right)$ for A) Atlantic, B) Southern Ocean and C) Indo-Pacific basin. The dashed contours indicate the average observed $\left[\mathrm{Fe}_{T}\right]$ for each basin. The optimal solution is for $k_{b} / k_{s c} \sim 150-170$. 
For thorium, the desorption to scavenging ratio is calculated to be an order of magnitude smaller. I might interpret these model results to suggest that iron and thorium may behave in a similar manner, but have different desorption to scavenging ratios, implying that $\mathrm{Th}$ is much more particle reactive than Fe. On the other hand, there are other processes which may be significant for iron and which I should include in the model.

\subsubsection{Case III: Complexation}

Case II again found a plausible solution of the model by representing iron as an analogue of thorium, provided appropriate scavenging and desorption rates are applied. New methods and observations of iron in the ocean would be required to directly confirm such a mechanism at work. However, there is a great deal of evidence that another biogeochemical process - complexation with organic ligands - plays a significant role in the control of deep water iron distributions.

Observational evidence (Gledhill and van den Berg, 1994; Rue and Bruland, 1995; van den Berg, 1995; Wu and Luther, 1995; Rue and Bruland, 1997; Gledhill et al., 1998; Nolting et al., 1998; Witter and Luther, 1998; Witter et al., 2000; Boye et al., 2001; Powell and Donat, 2001) indicates that over 99\% of "dissolved" iron is bound to a ligand. In this third case I add a mechanistic description of Fe complexation to our box model (Figure 2-5). Representations of the effect of complexation have been introduced in two previous models (see Chapter 1). The model applied here is closely related to the (second) model of Archer and Johnson (2000), representing complexation with a single ligand imposing $\left[\mathrm{L}_{T}\right]$. In the light of new data, I explore the sensitivity of modeled deep water $\left[\mathrm{Fe}_{T}\right]$ to a wide range of parameter values. For example, in the Archer and Johnson (2000) model, $\mathrm{L}_{T}$ is fixed at $0.6 \mathrm{nM}$, while I test the sensitivity of deep water $\left[\mathrm{Fe}_{T}\right]$ to the value of $\left[\mathrm{L}_{T}\right]$, which varies between $0.5-6 \mathrm{nM}$ in the global ocean (see Chapter 1.1). I also assess the sensitivity of deep water $\left[\mathrm{Fe}_{T}\right]$ to a range of scavenging rates and ligand strengths, since they are poorly constrained. 


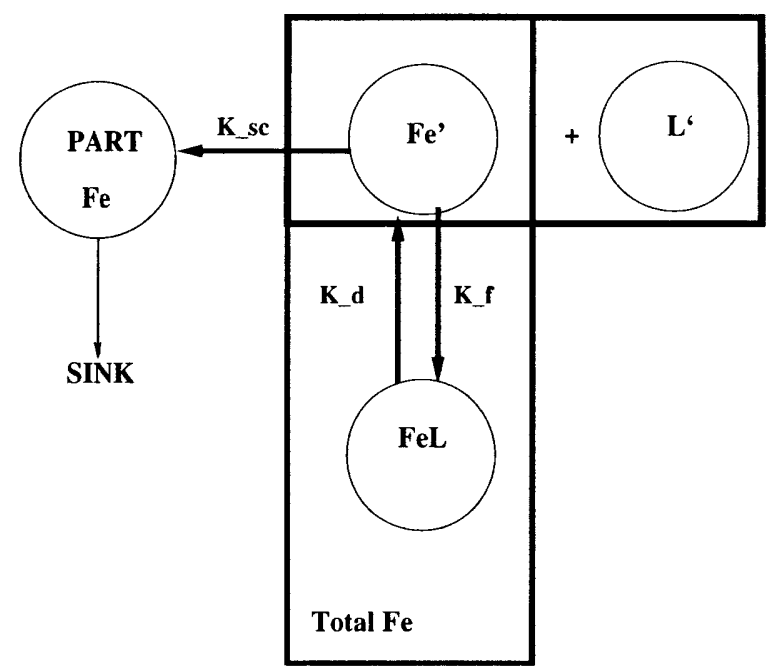

Figure 2-5: Schematic diagram of the complexation model. Dissolved Fe can undergo two transformations: it can be scavenged or it can be complexed. The box represents the reaction $\mathrm{Fe}^{\prime}+\mathrm{L}^{\prime}=\mathrm{FeL}$. We assume that chemical forms within the box $\left(\mathrm{Fe}^{\prime}\right.$ and $\mathrm{FeL}$ ) can be utilized biologically, but only $\mathrm{Fe}^{\prime}$ can be scavenged.

Here, dissolved iron is assumed to be the sum of "free" and "complexed" forms:

$$
F e_{T}=F e^{\prime}+F e L .
$$

where $\mathrm{FeL}$ represents the iron complexed with an organic ligand. Only the free form is available for scavenging and hence

$$
J_{F e}=-k_{s c} F e^{\prime} .
$$

Since complexation occurs on the timescales of minutes to hours (Witter et al.,2000), it is assumed that the reaction goes to equilibrium. I specify the total ligand concentration, $\mathrm{L}_{T}=[\mathrm{FeL}]+\left[\mathrm{L}^{\prime}\right]$, and use the equilibrium relationship $\mathrm{K}_{\mathrm{FeL}}^{c o n d}=\mathrm{k}_{f} / k_{d}=[\mathrm{FeL}] /\left[\mathrm{Fe}^{\prime}\right]\left[\mathrm{L}^{\prime}\right]$ to determine the speciation of the iron. $F e_{T}$ is a conserved property and is advected. Desorption from particles is neglected in this case since its impact is overwhelmed by the strong complexation reaction. In the complexation-scavenging case the Fe:C ratio is set to $15 \mu \mathrm{mol}: 1 \mathrm{~mol}$. 
Setting $\mathrm{L}_{T}$ to $1 \mathrm{nM}$ in Figure 2-6, I plot the relationship of the deep water dissolved iron concentration in each basin to scavenging rate, ranging between 0.2-1.8 $\mathrm{yr}^{-1}$ and conditional stability constant, $K_{F e L}$, between $10^{10} \mathrm{M}^{-1}$ and $10^{13} \mathrm{M}^{-1}$, reflecting the range of values inferred from ocean observations (Gledhill and van den Berg, 1994; Rue and Bruland, 1995; van den Berg, 1995; Wu and Luther, 1995; Rue and Bruland, 1997; Gledhill et al., 1998; Nolting et al., 1998; Witter and Luther, 1998; Witter et al., 2000; Boye et al., 2001; Powell and Donat, 2001). Deep iron concentrations generally increase with increasing stability constant and decreasing scavenging rate. Since only the uncomplexed form of iron can be scavenged, at high scavenging rates a strong ligand is required to maintain deep water "dissolved" $\left[\mathrm{Fe}_{T}\right]$ concentrations at observed levels, sequestering it in a form which I assume is not available for scavenging. At very low scavenging rates, the sensitivity to the conditional stability constant decreases, since it is no longer necessary for iron to be in complexed form to remain in the water column for a significant period. The sensitivity to the scavenging constant is weak when scavenging is strong because there is very little scavengable iron and the limiting process is complexation.

Observations indicate that, while most "dissolved" iron is in complexed form, a significant fraction of ligand is free (Gledhill and van den Berg, 1994; Rue and Bruland, 1995; van den Berg, 1995; Wu and Luther, 1995; Rue and Bruland, 1997; Gledhill et al., 1998; Nolting et al., 1998; Witter and Luther, 1998; Witter et al., 2000; Boye et al., 2001; Powell and Donat, 2001). This is in contrast to the models of Archer and Johnson (2000) and Lefévre and Watson (1999) where, due to the low total ligand concentration and high conditional stability constant, the dissolved iron concentration was about the same as the total ligand concentration $(0.6 n M)$ over much of the ocean. This case, where the ligand is saturated, represents a limit case of the scheme used here. By relaxing these constraints, it is possible to find a solution consistent with the observed iron distribution which also predicts a significant presence of free ligand, $L^{\prime}$. Figure 2-7 shows the dependency of $\left[L^{\prime}\right]$ on $K_{F e^{\prime} L}$ and scavenging rate constant 
A.

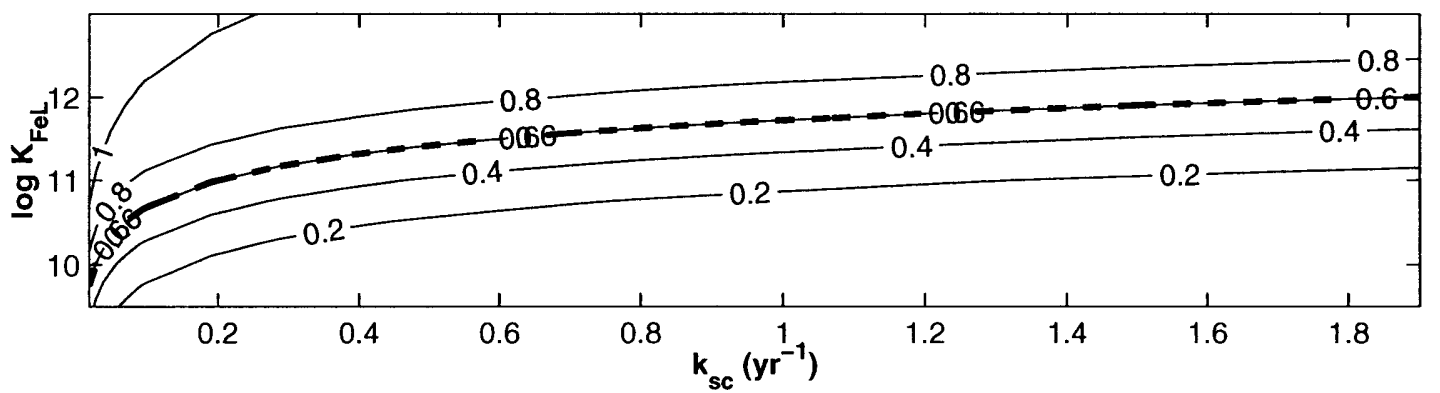

B.

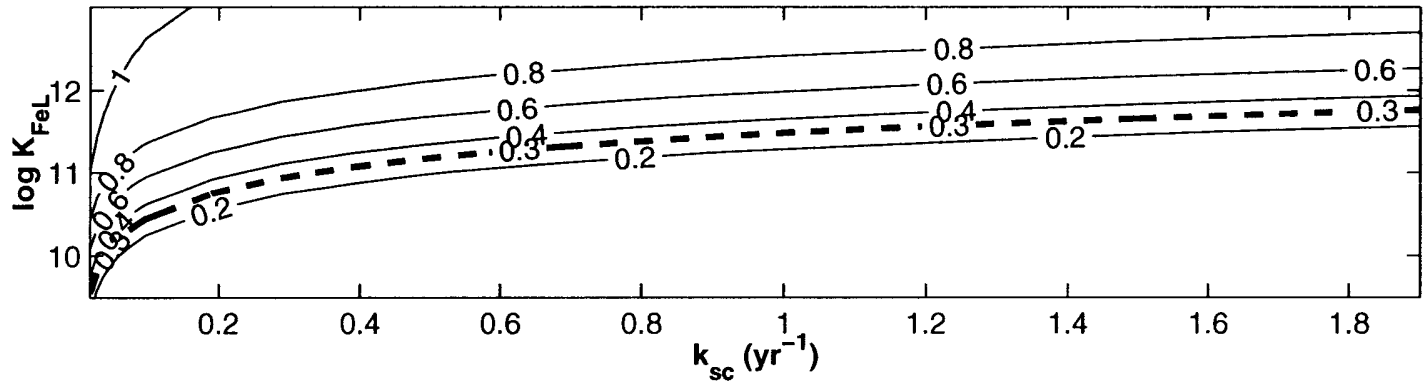

C.

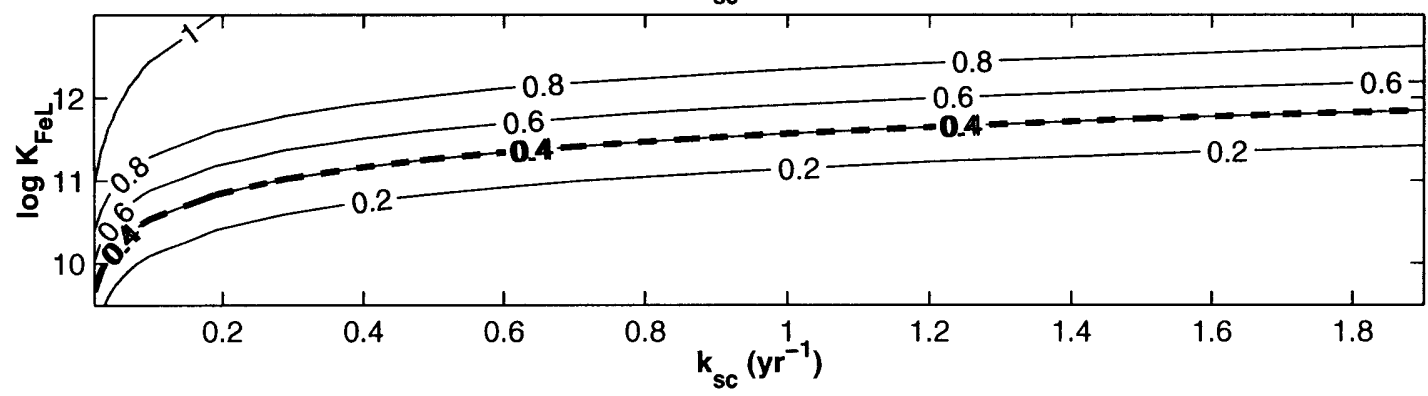

Figure 2-6: Complexation model: Sensitivity of $\left[\mathrm{Fe}_{T}\right](\mathrm{nM})$ to scavenging $\left(k_{s c}, \mathrm{yr}^{-1}\right)$ and conditional stability constant $\left(\log K_{F e^{\prime} L}\right)$ for the A) Atlantic, B) Southern Ocean, and C) Indo-Pacific basin with $\left[\mathrm{L}_{T}\right]=1 \mathrm{nM}$. The dashed contour represents the average observed deep water $[\mathrm{Fe}]$ for each basin. The optimal solution is for $k_{s c}$ between $0.2-1.8$ $\mathrm{yr}^{-1}$. 
A.

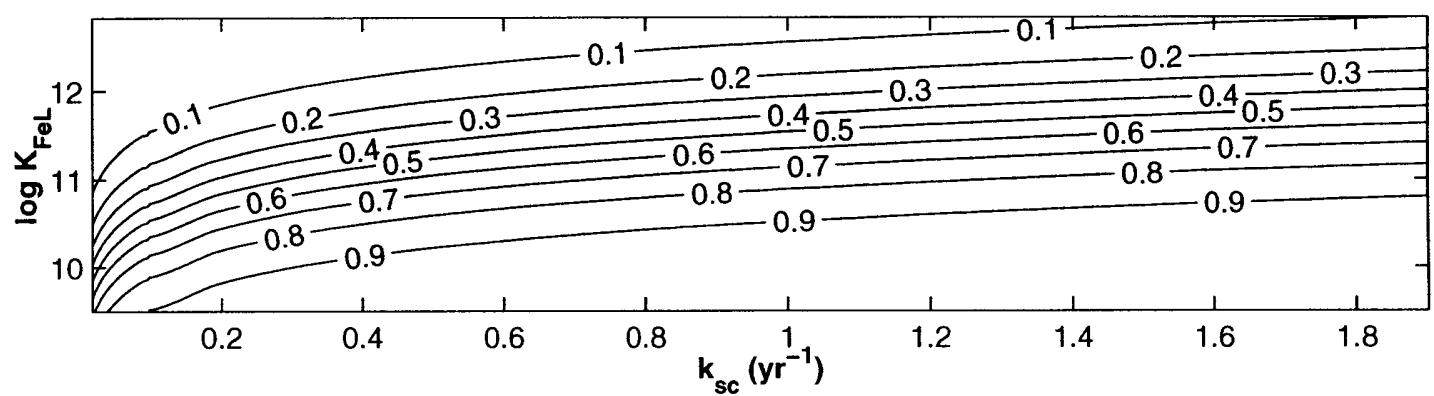

B.

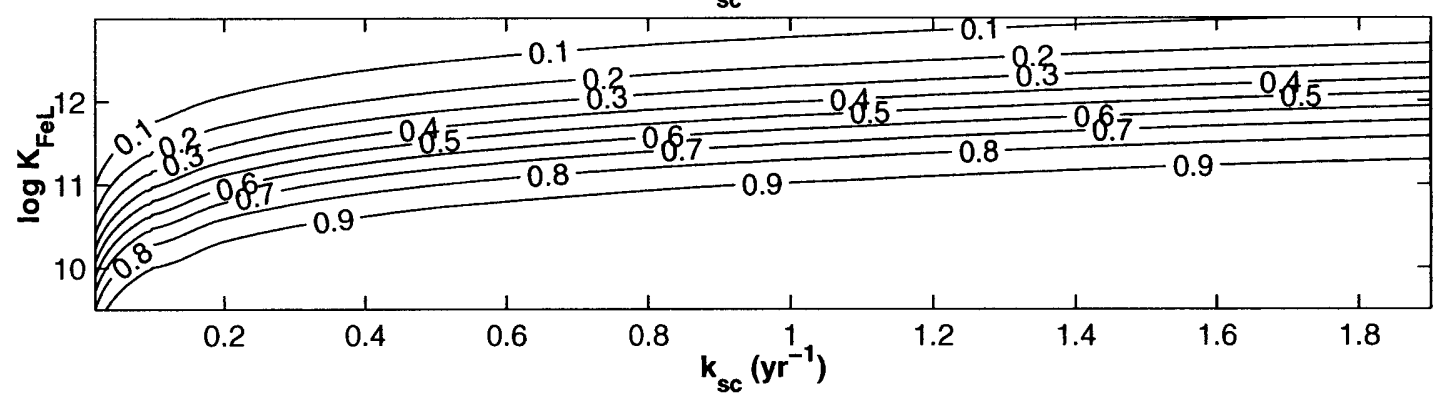

C.

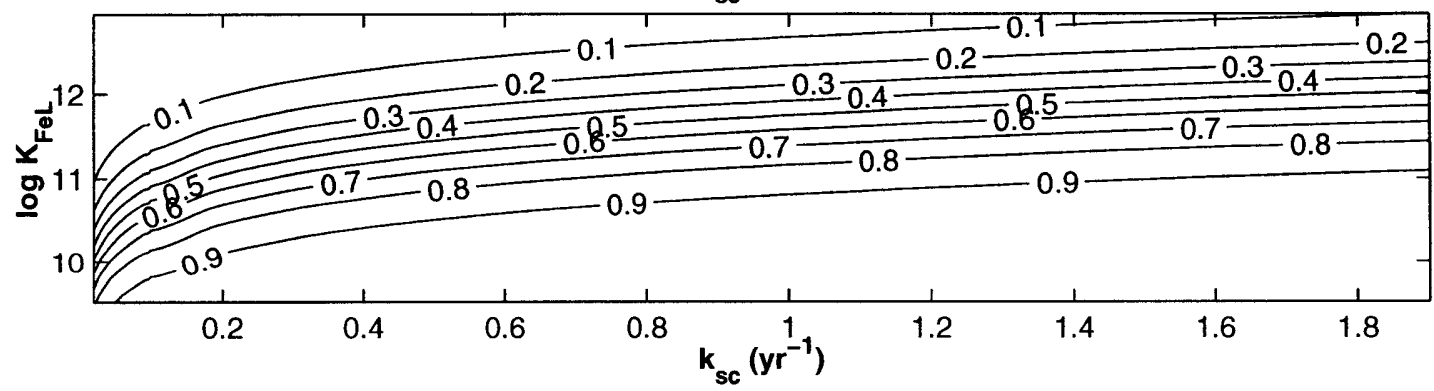

Figure 2-7: Complexation model: Sensitivity of the free ligand concentration $\left(\left[\mathrm{L}^{\prime}\right]\right)$ $(\mathrm{nM})$ to scavenging rate $\left(k_{s c}, \mathrm{yr}^{-1}\right)$ and conditional stability constant $\left(\log \mathrm{K}_{F e^{\prime} L}\right)$ for the A) Atlantic, B) Southern Ocean and C) Indo-Pacific basin with $\left[\mathrm{L}_{T}\right]=1 \mathrm{nM}$. As $\log K_{F e^{\prime} L}$ increases, [L] decreases due to forward reaction $\mathrm{L}^{\prime}+\mathrm{Fe}^{\prime}=\mathrm{FeL}$. As scavenging increases, $[\mathrm{L}]$ increases, as forward reaction is limited by $\mathrm{Fe}$, resulting in excess $\mathrm{L}$. Observations indicate $\mathrm{L}_{T}$ ranges between $0.5-6 \mathrm{nM}$. 
for this model with specified total ligand concentration of $1 \mathrm{nM}$. As the scavenging rate increases, the loss of Fe limits the complexation reaction, resulting in excess free ligand, $\left[\mathrm{L}^{\prime}\right]$. Comparing Figure 2-6 and Figure 2-7, $\mathrm{Fe}_{T}$ and $\mathrm{L}$ are inversely related. For strong $K_{F e L}, \mathrm{Fe}_{T} \approx \mathrm{FeL}$, which is the limit modeled by Archer and Johnson (2000) and implicitly by Lefévre and Watson (1999) .

Observations also indicate a significant variation in ligand concentration around the ocean but, as yet, without a clearly emerging large scale pattern (Gledhill and van den Berg, 1994; Rue and Bruland, 1995; van den Berg, 1995; Wu and Luther, 1995; Rue and Bruland, 1997; Gledhill et al., 1998; Nolting et al., 1998; Witter and Luther, 1998; Witter et al., 2000; Boye et al., 2001; Powell and Donat, 2001). Still without introducing any spatial variations in the ligand concentration, I also illustrate the sensitivity of dissolved iron and free ligand concentrations to the concentration of total ligand. Figure 2-8 and Figure 2-9 show the deep ocean iron concentration and free ligand concentration respectively, (as Figures 2-6 and 2-7), but with increased total ligand concentration, $\mathrm{L}_{T}=4 \mathrm{nM}$. For identical choices of $k_{s c}$ and $K_{F e L}$ with increased total ligand, I find increased $\left[\mathrm{Fe}_{T}\right]$. Hence, to the fit the modern observed distribution with $\mathrm{L}_{T}=4 \mathrm{nM}$, I must adjust $k_{s c}$ by a factor of $\approx 15-25$ times. However, the sensitivity pattern is the same as the case where $L_{T}$ is fixed to $1 \mathrm{nM}$.

The model predicts an excess $\left[\mathrm{L}^{\prime}\right]$ ranging from $0.5-3 \mathrm{nM}$ for scavenging rates between 0.2-1.8 $\mathrm{yr}^{-1}$ and ligand strengths ranging from $\log \left(K_{F e L}\right)$ of 10-13 (Figure 2-9). It suggests highest excess $\left[L^{\prime}\right]$ for the Atlantic basin, in broad agreement with observations (Gledhill and van den Berg, 1994; Rue and Bruland, 1995; van den Berg, 1995; Wu and Luther, 1995; Rue and Bruland, 1997; Gledhill et al., 1998; Nolting et al., 1998; Witter and Luther, 1998; Witter et al., 2000; Boye et al., 2001; and Powell and Donat, 2001). 
A.

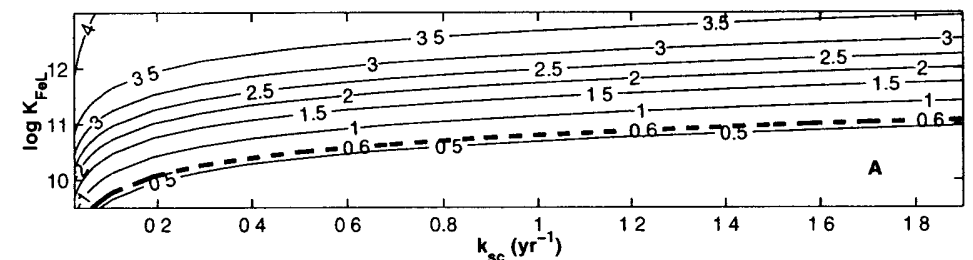

B.

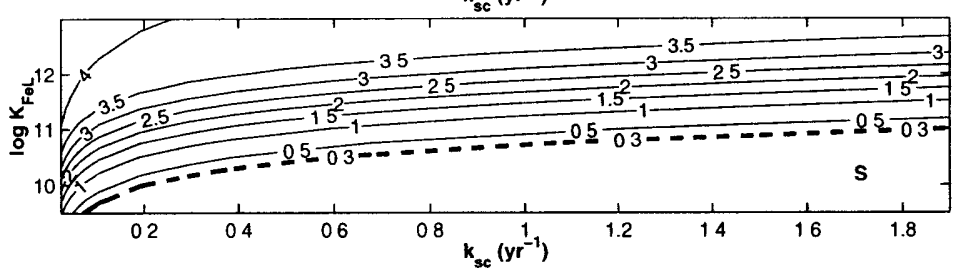

c.

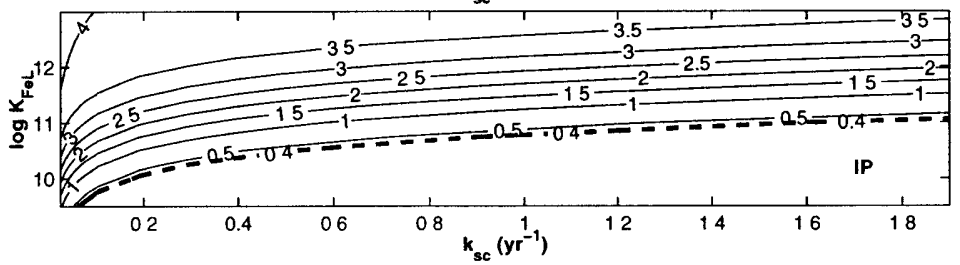

Figure 2-8: Complexation model: Sensitivity of modeled deep water $\left[\mathrm{Fe}_{T}\right]$ to scavenging rate $\left(k_{s c}, \mathrm{yr}^{-1}\right)$ and conditional stability constant $\left(\log K_{F e^{\prime} L}\right)$ for the A) Atlantic, B) Southern Ocean, and C)Indo-Pacific basin with $\left[\mathrm{L}_{T}\right]=4 \mathrm{nM}$. The dashed contour represents the observed average deep water $\left[\mathrm{Fe}_{T}\right]$ for each basin.

\subsection{Discussion}

I have examined three parameterizations of water column iron biogeochemistry in the framework of an idealized, six-box ocean biogeochemistry model. In the light of the latest available observations of the deep ocean distribution of iron, an extremely simple model which parameterizes deep ocean biogeochemical cycling of iron as a first order net scavenging, is able to capture the broad basin to basin $\left[\mathrm{Fe}_{T}\right]$ gradients. However, this parameterization does not explicitly represent the processes believed to control the system. A second parameterization treated iron as an analogue of thorium, with rapid scavenging and desorption of iron to and from particles. For a scavenging-desorption rate constant of $\sim 150$, this model can also reproduce the broad features of the large scale distribution of dissolved iron.

In a third parameterization, following Archer and Johnson (2000), I introduce complexation to an organic ligand. Sensitivity studies showed that this model can 


\section{A.}
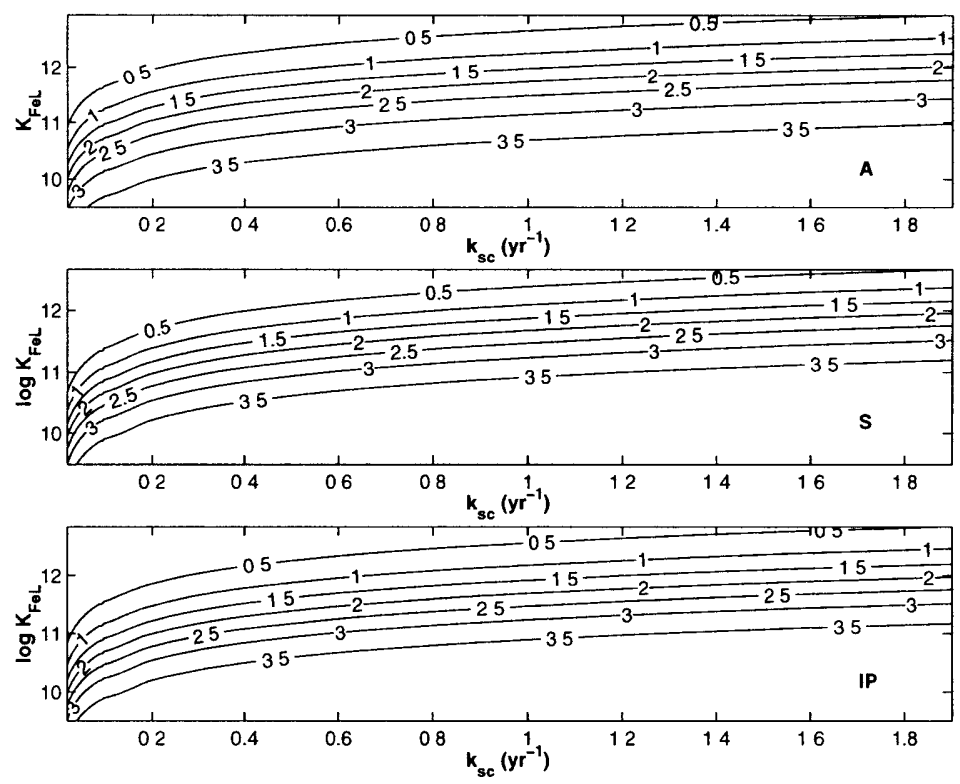

Figure 2-9: Complexation model: Same as Figure 2-7, but $\left[\mathrm{L}_{T}\right]=4 \mathrm{nM}$.

reproduce the large scale iron distribution for a range of ligand strengths, $K_{F e L}$ and scavenging rates, $k_{s c}$, (in appropriate combination) and for a range of total ligand concentrations, $L_{T}$. The ligand parameterization of Lefévre and Watson (1999) and Archer and Johnson's (2000) complexation with one ligand case, with a very strong ligand and low total ligand concentration, both led to quite uniform deep ocean iron distributions and saturated ligand. This is a limit case of the more general model presented here. The model and recent observational data suggest that the parameter choices of Archer and Johnson's (2000) two ligand model, with a very strong ligand in the upper ocean resulting in fairly uniform deep water $\left[\mathrm{Fe}_{T}\right]$, is at odds with recent observational evidence. It would also lead to high iron and low phosphorus concentrations at the surface. To prevent the accumulation of iron in surface waters, Archer and Johnson (2000) remove any surface iron from the system that is not utilized biologically, but the process this should represent is not clearly identified. Based on the sensitivity studies performed here and recent observational data, I suggest that a parameter regime with a weaker ligand and greater concentration of total ligand may be more realistic. In the latter case, the model can reproduce both the deep iron 
distribution, but also the observed presence of significant amounts of free ligand. 


\section{Chapter 3}

\section{Sensitivity of Surface Phosphate to Aeolian Iron Source and Upwelling Strength}

A strong motivation for modeling the iron cycle is to be able to explicitly describe and explore the role of iron in setting current, past and future ocean distributions of carbon and macronutrients. Of particular interest is the possible impact and feedbacks of climate change and the aeolian supply of iron to the efficiency of the carbon pump in the remote Southern Ocean. Martin (1990) suggested increased dust flux during the Last Glacial Maximum (LGM) could have increased export production in the Southern Ocean and decreased atmospheric $\mathrm{pCO}_{2}$. While data from ice cores (Petit et al., 1999) and atmospheric dust models (Mahowald et al., 1999) suggest that aeolian iron supply increased up to twenty times in the Southern Ocean and globally 2-5 times relative to present day, paleo productivity proxies do not suggest that export production was higher during the Last Glacial Maximum (LGM) in the Southern Ocean (Francois et al., 1997; Kumar et al., 1995). Rather $\delta^{15} \mathrm{~N}$ data suggests increased efficiency of nutrient utilization in the high latitudes, perhaps due to increased stratification between surface and deep waters leading to weaker vertical 
exchange (Francois et al., 1997). Keeling and Visbeck (2001) argue that the response of ocean eddies to increased stratification would increase the upwelling rate of deep waters in the Southern Ocean. They propose instead that enhanced sea-ice coverage in the Southern Ocean could have prevented the outgassing of $\mathrm{CO}_{2}$.

Watson et al. (2000) used a simplified ocean biogeochemistry model with explicit representation of iron cycling, forced with glacial-interglacial cycles in Southern Ocean iron deposition derived from ice core dust records. Representing deep water iron cycling as a particulate scavenging process, their study suggests that a significant fraction of the observed glacial-interglacial change in atmospheric $\mathrm{CO}_{2}$ may be accounted for by increased export production due to the increased dust supply. This is in contrast to the results of a study using a six-box model in which complexation and scavenging of iron are parameterized (Lefévre and Watson, 1999). There, despite increasing Southern Ocean dust flux by a factor of twenty, $\mathrm{pCO}_{2}$ drawdown was by only $1 \mu \mathrm{atm}$. However, the latter model did suggest a $\mathrm{pCO}_{2}$ drawdown of $50 \mu$ atm when global dust flux increased ten times. Lefévre and Watson (1999) also found very little sensitivity to the strength of upwelling. Archer and Johnson (2000) also examined the response of surface phosphate loading to increased aeolian dust supply in their global, three-dimensional model in which deep ocean iron cycling is represented as a combination of complexation to organic ligands and scavenging by particles. They show that a significant drawdown of the surface macro-nutrients can be achieved with high ligand concentrations. The nature of the parameterization of iron, as well as the distribution of and amount of dust flux increase, appears to affect the sensitivity of $\mathrm{pCO}_{2}$ drawdown and surface $\mathrm{PO}_{4}$ drawdown in the Southern Ocean, but varying results are drawn from a diverse suite of models and experiments. 


\subsection{Results: Increased Aeolian Flux Simulations}

Here I examine these issues and apparent contradictions through a set of sensitivity experiments in a unified model framework, the six-box model described in the previous chapter. I present results that illustrate the sensitivity of surface phosphate drawdown to 1) the magnitude and distribution of the dust supply and 2) the strength of the vertical exchange between the Southern Ocean surface and deep waters for the three parameterizations (see Chapter 2) of iron. I find considerable differences in the response due to the parameterization of iron and the distribution and magnitude of the increased dust flux.

\subsubsection{Increased Dust Flux: Southern Ocean}

I test the sensitivity of Southern Ocean surface $\mathrm{PO}_{4}$ to increased dust flux in only the Southern Ocean and vertical exchange for each of the parameterizations as described in Chapter 2. In Figure 3-1, I plot the Southern Ocean surface $\left[\mathrm{PO}_{4}\right]$ from the model as a function of increased aeolian dust flux in the Southern Ocean only, relative to today's, and for several rates of Southern Ocean vertical mass exchange. Even with vertical exchange weakened by $50 \%$ and and Southern Ocean aeolian flux increased 20 times relative to modern day flux in the Southern Ocean, surface $\mathrm{PO}_{4}$ drawdown is only $0.3 \mu \mathrm{M}$ for the scavenging and scavenging-desorption case and $0.45 \mu \mathrm{M}$ for the complexation case. Yet the model of Watson et al. (2000) had predicted a maximum drawdown of $\mathrm{PO}_{4}$ of $0.6 \mu \mathrm{mol}$ with a 25 fold increase in the dust flux reaching the Southern Ocean above modern day flux. I must increase Southern Ocean dust flux more than 50 fold to observe a similar drawdown of $\mathrm{PO}_{4}$ with my model for all three parameterizations. While my model results agree qualitatively with Watson et al. (2000), quantitative differences in the sensitivity of surface $\mathrm{PO}_{4}$ to increases in dust flux can potentially be attributed to differences in the parameterization of iron. Watson et al. (2000) parameterize the loss of iron due to particulate scavenging, 

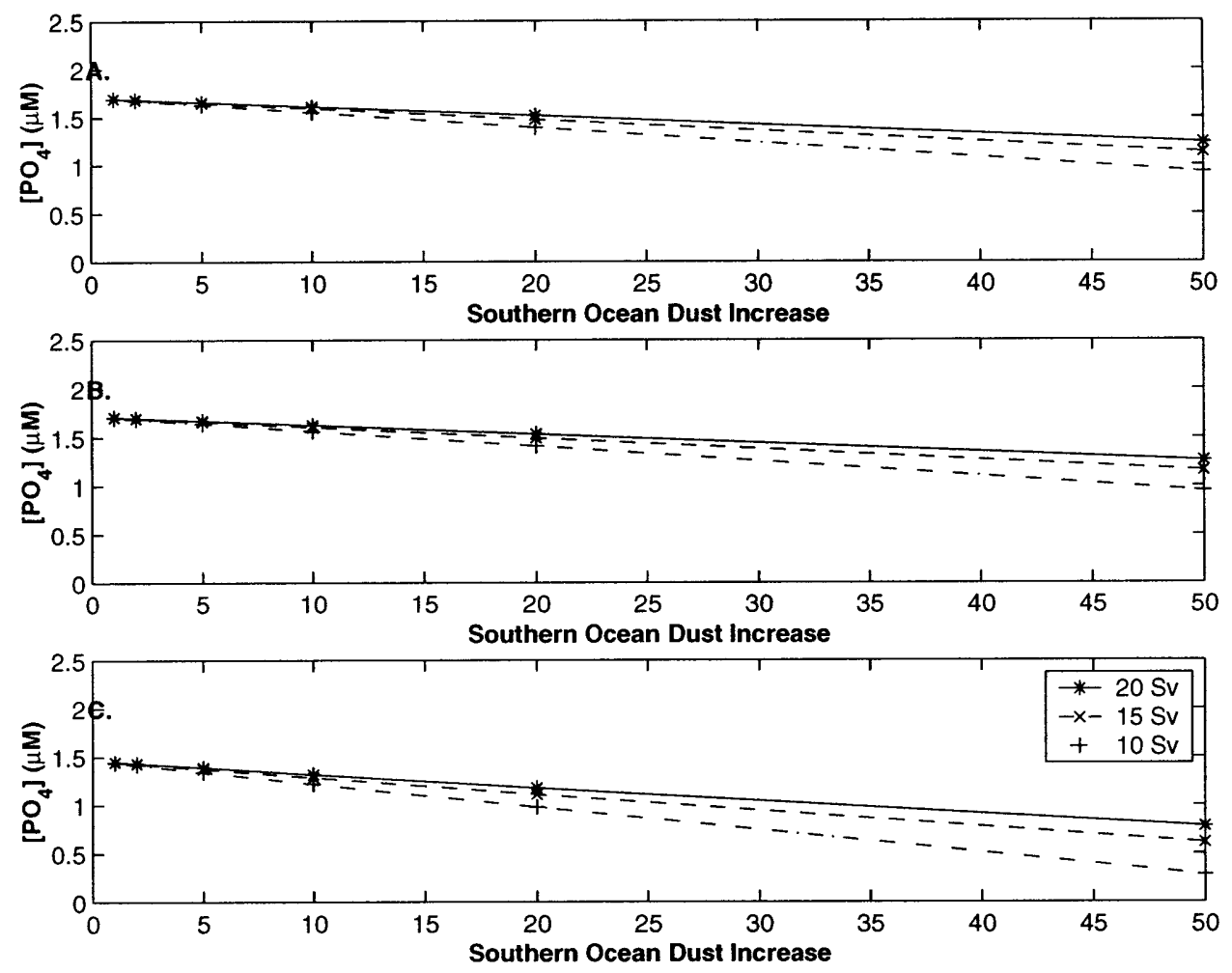

Figure 3-1: Steady state surface Southern Ocean $\mathrm{PO}_{4}$ sensitivity to Southern Ocean only dust increase (absolute factor) and S. Ocean overturning (Sv) for A) net scavenging case, B) scavenging-desorption case, and C) complexation case.

with the scavenging rate varying as a function of particulate organic matter flux. In addition, the Fe:C ratio is variable in the Watson et al. (2000) model. It is interesting to note that a fifty fold increase in Southern Ocean aeolian flux is approximately equal to estimates of current day average aeolian flux to the Atlantic basin per unit area. My results suggest that deep water transport of iron from the other basins may be necessary for $\mathrm{Fe}$ to affect the drawdown of surface $\mathrm{PO}_{4}$.

\subsubsection{Increased Dust Flux: Globally}

Since increasing dust flux in only the Southern Ocean does not result in significant increased utilization of surface $\mathrm{PO}_{4}$, I test the sensitivity of surface $\mathrm{PO}_{4}$ to a global increase in dust flux. In Figure 3-2, for each parameterization, I plot the Southern 
A.

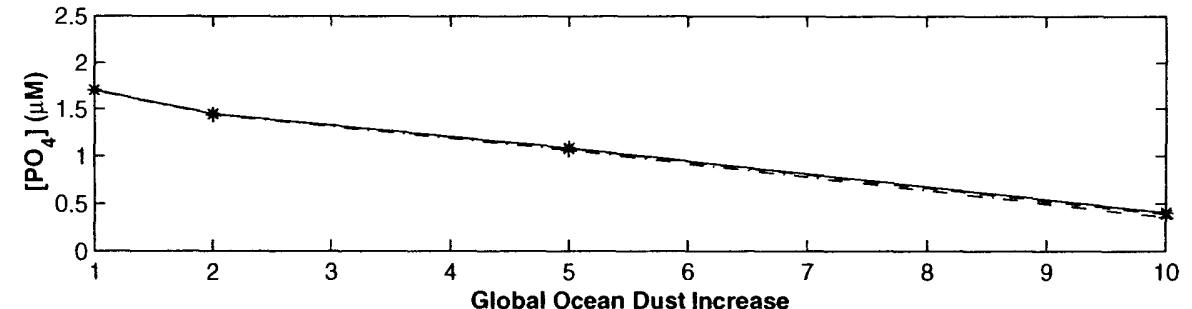

B.

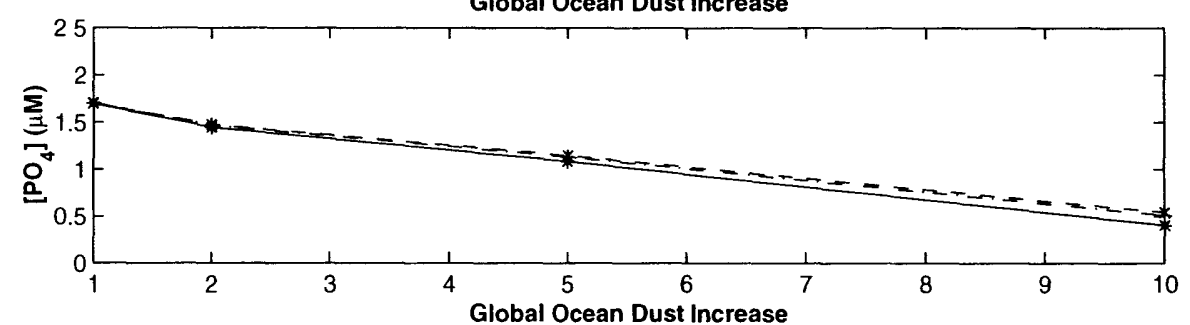

c.

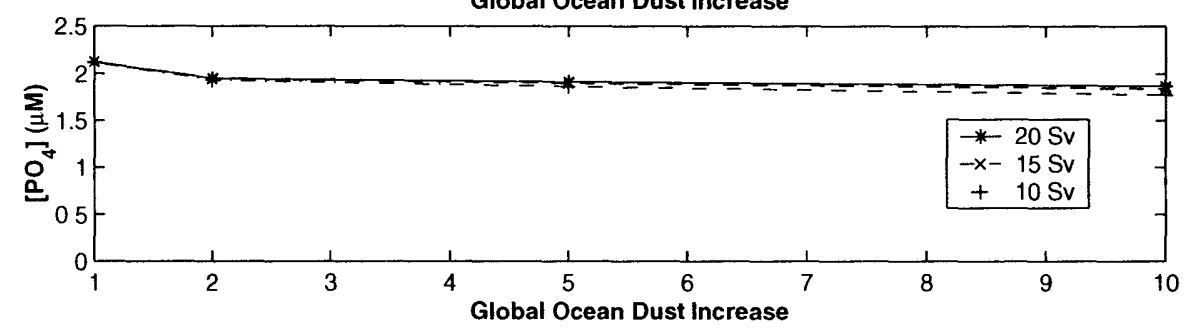

Figure 3-2: Steady state surface Southern Ocean $\mathrm{PO}_{4}$ sensitivity to global dust increase (absolute factor) and S. Ocean overturning (Sv) for A) net scavenging case, B) scavenging-desorption case, and $\mathrm{C}$ ) complexation case. For the net scavenging and scavenging-desorption case, an increase in global dust supply results in the drawdown of $\mathrm{PO}_{4}$ with little sensitivity to the strength of vertical exchange. For the complexation case $(\mathrm{C}), \mathrm{PO}_{4}$ drawdown is muted, with greatest drawdown when the vertical exchange flux is weakened to $10 \mathrm{~Sv}$.

Ocean surface $\left[\mathrm{PO}_{4}\right]$ as a function of a global increase in aeolian iron supply, relative to today's, and for several rates of Southern Ocean vertical mass exchange. By increasing the dust flux 10 times globally, surface $\left[\mathrm{PO}_{4}\right]$ is depleted in both the net scavenging and scavenging-desorption models (Figure 3-2 A and B). There is little sensitivity to the strength of Southern Ocean overturning. In strong contrast, for the complexation parameterization (Figure 3-2 C), even with global dust increase of 10 times and the strength of vertical exchange decreased by $50 \%$, it is not possible to completely drawdown surface $\left[\mathrm{PO}_{4}\right]$ in this model.

Comparing the importance of Fe supplied to the euphotic zone by dust to upwelled Fe gives insight into the underlying mechanistic differences. I plot the fraction of iron 
directly supplied by dust to the surface Southern Ocean (Figure 3-3) and the deep water dissolved iron concentration (Figure 3-4) for the three models. For the net scavenging and scavenging-desorption parameterization, the fraction of iron supplied to the Southern Ocean euphotic zone regionally by dust is small (5-10\%). I find that this fraction does not respond to increased global aeolian dust supply (Figure 3-3 A and $\mathrm{B}$ ) because the slow net scavenging rate enables iron derived from lowlatitude dust to be transported at depth to the deep Southern Ocean. Therefore the upwelled source of iron from the Southern Ocean increases in proportion to the global dust deposition (Figure 3-4 A and B), tracking the total dust supply. For the complexation parameterization, the fraction of iron supplied by dust increases strongly with aeolian dust deposition (Figure 3-3 C). This is because the imposed, finite ligand concentration places an upper limit on the deep water iron concentration (Figure 3-4 C) and therefore on the upwelled iron source.

It is possible that ligand production increases as a function of increased dust flux, as evidenced by Rue and Bruland (1997) during the Iron-Ex II study in the equatorial Pacific. As my sensitivity study using the complexation model with an elevated $\left[L_{T}\right]=4 \mathrm{nM}$ shows (see Chapter 2), deep water $\left[\mathrm{Fe}_{T}\right]$ would increase with total ligand concentration and so might the upwelling supply. However I have not parameterized this specific mechanism here.

The three different parameterizations of deep water iron cycling are able to capture the observed distribution of iron in the modern ocean. However these parameterizations lead to very different sensitivities of surface phosphate drawdown in conditions of increased dust supply. It is perhaps premature to suggest that one parameterization is more realistic than another in this regard, though the complexation parameterization resolves more details of the system as it is presently understood. This result is very significant for model projections of glacial-interglacial biogeochemical change, such as that of Watson et al. (2000) which applied a scavenging based parameterization. Clearly it is imperative to continue to seek more observational data and a 
A.

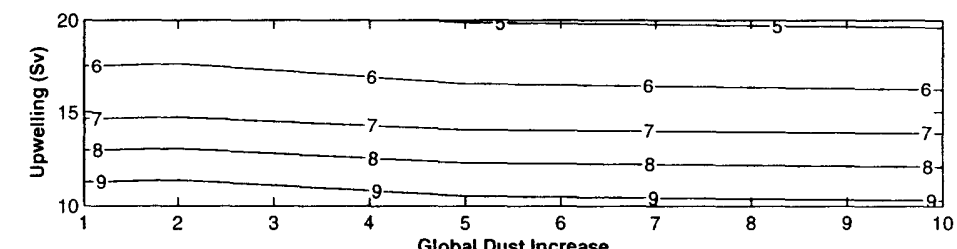

B.

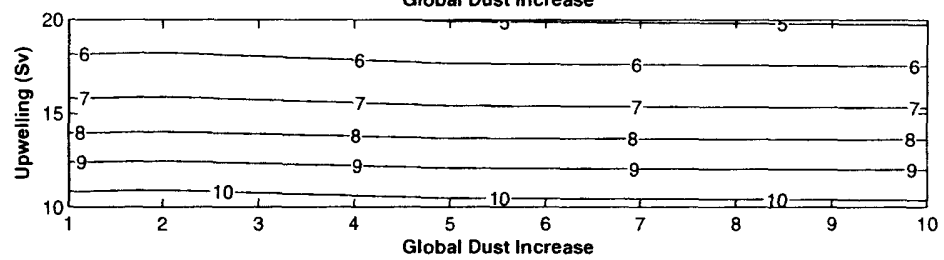

c.

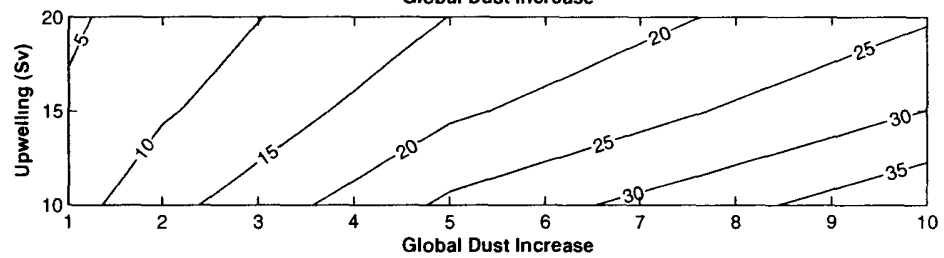

Figure 3-3: Percent Iron in surface Southern Ocean derived from dust (dust/dust+upwelling) for the A) net scavenging case, B) scavenging and desorption case and C) complexation case as a function of dust flux and S. Ocean overturning.

A.

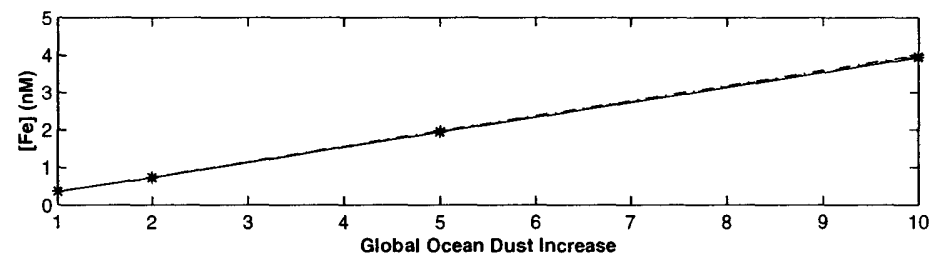

в.

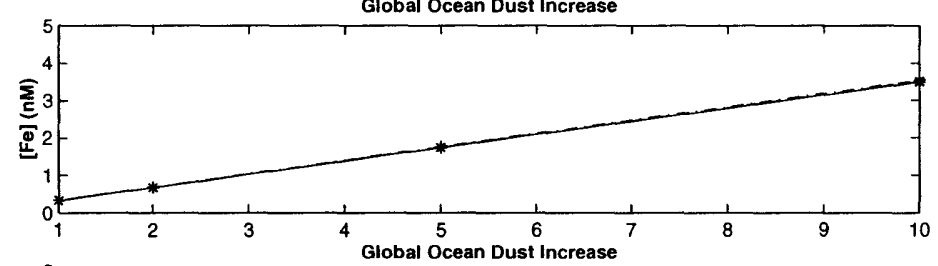

c.

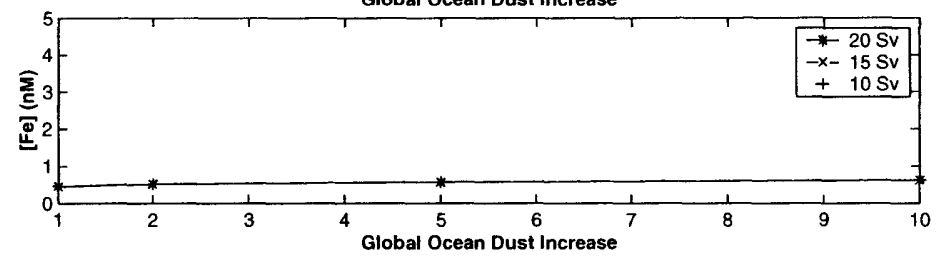

Figure 3-4: Southern Ocean deep $\mathrm{Fe}_{T}$ response to global ocean dust increase and upwelling strength for A) net scavenging case, B) scavenging-desorption case, and C) complexation case. For the net scavenging and scavenging-desorption case, an increase in global dust supply results in a proportional increase in deep water $\left[\mathrm{Fe}_{T}\right]$. For the complexation case (C) Southern Ocean deep water $\left[\mathrm{Fe}_{T}\right]$ increase is much less than for A and B. 
deeper understanding of the key processes in order to make more appropriate models for climate change studies. 


\section{Chapter 4}

\section{Global Iron Cycling: Simulations Using an Ocean General Circulation Model}

\subsection{Introduction}

Explorations with a multi-box model showed that three different parameterizations are able to capture the observed deep water Fe gradients. A box model is qualitatively informative and provides a simple framework to focus on the biogeochemical controls on iron cycling. Due to its economical efficiency, a box model also allows for the exploration of parameter values, not possible with a three-dimensional general circulation model because of computational restraints. But there are limitations to the box model, as it does not resolve intra-basinal and vertical gradients. In addition, the parameterization of physical terms such as advection and mixing are very crude. In order to gain insight into the role of physical processes on iron cycling, as well as higher resolution results than box model simulations can provide, I implement my iron cycling parameterizations within the framework of a three-dimensional ocean general circulation model (GCM). Results from the sensitivity studies with the box model 
guides the choice of parameter values in the general circulation model. In this chapter, I discuss the physical properties of the GCM, the biogeochemical components of the model and the aeolian forcing fields. I also present results from the implementation of the A) Net Scavenging, B) Scavenging-Desorption and C) Scavenging-Complexation iron parameterizations in the three-dimensional, coarse resolution general circulation model.

\subsection{Physical Model}

The MIT GCM is configured at coarse resolution (2.8x2.8 degrees, 15 levels) globally (Marshall et al. 1997a, b; Adcroft et al., 1997). The model is forced with climatological surface wind stresses. Surface heat flux is imposed from climatology with an additional relaxation toward observed SST, and surface salinity is relaxed toward climatology. In these coarse resolution, global ocean circulation studies, mesoscale eddy transfer effects are achieved using schemes related to the parameterization of Gent and McWilliams (1990). Vertical turbulent mixing in the surface mixed layer of the ocean is parameterized using convective adjustment (Dutay et al., 2002).

In order to assess the physical controls on Fe cycling in the global ocean, it is necessary that the the general circulation model adequately represents major physical processes occurring in the ocean. In this section, I briefly describe the residual circulation of the model and present meridional sections of temperature and salinity in the Atlantic and Pacific basins.

\subsubsection{Residual Circulation}

Modern ocean models transport tracers using the 'residual circulation' - the net effect of advection by mean flow and a contribution from induced circulation (Gent and McWilliams, 1990; Karsten et al., 2002; Marshall et al., 2002). The residual circulation of this configuration is presented in Figure 4-1. The overturning is strongest 


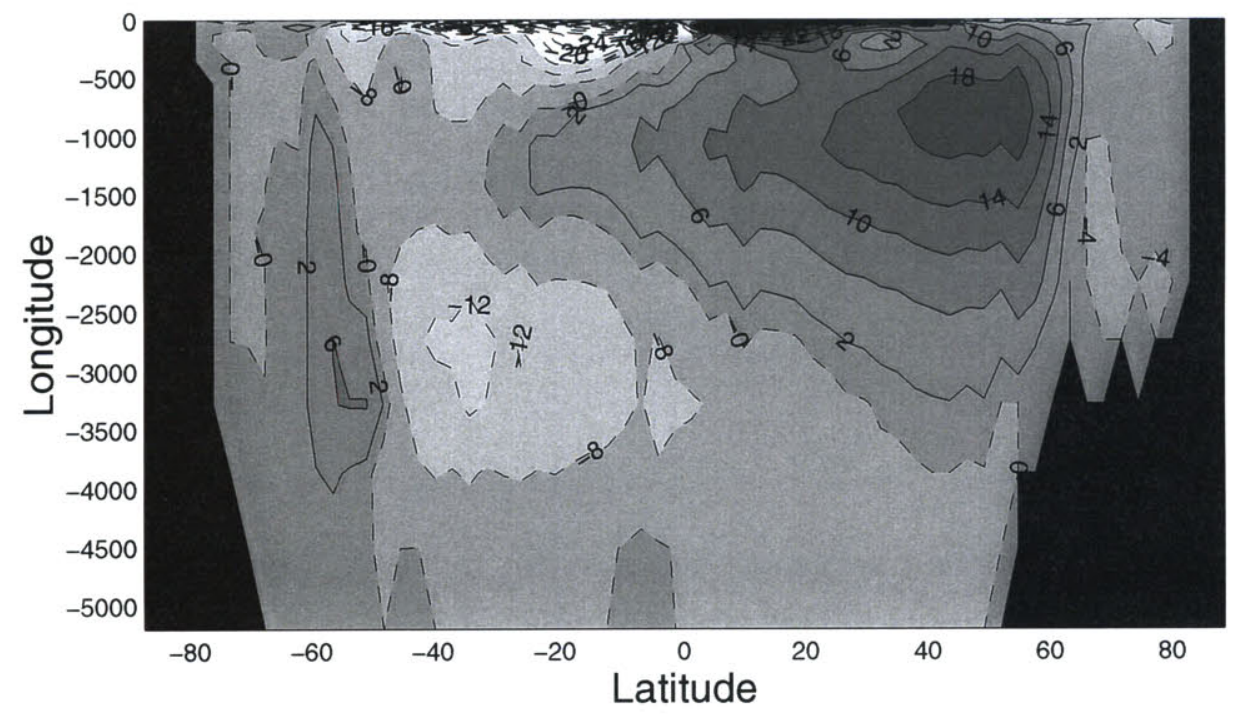

Figure 4-1: The Global Residual Mean of the model. Fluxes are in $\mathrm{Sv}\left(10^{6} \mathrm{~m}^{3} \mathrm{~s}^{-1}\right)$. Figure courtesy of Takamitsu Ito.

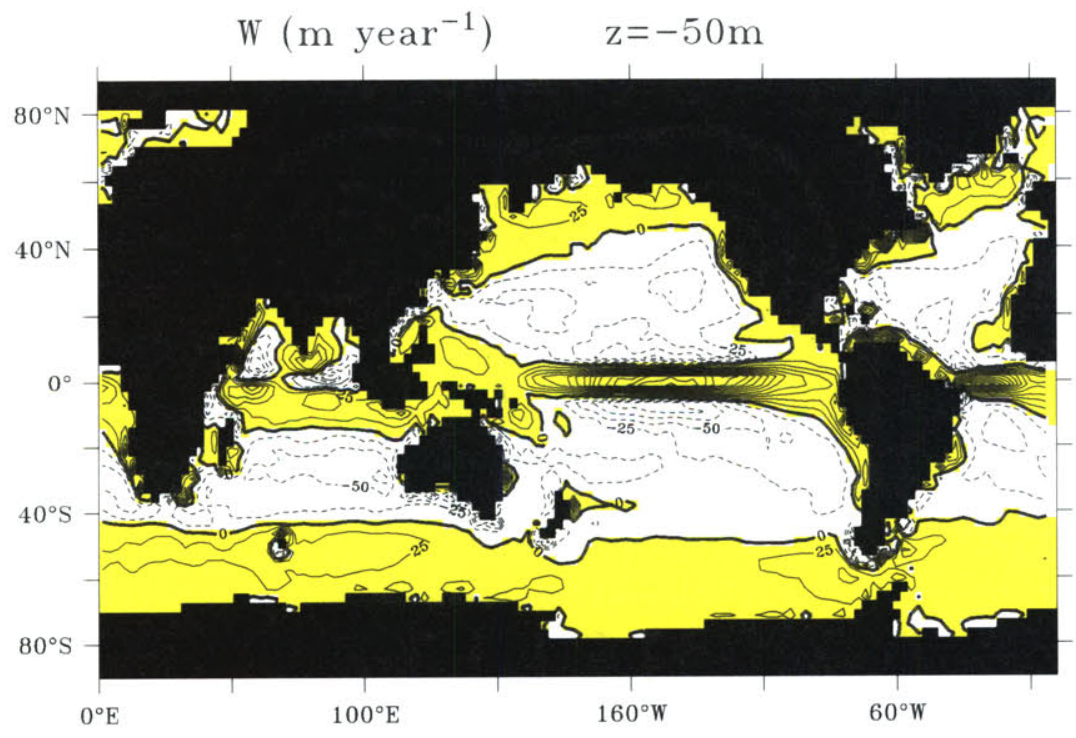

Figure 4-2: Modeled vertical velocity $\left(\mathrm{m} \mathrm{yr}^{-1}\right)$ at depth of 50 meters. Upwelling is occurring in yellow-shaded areas. Figure courtesy of Mick Follows. 
in the North Atlantic at $\sim 45^{\circ} \mathrm{N}$ due to the formation of North Atlantic Deep Water. The residual circulation of the model is weaker in the Southern Ocean than estimates of the meridional overturning circulation from data and inverse modeling suggest (Karsten and Marshall, 2002; Sloyan et al., 2001). The wind driven gyres are apparent in the upper layers.

\section{Vertical Velocity}

Upwelling is an important transport pathway for nutrients from the deep to return to the euphotic zone. Near the surface, upwelling is strongly related to wind stress forcing and Ekman pumping. In Figure 4-2, I plot the vertical velocity of the model at 50 meters. As seen in the figure, the ocean gyres are areas of downwelling, suppressing the return of nutrients from the deep. This results in low biological productivity in the ocean gyres. Major areas of upwelling are the Southern Ocean, the equatorial Pacific and the subpolar gyres.

\subsubsection{Temperature and Salinity Sections}

Figure 4-3 illustrates sections of modeled temperature in the Atlantic $\left(330^{\circ} \mathrm{E}\right)$ and the Pacific $\left(198^{\circ} \mathrm{E}\right)$ compared to observed temperature sections (Levitus and Boyer, 1994). In both basins, the model captures the structure of the thermocline. In the equatorial regions and subtropics of both basins, the modeled thermocline is too shallow, resulting in lower temperatures than observed. In the North Atlantic, the plume of anomalously warm water at $55^{\circ} \mathrm{N}$ suggests that deep mixing is too vigorous in this region of the model.

In Figure 4-4, I present sections of modeled salinity in the Atlantic and the Pacific. The high salinity signature of North Atlantic Deep Water and the low salinity signature of the Antarctic Intermediate Water are clearly visible, although modeled values are slightly higher than observations (Levitus et al., 1994). The model agrees well with observations in the subtropical waters of the Atlantic. Although modeled 

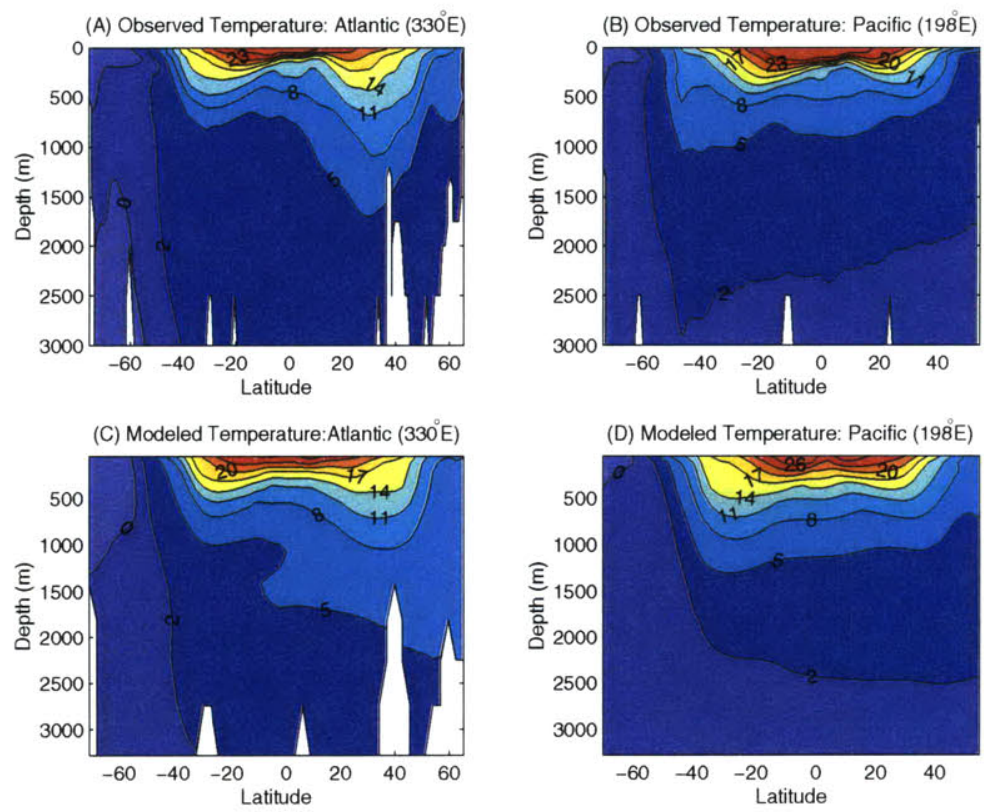

Figure 4-3: Comparison of observed and model temperature. Meridional section of observed temperature $\left({ }^{\circ} \mathrm{C}\right.$, Levitus and Boyle, 1994) in the A) Atlantic basin at $330^{\circ} \mathrm{E}$ and B) Pacific basin at $199^{\circ} \mathrm{E}$. Model temperature for the C) Atlantic basin and D) the Pacific basin.

salinity is higher than observed throughout the Pacific, the model is able to capture the structure of the salinity field.

\subsection{Biogeochemical Component}

In addition to iron, the biogeochemical tracers explicitly carried in my model are phosphate $\left(\mathrm{PO}_{4}\right)$ and dissolved organic phosphorus (DOP). Biological uptake and regeneration are indexed to phosphorus. The governing equations for $\mathrm{PO}_{4}$ and $\mathrm{DOP}$ in the biogeochemical model at the surface are: 
(A) Observed Salinity: Atlantic (330 E)

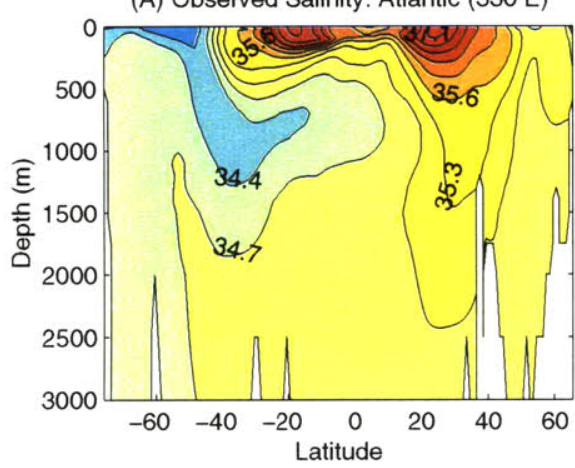

(C) Modeled Salinity:Atlantic $\left(330^{\circ} \mathrm{E}\right)$

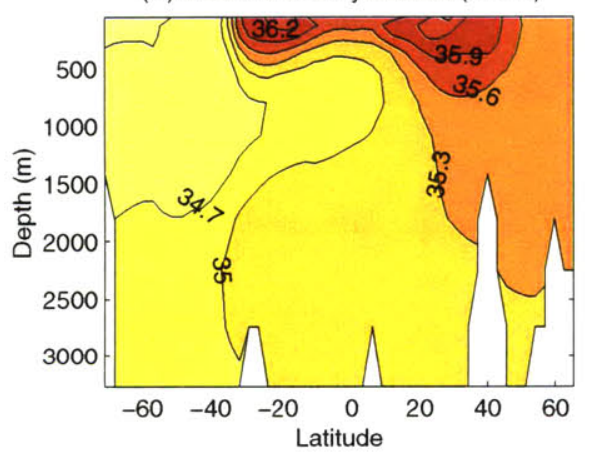

(B) Observed Salinity: Pacific (198 E)

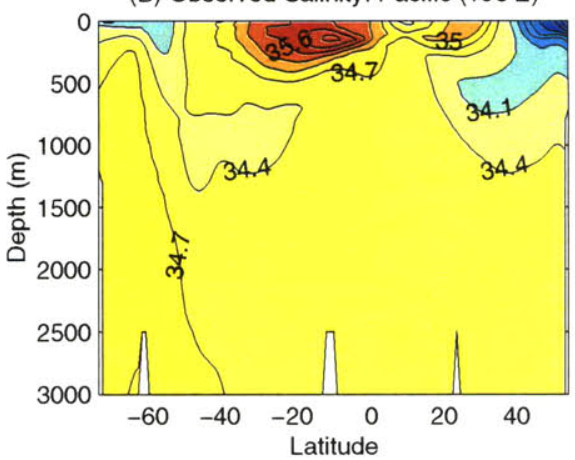

(D) Modeled Salinity: Pacific (198 E)

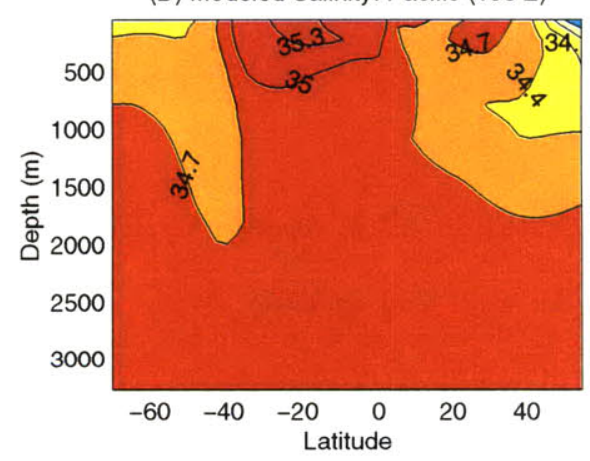

Figure 4-4: Comparison of observed and model salinity. Meridional section of observed salinity (ppt, Levitus et al., 1994) in the A) Atlantic basin at $330^{\circ} \mathrm{E}$ and B) Pacific basin at $199^{\circ} \mathrm{E}$. Model salinity for the C) Atlantic basin and D) the Pacific basin. 


$$
\begin{aligned}
\frac{\partial P O_{4}}{\partial t} & =-\nabla \cdot\left(\mathbf{u} P O_{4}\right)+\nabla \cdot\left(\kappa \nabla P O_{4}\right)-\Gamma+\lambda D O P \\
\frac{\partial D O P}{\partial t} & =-\nabla \cdot(\mathbf{u} D O P)+\nabla \cdot(\kappa \nabla D O P)+\nu \Gamma-\lambda D O P \\
\Gamma & =\mu P O_{4} \frac{F e_{T}}{F e_{T}+K_{s}} \frac{I}{I+I_{o}}
\end{aligned}
$$

At depth, the equations are:

$$
\begin{aligned}
\frac{\partial P O_{4}}{\partial t} & =-\nabla \cdot\left(\mathbf{u} P O_{4}\right)+\nabla \cdot\left(\kappa \nabla P O_{4}\right)+(1-\nu) \Gamma+\lambda D O P-\frac{\partial F(z)}{\partial z} \\
\frac{\partial D O P}{\partial t} & =\nabla \cdot(\mathbf{u} D O P)+\nabla \cdot(\kappa \nabla D O P)-\lambda D O P \\
\text { Export } & =\int_{h m i x}^{0}(1-\nu) \Gamma d z \\
F(z) & =\operatorname{Export}\left(\frac{z}{h m i x}\right)^{-b}
\end{aligned}
$$

In the above equations, $\mathbf{u}$ is the transformed Eulerian mean velocity and $\kappa$ is a mixing tensor representing isopycnal mixing following Gent and McWilliams (1990). A third-order upwind, flux corrected advection scheme is used for tracers (Dutkiewicz et al., 2001).

$\Gamma$ represents the biological uptake, which is limited by light, phosphate, and iron. In conditions where $\mathrm{Fe}$ and light are replete, I assume surface $\mathrm{PO}_{4}$ to be the limiting nutrient which is utilized with a characteristic timescale, $1 / \mu$ of about 1 month. Iron limitation is represented by Michaelis-Menten kinetics. The half saturation constant for iron $\left(K_{s}\right)$ is globally uniform but is adjusted, within the range of measured values (Price et al., 1994; Fitzwater et al., 1996), to optimize the modeled surface $\left[\mathrm{PO}_{4}\right]$ and $\left[\mathrm{Fe}_{T}\right]$ distributions.

Two-thirds of exported nutrient $(\nu)$ enters the surface dissolved organic phosphorus (DOP) pool. The imposed timescale for remineralization of DOP $(1 / \lambda)$ is 6 
months. One-third of biological uptake $[(1-\nu) \Gamma]$ is rapidly exported as particulate at depth to the $\mathrm{PO}_{4}$ pool (Yamanaka and Tajika, 1997) using an empirical power law relationship determined by Martin et al. (1987). The depth of the euphotic zone $(h m i x)$ is 75 meters and the power law coefficient $(b)$ is 0.9 .

The light field varies as a function of time and latitude by the following equation:

$$
\begin{aligned}
I & =Q_{o}(1-\alpha) \cos (z) \\
\cos (z) & =\frac{D}{\pi}\left[\sin \delta \sin \phi+\frac{\cos \delta \cos \phi \sin D}{D}\right] \\
D & =\cos ^{-1}(-\tan \delta \tan \phi)
\end{aligned}
$$

The solar constant $\left(Q_{o}\right)$ is $1,367 \mathrm{Wm}^{-2}$. The albedo $(\alpha)$ varies latitudinally and temporally according to North et al. (1981). $D / \pi$ is the the sunlit region as a fraction of latitude circle and the term in brackets in equation 4.9 is the average cosine zenith angle over the sunlit region. Solar declination $(\delta)$ is calculated daily using the astronomical formula of Paltridge and Platt (1976). The half-saturation constant for light $\left(I_{o}\right)$ is $30 \mathrm{Wm}^{-2}$.

\subsubsection{Aeolian Flux Forcing Field}

The primary source of iron to the global ocean is aeolian. Gao et al (2001) create seasonal aeolian iron flux maps extrapolated from in situ marine boundary layer measurements. Based on the average concentration of Fe in continental crust, they assume 3.5 weight percent of dust is iron. Dust deposition is strongest in the Northern Hemisphere with maximum deposition in the subtropical and tropical Atlantic and the North Pacific (Figure 4-5). The Fe flux is strongest during the summer months in the Atlantic. The trade winds carry Saharan dust westward depositing Fe across the Atlantic. In the North Pacific, dust deposition is highest during the spring. The prevailing westerlies transport dust originating from the Asian desert into the North 

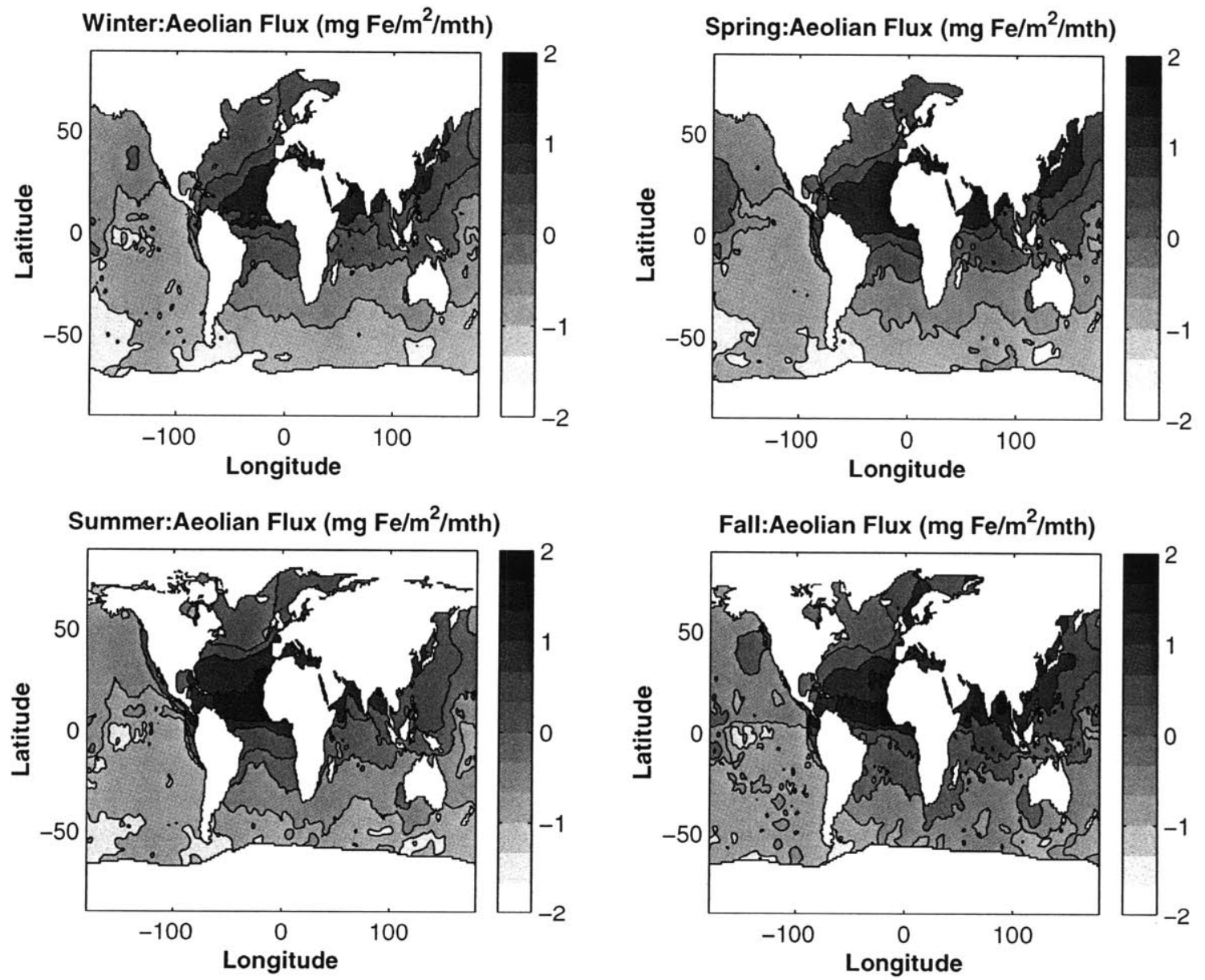

Figure 4-5: Aeolian flux field used to force the model (Gao et al., 2001). The model is forced seasonally. 
Pacific. In contrast, the eastern Southern Pacific and the Southern Ocean receive very little dust throughout the year.

The model is forced seasonally to capture the spatial and temporal variability in dust deposition. Based on explorations with the box model (see Chapter 2), I assume $1 \%$ of the iron entering the surface ocean is soluble (Jickells and Spokes,2001).

\subsubsection{Iron Parameterization}

The three iron parameterizations described and tested in Chapter 2 using a multi-box model framework are implemented here in the ocean general circulation model with the exception of the description of scavenging. In the box model simulations, scavenging was modeled as a first order process, limited only by [ $\left.\mathrm{Fe}^{\prime}\right]$. Laboratory experiments using thorium and oceanic field observations indicate that particle concentration also limits scavenging (Honeyman et al., 1998 and references therein). Compiling oceanic field data, Honeyman et al. (1988) fit a power law function to describe the relationship between scavenging rate $\left(k_{s c}\right)$ and particle concentration $\left(C_{p}\right)$ :

$$
k_{s c}=k_{0} C_{p}^{\phi}
$$

where $k_{0}$ represents the scavenging rate when particles are not limiting, $C_{p}$ is the particle concentration and $\phi$ is the slope. I employ this relationship to model scavenging as a function of $C_{p}$. In the model, $\left[\mathrm{C}_{p}\right]$ is calculated for every grid point for each level from the modeled biological flux. Thus, $k_{s c}$ is faster in biologically active regions of the ocean and since $\left[\mathrm{C}_{p}\right]$ decreases with depth, the modeled scavenging rate becomes slower at depth. Since the empirical relationship was calculated using thorium, I scale the scavenging rate for iron such that the average surface scavenging rate falls within the range used in the box model simulations. 

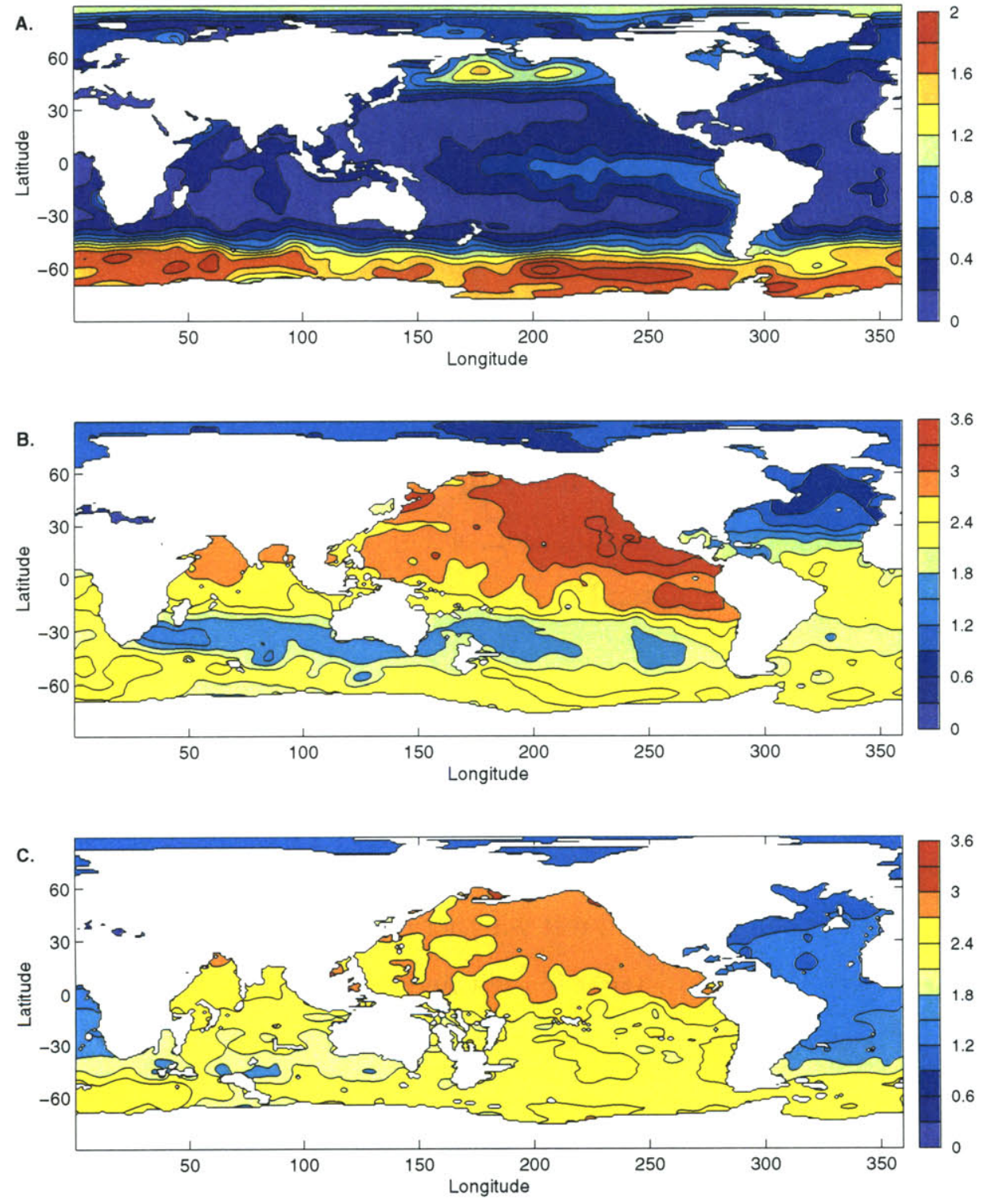

Figure 4-6: Observed $\left[\mathrm{PO}_{4}\right](\mu \mathrm{M})$ at A) surface, B) $935 \mathrm{~m}$ and C) $2495 \mathrm{~m}$ (Conkright et al., 1994). 


\subsection{Results}

While all three parameterizations successfully reproduced the broad observed patterns of deep water iron gradients in the box model simulations, the ocean general circulation model, with a more sophisticated representation of physics, identifies some differences. In this section, I present results for the three different iron parameterizations within the context of an ocean general circulation model: A) net scavenging case, B) scavenging-desorption case, and C) scavenging-complexation case.

For each case, I compare the modeled $\mathrm{PO}_{4}$ distributions to maps of observed $\left[\mathrm{PO}_{4}\right]$ (Figure 4-6, Conkright et al., 1994). Due to the paucity of iron measurements in the ocean, it is not possible to make detailed comparisons between modeled $\left[\mathrm{Fe}_{T}\right]$ and observations. To assess the model's ability to reproduce observed $\left[\mathrm{Fe}_{T}\right]$ distributions, I compare the $\left[\mathrm{Fe}_{T}\right]$ with the compilation of $\mathrm{Fe}_{T}$ measurements at various depths presented (Figure 1-4) in Chapter 1.

\subsubsection{Net Scavenging Results}

In the context of the box model, the net scavenging case was the simplest description of iron that resolved the deep water iron gradients. I set the variable scavenging scaling parameter $(\tau)$ to 0.0035 and test whether this simple description is able to still capture the observed global distribution within the context of a more sophisticated description of ocean circulation and transport processes.

\section{Phosphate}

Figure 4-7 shows the $\left[\mathrm{PO}_{4}\right]$ distribution at the surface, $935 \mathrm{~m}$, and $2495 \mathrm{~m}$ using the net scavenging parameterization. In the Southern Ocean and major portions of the Pacific, the model does predict excess (i.e. nutrient concentration greater than the limiting nutrient multiplied by the Refield ratio) surface $\left[\mathrm{PO}_{4}\right]$, but does a poor job of

distinguishing the HNLC equatorial region from the low $\mathrm{PO}_{4}$ regions of the subtrop- 
ical gyres. This may be due to a lack of resolution of important physical processes (Aumont et al., 1999). Coarse resolution ocean GCMs, such as this, do not resolve important equatorial dynamical processes, resulting in an overestimation of upwelling velocity. This has been pointed out as the underlying cause of 'nutrient trapping' in such models with surface nutrient restoring (Najjar et al., 1992). Since I do not restore $\mathrm{PO}_{4}$ to observations at the surface, the excess $\mathrm{PO}_{4}$ brought to the surface by upwelling may be advected laterally, resulting in high $\left[\mathrm{PO}_{4}\right]$ in the subtropics. In addition, due to the high fraction of biologically utilized $\mathrm{PO}_{4}$ transfered to DOP and the slow remineralization rate of DOP, the lifetime of DOP is very long in the upper layers of the model. This can result in the remineralization of DOP in the upwelling water, near to the surface, resulting in high $\left[\mathrm{PO}_{4}\right]$ in surface waters. Additionally, the flux of iron to the subtropical Pacific may be higher than the prescribed dust forcing in the model. This is further discussed in Chapter 5.3.1. While the magnitude of excess $\left[\mathrm{PO}_{4}\right]$ is lower than observed in the Northern Pacific, the model does not completely deplete $\left[\mathrm{PO}_{4}\right]$ in this area. At depth, the model reproduces the observed deep water $\left[\mathrm{PO}_{4}\right]$ gradients.

\section{Iron}

The $\left[\mathrm{Fe}_{T}\right]$ is depleted in the surface ocean, except in the high aeolian flux regions the North Atlantic, the North Pacific and Indian Ocean. The concentration in the North Atlantic is much higher than observations (Figure 4-8). The model may be missing processes that occur in the surface ocean. This is discussed in more detail in section 4.4.3. While the model successfully reproduces the observed deep water $\left[\mathrm{Fe}_{T}\right]$ gradients at 935 meters and 2495 meters, the $\left[\mathrm{Fe}_{T}\right]$ is much higher than observed in the Atlantic. In the Indo-Pacific basin and the Southern Ocean, the $\left[\mathrm{Fe}_{T}\right]$ is in general agreement with the observations, but higher by $\sim 0.2 \mathrm{nM}$.

The high $\left[\mathrm{Fe}_{T}\right]$ signature of the Atlantic water is carried by North Atlantic Deep Water into the the Indian sector of the Southern Ocean. There are no observations 

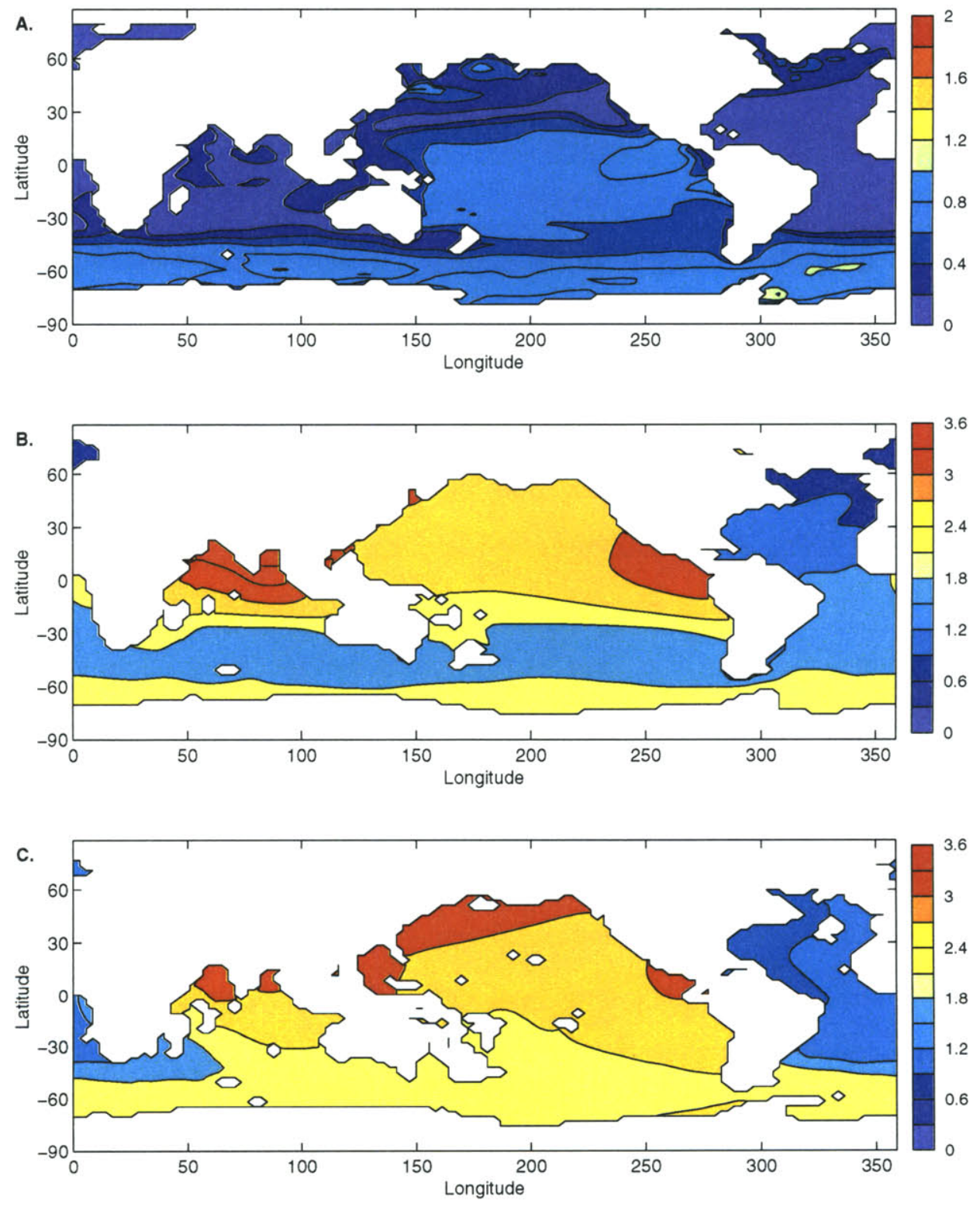

Figure 4-7: Modeled $\left[\mathrm{PO}_{4}\right](\mu) \mathrm{M}$ at A) surface, B) $935 \mathrm{~m}$ and C) $2495 \mathrm{~m}$ for the net scavenging case. 

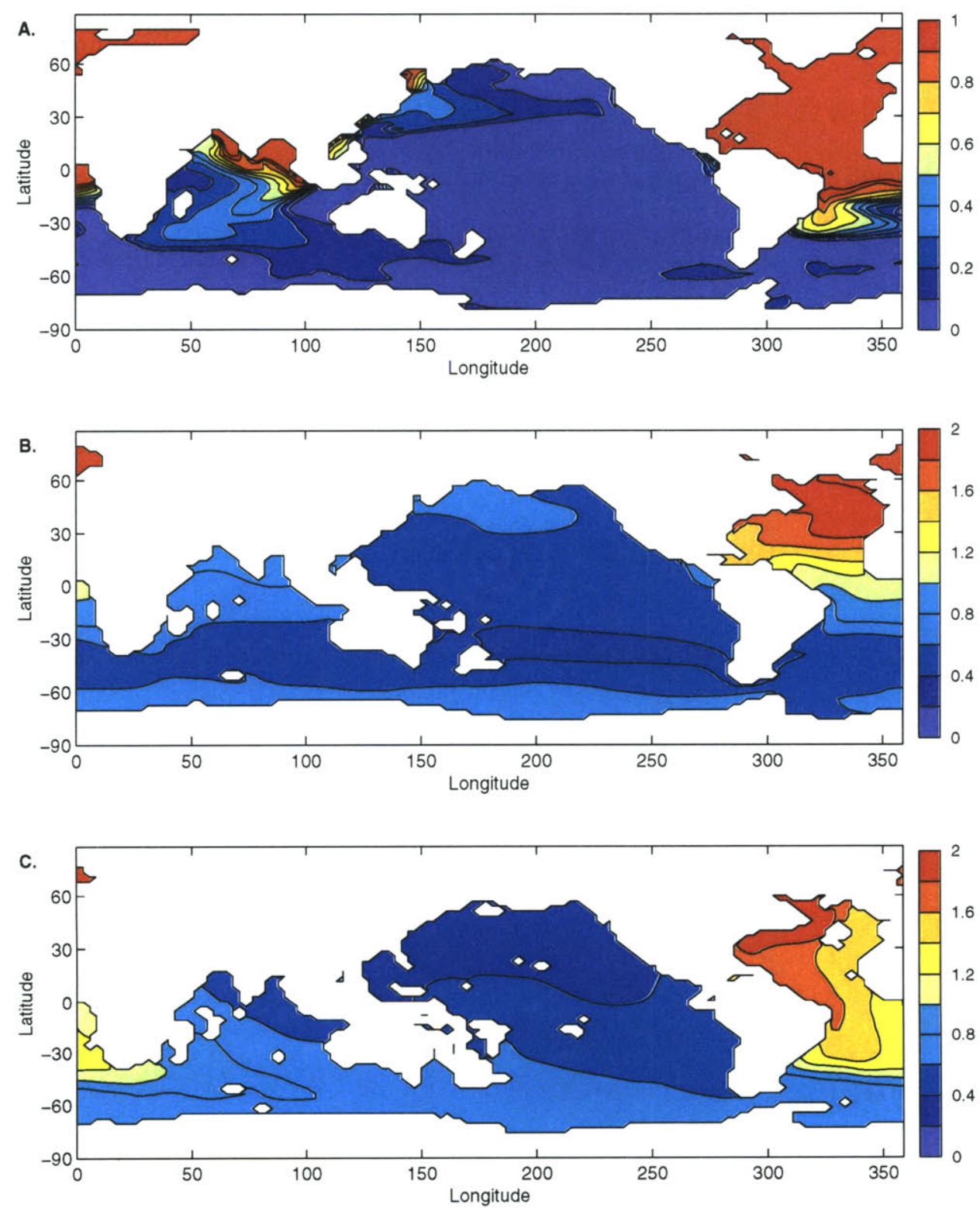

Figure 4-8: Modeled $\left[\mathrm{Fe}_{T}\right](\mathrm{nM})$ at A) surface, B) $935 \mathrm{~m}$ and C) $2495 \mathrm{~m}$ for the net scavenging case. 
from this area at depths greater than $1000 \mathrm{~m}$ against which to compare the model results. This high $\left[\mathrm{Fe}_{T}\right]$ at depth is much higher than observations. Allowing the net scavenging rate to increase would improve the deep water $\left[\mathrm{Fe}_{T}\right]$ results in the North Atlantic, but it would also result in lowering the $\left[\mathrm{Fe}_{T}\right]$ in the other basins, which are consistent with observations.

While the net scavenging case does reproduce the observed deep water $\left[\mathrm{Fe}_{T}\right]$ gradients, it is not able to deplete $\mathrm{Fe}$ in the Atlantic waters within the context of this more sophisticated physical framework. Perhaps complexation and/or desorption are necessary to accurately describe the global iron cycle.

\subsubsection{Scavenging-Desorption Results}

In the box model, the scavenging-desorption parameterization was able to reproduce the broad features of the large scale distribution of dissolved iron. Due to technical difficulties with the sinking flux, I was not able to test whether this parameterization is still able to capture the deep water iron gradients within a context of a more sophisticated circulation. This is work I plan to pursue in the future.

\subsubsection{Complexation Results}

Of the three parameterizations, the complexation model is the most detailed and explicitly describes Fe-ligand interactions. Within the context of the box model simulations, it is the only parameterization that explicitly accounts for iron's speciation. In the GCM simulation, I set the variable scavenging scaling parameter $(\tau)$ to 0.125 for the complexation case and ligand strength to $\log (K)=11$ based on the results of sensitivity studies using the box model presented in chapter 2 . 


\section{Phosphate}

Figure 4-9 illustrates the modeled phosphate distribution compared to global $\mathrm{PO}_{4}$ maps (Conkright et al., 1994), Figure 4-6). The model captures the broad pattern of the observed phosphate distribution, most notably excess $\left[\mathrm{PO}_{4}\right]$ in the Southern Ocean. Although the excess $\left[\mathrm{PO}_{4}\right]$ is lower than observed in the Southern Ocean, this is an improvement over earlier nutrient cycling models that did not include iron. It was necessary to retain surface $\mathrm{PO}_{4}$ to observed values (Orr, 2002) or set a long export timescale in order to return excess $\mathrm{PO}_{4}$ in the Southern Ocean (Mc Kinley et al., 2000). Here it is explicitly achieved. In the South Pacific, the model is not able to capture the $\mathrm{PO}_{4}$ surface gradients between the equatorial and subtropical regions. Possible explanations are discussed in section 4.4.1. In the thermocline and below $2000 \mathrm{~m}$, the model successfully reproduces the magnitude and direction of the deep water gradients.

\section{Iron}

In qualitative agreement with observations, the model predicts elevated surface $\left[\mathrm{Fe}_{T}\right]$ in the Atlantic basin (Figure 4-10). This is the case because the flux of iron to the ocean is highest in the Atlantic. The magnitude of the modeled $\left[\mathrm{Fe}_{T}\right]$ in the Atlantic is much higher than observed and exceeds the solubility of iron (Liu and Millero, 2002), which should result in precipitation of iron. Also, formation of colloids and aggregation of iron may be occurring in surface waters (Wu et al., 2001). These processes are not included here and I suggest, may explain the offset in the magnitude of excess $\left[\mathrm{Fe}_{T}\right]$ between observations and modeled results. I plan to include them in future work.

Additionally, some studies have suggested (Fridlind and Jacobsen, 2000; Siefert, 1999; Willey et al., 2000) that the further iron travels in the atmosphere, the more it is chemically processed, increasing its solubility when deposited in the ocean. Thus Fe deposited near its source may be less soluble than iron that has traveled farther. 

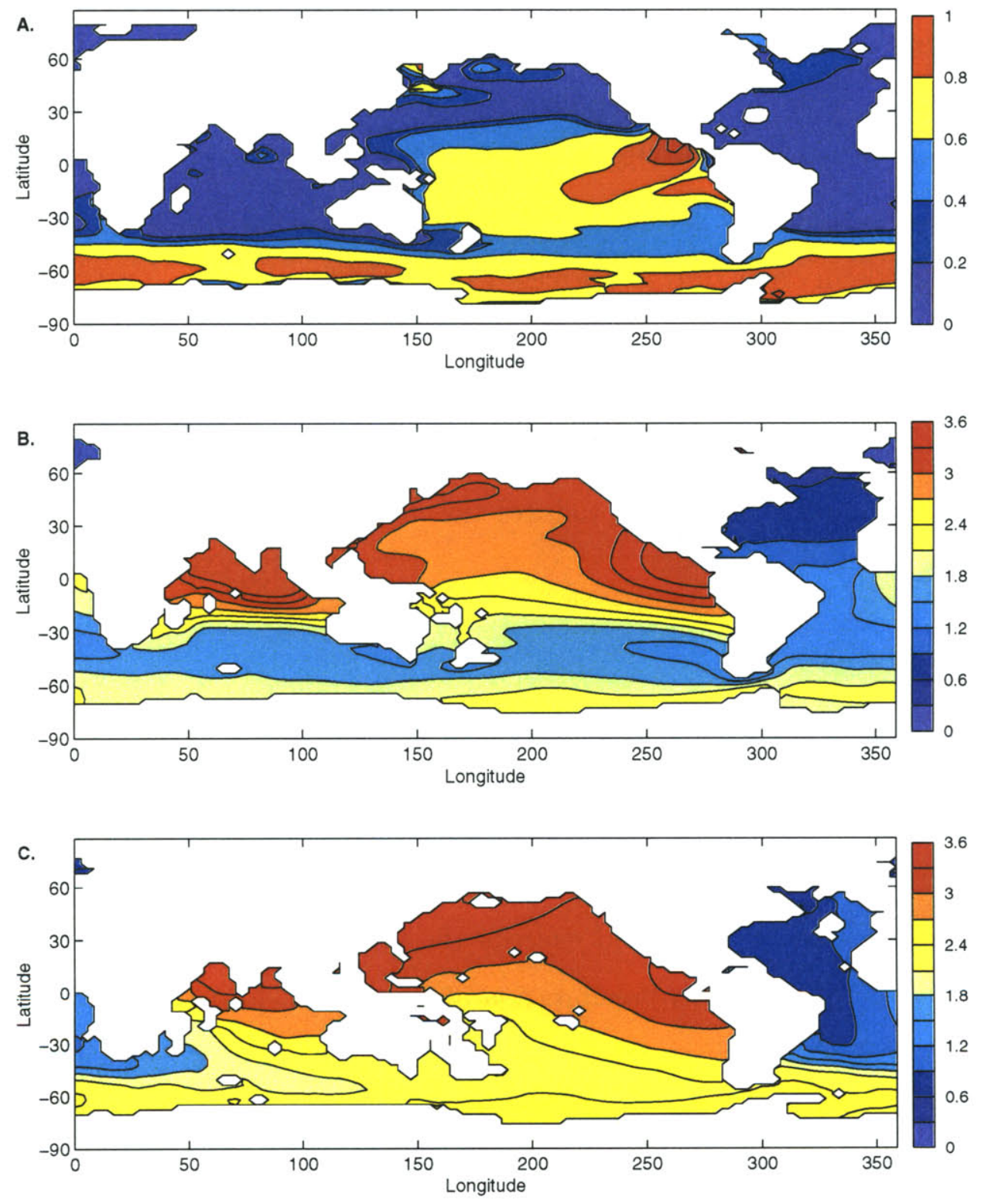

Figure 4-9: Modeled $\left[\mathrm{PO}_{4}\right](\mu \mathrm{M})$ at A) surface, B) $935 \mathrm{~m}$ and C) $2495 \mathrm{~m}$ for the complexation case. 

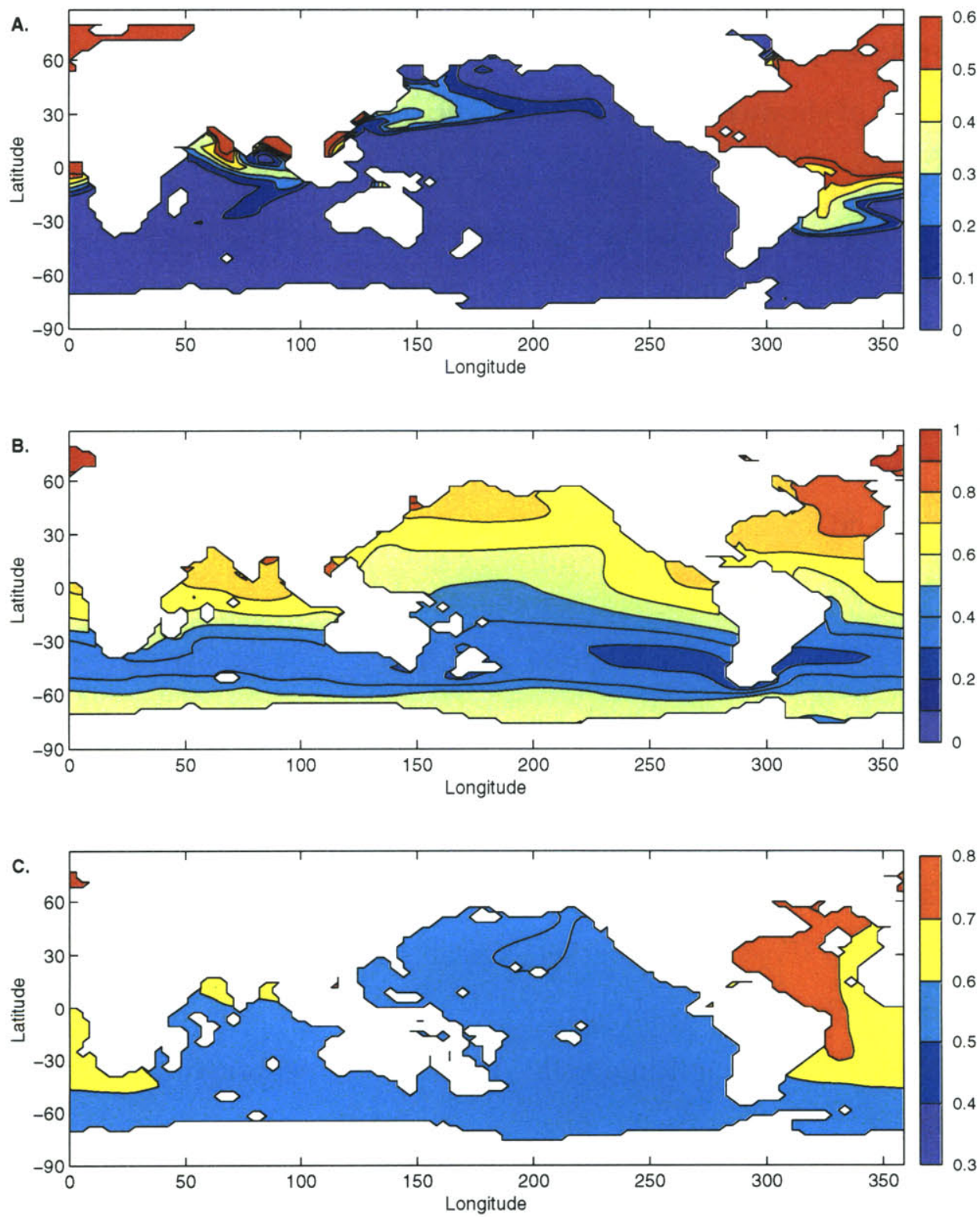

Figure 4-10: Modeled $\left[\mathrm{Fe}_{T}\right](\mathrm{nM})$ at A) surface, B) $935 \mathrm{~m}$ and C) $2495 \mathrm{~m}$ for the complexation case. 
The solubility of the dust may also be affected by the iron concentration in surface waters. In iron rich waters, the ability to dissolve the aeolian derived iron may be lower if the water is already close to saturation.

The model also predicts excess surface iron in the North Pacific and Indian Ocean, reflecting areas of elevated dust flux (see Figure 4-5), in good agreement with observations. In the rest of the Indo-Pacific basin and the Southern Ocean, $\left[\mathrm{Fe}_{T}\right]$ is close to complete drawdown as is to be expected since these are the traditional high nutrient, low chlorophyll regions of the ocean. Broadly, the modeled surface patterns are generally consistent with observations, but quantitative differences do exist, most notably high $\left[\mathrm{Fe}_{T}\right]$ in the Atlantic. Not allowing $\left[\mathrm{Fe}_{T}\right]$ to exceed solubility limits and considering the role of colloids and aggregation would likely improve model results in surface waters and are mechanistically reasonable. I plan to study controls on surface $\left[\mathrm{Fe}_{T}\right]$ in the future.

Figure 4-10B compares the modeled $\left[\mathrm{Fe}_{T}\right.$ ] distribution at 935 meters with measurements. In good agreement with the observations, $\left[\mathrm{Fe}_{T}\right]$ is highest in the North Atlantic and North Pacific. Modeled $\left[\mathrm{Fe}_{T}\right]$ is also high in the Northern Indian Ocean, but there are, as yet, no observations to compare with. The model successfully reproduces the pattern of decreasing $\left[\mathrm{Fe}_{T}\right]$ in the Pacific moving from north to south and predicts lowest $\left[\mathrm{Fe}_{T}\right]$ in the Southern Ocean, in agreement with the few available measurements. There are no published measurements of iron in the South Pacific and South Atlantic, making it impossible to assess the performance of the model for these regions.

There are very few Fe measurements at depths greater than 2000 meters (see Figure 1-4, bottom panel). Observations suggest highest concentrations in the Atlantic basin and the North Pacific. The rest of the Pacific and the Southern Ocean appear to have lower values, ranging between $0.4-0.6 \mathrm{nM}$. My model results show good agreement with the few measurements that exist. The model predicts a maximum $\left[\mathrm{Fe}_{T}\right]$ in the North Atlantic of $0.7 \mathrm{nM}$, reflecting the high aeolian input. The signature 

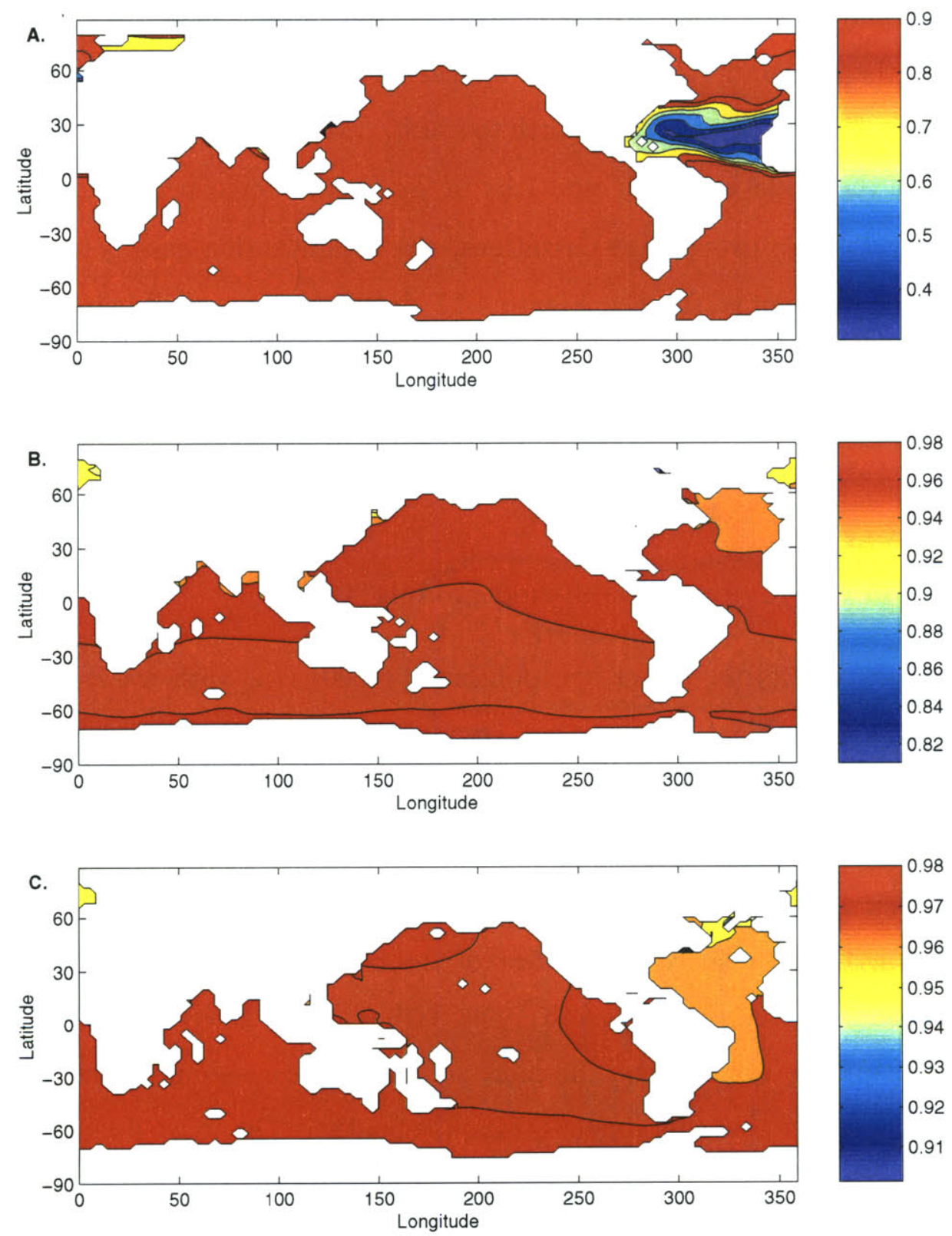

Figure 4-11: Modeled $[\mathrm{FeL}] /\left[\mathrm{Fe}_{T}\right]$ at A) surface, B) $935 \mathrm{~m}$ and C) $2495 \mathrm{~m}$ for the complexation case. 
of iron carried by North Atlantic Deep Water is visible in the Atlantic sector of the Southern Ocean. Since dust deposition is very low in the Southern Ocean, advection appears to play an important role in delivering iron to the deeper Southern Ocean waters. In the model, deep water $\left[\mathrm{Fe}_{T}\right]$ appear to be uniform, whereas observations suggest a decreasing gradient from north to south. More observational data is needed to constrain the model at depth, especially in the South Pacific and Southern Ocean.

Unlike the other two parameterizations, the complexation case is also able to predict the speciation of the Fe. Figure 4-11 shows the ratio of $\mathrm{FeL}$ to $\mathrm{Fe}_{T}$ in the model. In good agreement with observations, over $90 \%$ of the $\mathrm{Fe}$ is organically bound. Only in the North Atlantic, where surface $\left[\mathrm{Fe}_{T}\right]$ are higher than the imposed $\left[\mathrm{L}_{T}\right](1$ $\mathrm{nM}$ ), is the $\mathrm{FeL} / \mathrm{Fe}_{T}$ ratio low.

\section{Comparison to previously published models}

I compare my results to Archer and Johnson's (2000) case with a two-ligand iron model to a 3-dimensional ocean general circulation model (described in Chapter 2). Their modeled surface $\mathrm{PO}_{4}$ field (Figure 4-12) for the two ligand case does a better job of predicting elevated $\left[\mathrm{PO}_{4}\right]$ in the Southern Ocean. However, in order to achieve this result, Archer and Johnson (2000) have decreased the solubility of the dust reaching the Southern Ocean relative to the rest of the ocean. Yet, preliminary evidence (Fridlind and Jacobsen, 2000; Siefert, 1999; Willey et al., 2000) suggest the longer dust remains in the atmosphere, the more soluble it becomes due to the low $\mathrm{pH}$ of clouds. This then implies that dust reaching the Southern Ocean would have a higher solubility.

At 2500 meters depth, the $\left[\mathrm{Fe}_{T}\right]$ is uniform in Archer and Johnson's (2000) two ligand case (Figure $4-13$ ). The deep water $\left[\mathrm{Fe}_{T}\right]$ is $\sim 0.55 \mathrm{nM}$. In the southeastern coast off the coast of South America the Archer and Johnson (2000) model predicts

elevated $\left[\mathrm{Fe}_{T}\right]$. My model better captures the gradient between the Atlantic and Pacific basin. At the time of Archer and Johnson's (2000) work, it was thought that 


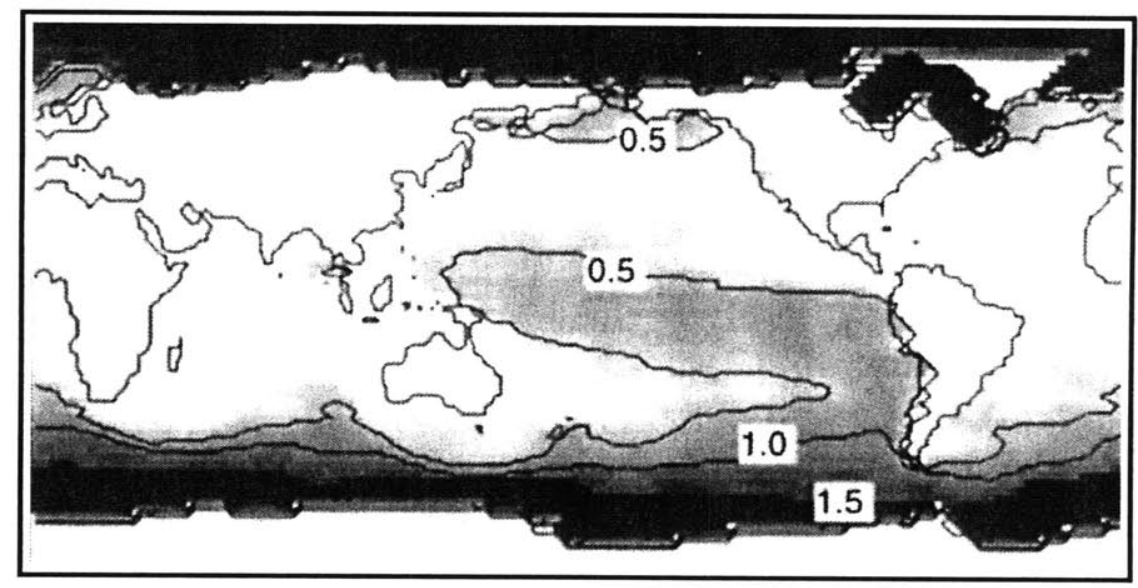

Figure 4-12: Modeled surface $\mathrm{PO}_{4}$ distribution for Archer and Johnson's (2000) twoligand case assuming 6\% of Mahowald et al. (1999) is soluble (Figure taken from Archer and Johnson, 2000).

deep water $\left[\mathrm{Fe}_{T}\right]$ were the same in both basins. Thus, Archer and Johnson (2000) tuned their model with this information in mind. Newer measurements show that a gradient does exist between the two basins.

While my model has a similar iron parameterization, differences in the solution can be attributed to the values chosen for certain parameters. Archer and Johnson's (2000) strong ligand has a very high stability constant $(\log (K)=13)$ and a concentration of 0.6 nM ensuring a saturated ligand. Additionally, Archer and Johnson (2000) use a scavenging rate of $0.8 \mathrm{yr}^{-1}$, four times greater than the scavenging rate I use. With such a fast scavenging rate, any iron that is not complexed is quickly removed from the system. Since $\left[\mathrm{L}_{T}\right]=0.6 \mathrm{nM}$, this essentially sets the iron concentration to be uniform, but is no longer consistent with the data. I suggest that Archer and Johnson's (2000) results are essentially a limit case. I find a better solution if the strong constraints of high $\log (K)$ and low $\left[\mathrm{L}_{T}\right]$ are relaxed. Archer and Johnson (2000) also remove 'excess' iron (i.e. iron above the amount needed to support biological production) from the surface, not allowing any of it to be transported at depth. While my results suggest there are mechanisms occurring in the surface waters to remove 

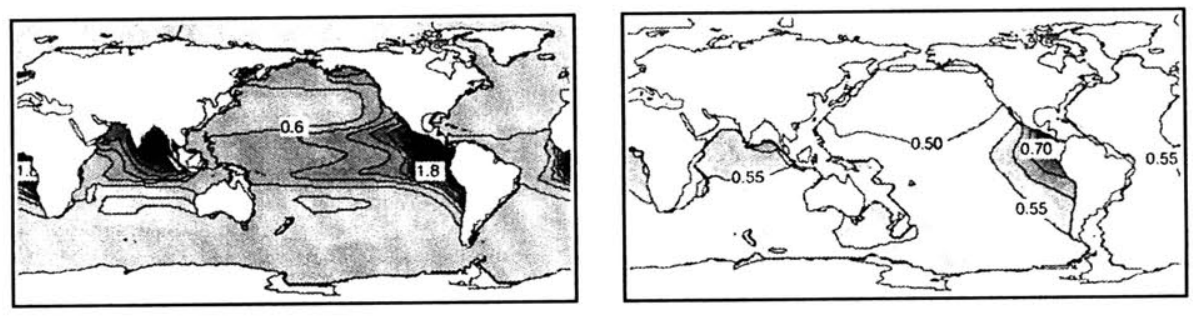

Figure 4-13: Modeled $\mathrm{Fe}_{T}$ distribution at $350 \mathrm{~m}$ and $2500 \mathrm{~m}$ from Archer and Johnson's (2000) two-ligand model case. (Figure taken from Archer and Johnson, 2000).

excess iron such as precipitation or aggregation of colloidal iron, it is still possible that a portion of the excess iron is transported at depth with the sinking of the North Atlantic Deep Water.

\subsection{Summary}

Using a coarse-resolution ocean general circulation model, I find it is not simple to reproduce observed Fe gradients and structure with the net scavenging and scavengingdesorption descriptions. In contrast, the complexation model easily captures the observed Fe distribution without much tuning. I compare the results of the complexation case with those of Archer and Johnson (2000). I suggest that their model is a special limit case and that by relaxing constraints, my model is better able to predict deep water $\mathrm{Fe}_{T}$ gradients. Differences in the solution of the two models can be attributed to how each model accounts for excess $\mathrm{Fe}_{T}$ at the surface, ligand strength, and scavenging rate. 


\section{Chapter 5}

\section{Regional and Global Iron Distributions}

In the previous chapter, I showed that the complexation parameterization of iron is best able to explain global iron distributions. In this chapter I further analyze the results from the complexation parameterization of iron. I define a tracer, $\mathrm{Fe}^{*}$ that calculates to what degree a water mass is iron limited. I also calculate the residence time of iron in the global ocean and evaluate the importance of upwelling as a source of iron to the euphotic zone.

In contrast to the last chapter, where I compared my model results to observations globally, I assess how well my model results capture temporal and regional variations in iron distribution. Lastly, I discuss the results of two sensitivity studies: the response of modeled global $\mathrm{Fe}_{T}$ distribution to A) a different aeolian forcing field and $\mathrm{B}$ ) parameterizing the uptake of $\mathrm{Fe}$ and $\mathrm{P}$ as a ratio that varies in relation to ambient $\left[\mathrm{Fe}_{T}\right]$. 


\subsection{A Tracer of Iron Limitation: $\mathrm{Fe}^{*}$}

The scavenging of iron from the water column results in the decoupling of Fe and $\mathrm{PO}_{4}$. Regions where upwelled waters are highly deficient in Fe require a high aeolian Fe flux to compensate, otherwise iron limitation occurs. Here, I construct a tracer which tracks the relative magnitude of decoupling between $\mathrm{Fe}$ and $\mathrm{PO}_{4}$. Similar to $\mathrm{N}^{*}$ (Gruber and Sarmiento, 1997), I subtract the contribution of the soft tissue pump from the $\mathrm{Fe}_{T}$ distribution to reveal the balance between physical transport and scavenging of iron. For the surface, I define:

$$
\begin{aligned}
F e * & =F e_{T}-R_{F e} P O_{4} \\
\frac{\partial F e *}{\partial t} & =\frac{\partial F e_{T}}{\partial t}-R_{F e} \frac{\partial P O_{4}}{\partial t} \\
\frac{\partial F e *}{\partial t} & =\alpha F_{i n}-u \cdot \nabla(F e *)-k_{s c} F e
\end{aligned}
$$

At depth:

$$
\frac{\partial F e *}{\partial t}=-u \cdot \nabla(F e *)-k_{s c} F e
$$

By removing the soft tissue pump contribution, $\mathrm{Fe}^{*}$ reveals the balance between advected and scavenged Fe. It is important to note that $\mathrm{R}_{F e}$, the ratio of $\mathrm{Fe}: \mathrm{PO}_{4}$ must be specified to calculate $\mathrm{Fe}^{*}$. In nature, the $\mathrm{Fe}: \mathrm{C}$ is not likely to be constant (Sunda and Huntsman, 1995), but in the model, I have assumed a constant Fe:C ratio of $4 \mu \mathrm{mol}: 1 \mathrm{~mol}$ and a Redfield ratio of C:P of 117:1, resulting in an Fe:P ratio of $.47 \mathrm{mmol}: 1 \mathrm{~mol}$. A positive $\mathrm{Fe}^{*}$ implies there is adequate $\mathrm{Fe}$ to support the complete biological utilization of $\mathrm{PO}_{4}$, while a negative $\mathrm{Fe}^{*}$ means that there is a deficit in Fe.

In Figures 5-1, 5-2 and 5-3, I have plotted zonally averaged sections of $\mathrm{Fe}^{*}$ for the Atlantic, Indo-Pacific and Southern Ocean basins, respectively. In the North Atlantic, where aeolian input is high, $\mathrm{Fe}^{*}$ is above zero for all depths (Figure 5-1). The signature of the strong aeolian deposition is carried to the deep waters by the western boundary 


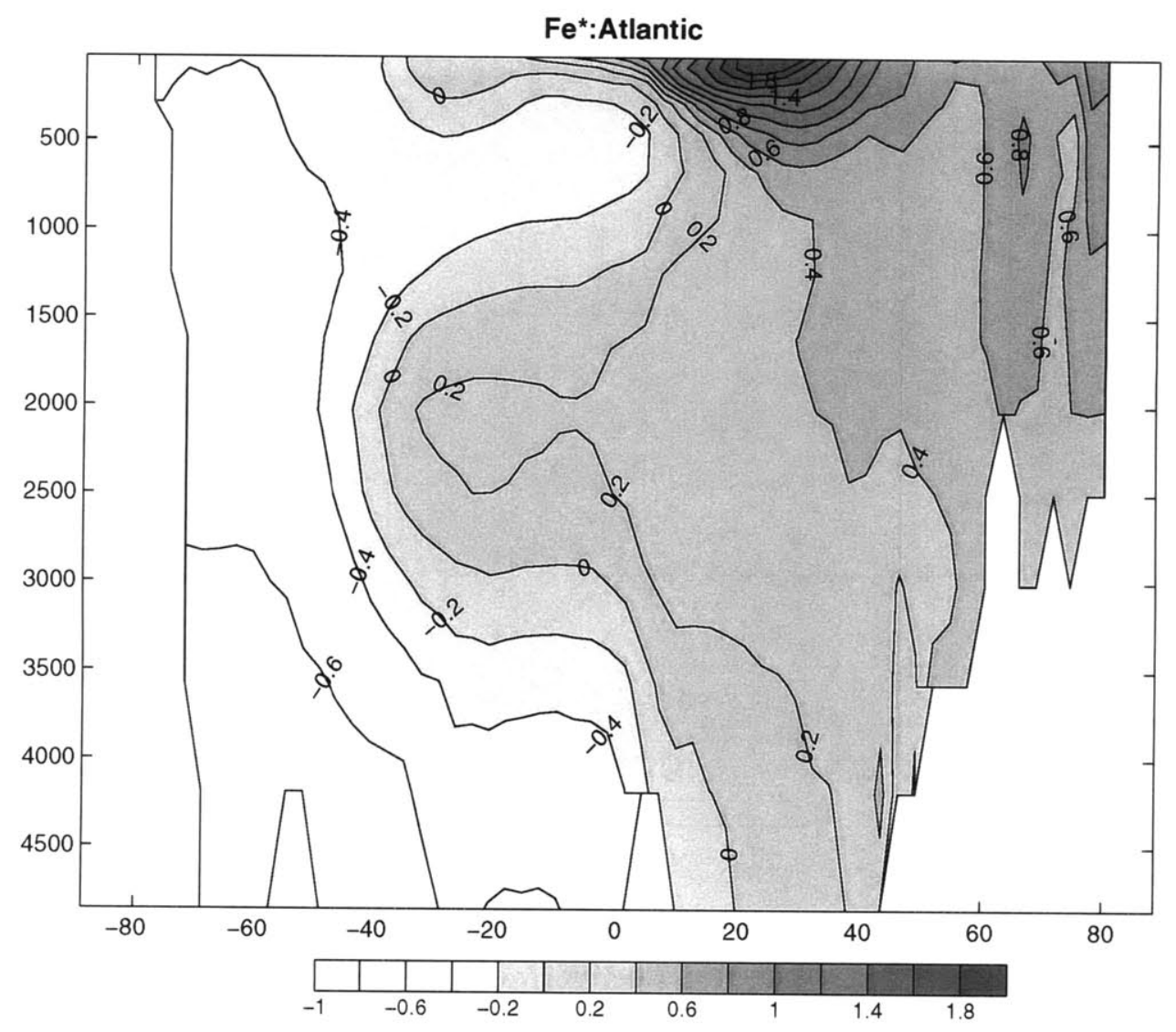

Figure 5-1: Zonally averaged section of $\mathrm{Fe}^{*}$ in the Atlantic basin.

current and southward by North Atlantic Deep Water to approximately $35^{\circ} \mathrm{S}$. Only southward of $35^{\circ} \mathrm{S}$ does scavenging deplete the excess Fe that originated from N. Atlantic surface waters.

Only in the surface waters of the Indo-Pacific basin from approximately $25^{\circ}-40^{\circ} \mathrm{N}$ is $\mathrm{Fe}^{*}$ above zero (Figure 5-2). The waters upwelled from below are deficient in $\mathrm{Fe}$ (negative $\mathrm{Fe}^{*}$ ), but aeolian deposition is able to compensate so macronutrients are still strongly drawn down in the surface. Fe* is most negative in the deep Northern Pacific waters. Since these are the oldest waters in the ocean, the iron has been stripped away by scavenging, while $\mathrm{PO}_{4}$ has been accumulating, resulting in the largest decoupling between $\mathrm{PO}_{4}$ and $\mathrm{Fe}$ in the ocean. Therefore, although dust deposition is high in the North Pacific, HNLC conditions are still prevalent. In the Southern Ocean (Figure 


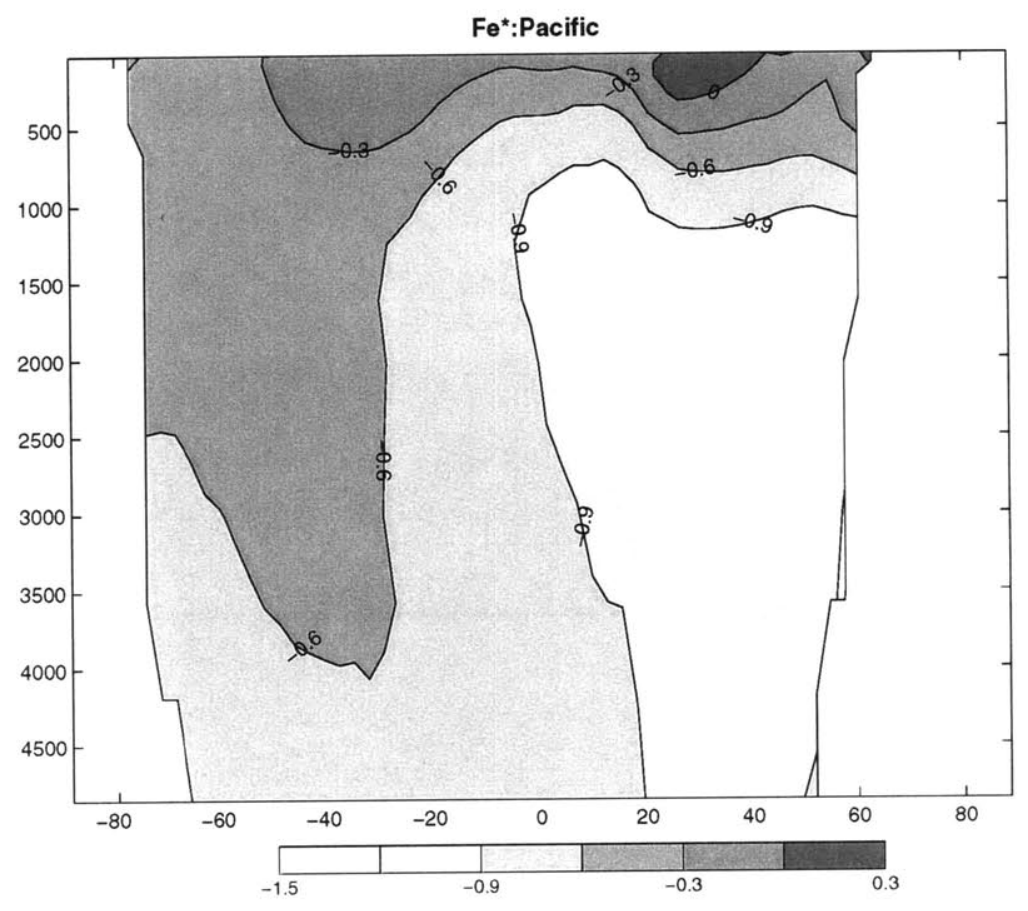

Figure 5-2: Zonally averaged section of $\mathrm{Fe}^{*}$ in the Indo-Pacific basin.

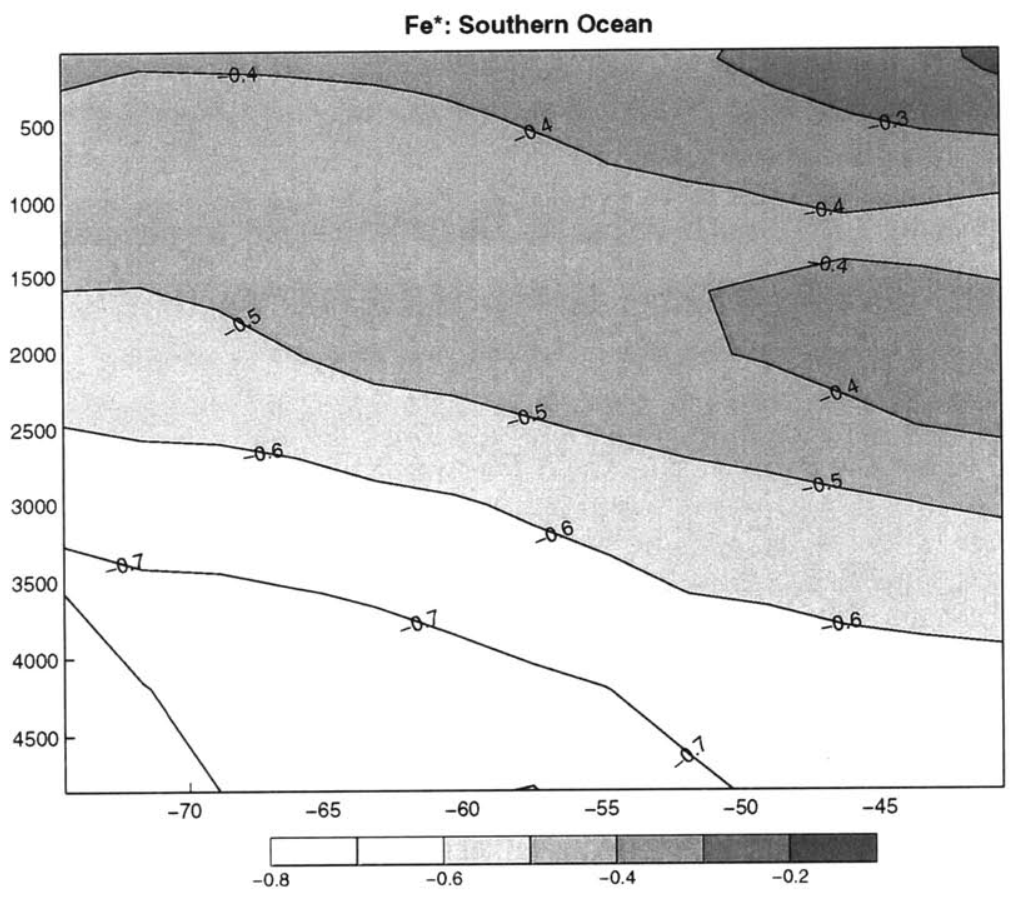

Figure 5-3: Zonally averaged section of $\mathrm{Fe}^{*}$ in the Southern Ocean basin. 
$5-3), \mathrm{Fe}^{*}$ is negative throughout the basin and decreases with depth, reflecting the dominance of scavenging over transport.

\subsection{Iron Residence Time}

For geochemical problems, we sometimes consider the ocean to be a well mixed reservoir in which the resulting concentration of an element is dependent on the rate of input of the element into the ocean and the rate of reactions that remove the element from the ocean. Assuming steady state, the input (source) and output (sink) should balance. Dividing the rate of input or output by the amount of the element in the ocean provides us with the residence time $(\tau)$, or mean lifetime of that element in the ocean, which is also an indicator of the amount of time it takes for an element to respond to a change in its input or output rate.

I calculate the residence time of Fe in the model and discuss how it compares to other estimates. The soluble dust flux entering the ocean is $\sim 2^{*} 10^{9} \mathrm{~mol} \mathrm{Fe} \mathrm{yr}^{-1}$ and the amount of $\mathrm{Fe}$ in the ocean at steady state averaged for one year is $5.76^{*} 10^{11} \mathrm{~mol}$ $\mathrm{Fe}$, resulting in a $\tau=285$ years. Such a long residence time implies that $\mathrm{Fe}$ can be transported quite far prior to scavenging, hence identified with water mass tracers.

Bacon and Anderson (1982) show that the residence time of a metal can be calculated by considering the amount of iron that is lost due to scavenging. They consider the ratio of the adsorbed metal concentration $\left(\left[\mathrm{Me}_{P}\right]\right)$ to the total metal concentration $\left(\left[\mathrm{Me}_{T}\right]\right)$ to be an estimator of residence time. Using this method, Bruland et al. (1994) estimate a residence time ranging between 70-140 years for Fe. While my estimate predicts a longer residence time than Bruland et al. (1994) for $\mathrm{Fe}$, due to the large uncertainties, they are probably not inconsistent. Bruland et al. (1994) estimate the $\left[\mathrm{Me}_{P}\right]$ by measuring the fraction of Fe that is leachable by acetic acid. Since the $\mathrm{pH}$ of acetic acid is lower than $\mathrm{pH}$ of the sea, it may leach off more Fe than was actually scavenged. This would imply that Bruland et al.'s (1994) estimate is a 
lower bound estimate. Additionally, Bruland et al. (1994) make a global residence time estimate using samples from the central North Pacific gyre. In my calculation, there are also uncertainties associated with the aeolian flux of iron into ocean. Due to the episodic nature of aeolian Fe input, it is difficult to accurately estimate the global average yearly dust flux. Furthermore, the solubility of aeolian iron is very uncertain in seawater. If less than $1 \%$ of aeolian $\mathrm{Fe}$ is soluble, as preliminary dust leaching experiments suggest (Jickells and Spokes, 2001), and the global dust flux I used is an overestimate, my estimate can be viewed as an upper bound. Hence, within uncertainties, the estimates are consistent.

\subsection{Importance of upwelled iron to the euphotic zone}

The two sources of 'new' iron to the euphotic zone are aeolian deposition and upwelling. The amount of soluble Fe entering the ocean in the model is $\sim 2^{*} 10^{9} \mathrm{~mol}$

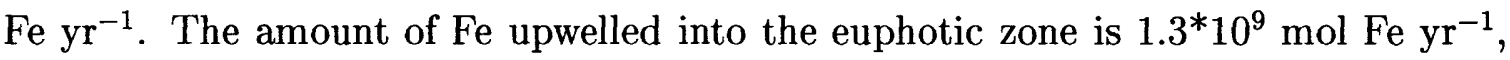
accounting for $40 \%$ of the supply to the surface. My calculation agrees well with the estimate of Fung et al. (2000) based on the results from a mixed layer model. Archer and Johnson (2000), though, predict that $\sim 70-75 \%$ of iron is supplied by upwelling. Archer and Johnson's model predicts a uniform $\left[\mathrm{Fe}_{T}\right]$ of $\sim 0.6 \mathrm{nM}$ throughout the deep waters, while more recent observations show that $\left[\mathrm{Fe}_{T}\right]$ are the lower in the Pacific and Southern Ocean. Thus, Archer and Johnson (2000) may have overestimated the contribution of upwelling as a source of iron to the euphotic zone. 


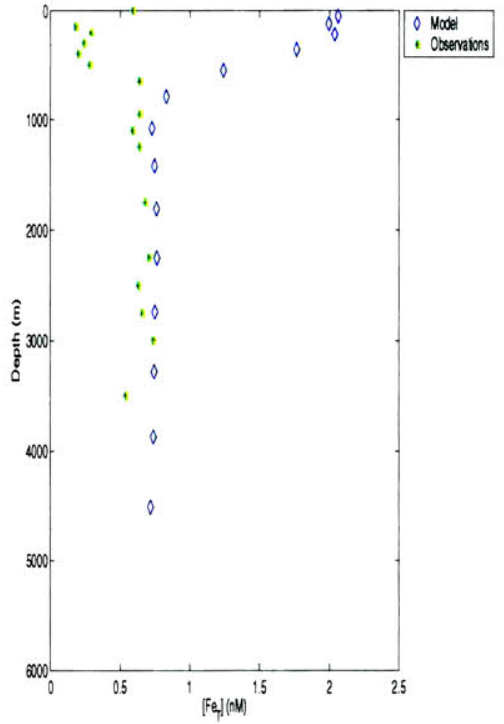

Figure 5-4: Modeled profile at BATS $\left(35^{\circ} \mathrm{N}, 58^{\circ} \mathrm{W}\right)$ (diamonds) compared to observations $\left(^{*}\right)$ for the month of July. Observational data provided by Boyle and co-workers (unpublished).

\subsection{Temporal and Vertical Variations: Compar- isons to Data}

In this section, I compare my model results with observational data from specific stations. Since the deposition of Fe varies episodically and the model is forced seasonally, I also examine the fluctuation of $\left[\mathrm{Fe}_{T}\right]$ seasonally in the surface layer.

Figure 5-4 displays the vertical profile of 'dissolved' $(<0.4 \mu \mathrm{m})\left[\mathrm{Fe}_{T}\right]$ from $35^{\circ} \mathrm{N}$, $58^{\circ} \mathrm{W}$ (Wu et al., 2001), as well as the modeled profile. The modeled $\left[\mathrm{Fe}_{T}\right]$ are much higher than observed, suggesting either that the soluble aeolian Fe estimates for the Atlantic are too high or there are unrepresented sinks in the model for iron in surface waters, such as precipitation or aggregation and subsequent sinking of Fe. I believe the latter is the more likely possibility. Below $800 \mathrm{~m}$, the model results agree well with observations. The iron profile is straight below $1000 \mathrm{~m}$, although the observed $\left[\mathrm{Fe}_{T}\right]$ decreases slightly at $\sim 3700 \mathrm{~m}$. The maximum $\left[\mathrm{Fe}_{T}\right]$ for both the model and observations is $\sim 0.7 \mathrm{nM}$. 


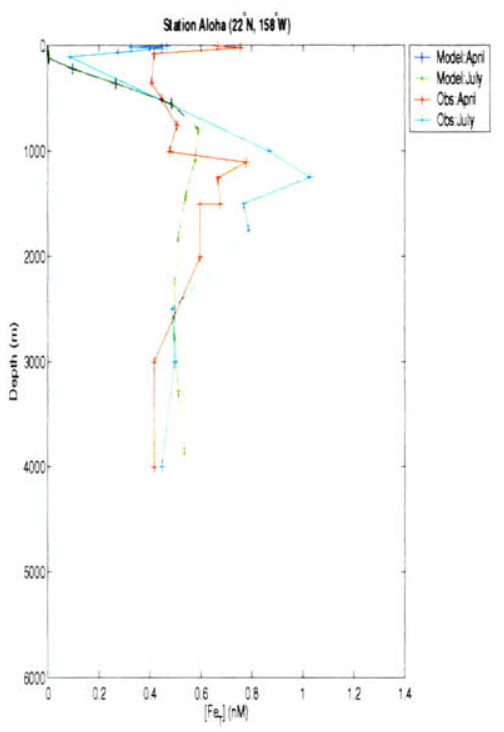

Figure 5-5: Modeled profile at Station ALOHA $\left(22^{\circ} \mathrm{N}, 158^{\circ} \mathrm{W}\right)$ compared to observations. Observational data provided by Boyle and co-workers (unpublished).

At station ALOHA, the model predicts a HNLC region since $\left[\mathrm{Fe}_{T}\right]$ is completely depleted, but $\left[\mathrm{PO}_{4}\right]$ is elevated. In contrast, the observations show excess $\left[\mathrm{Fe}_{T}\right]$ and depleted $\left[\mathrm{PO}_{4}\right]$ in surface waters here (Figure 5-5). This suggests that the aeolian forcing used in the model is too weak at station ALOHA ,'nutrient trapping' is occurring, or the DOP remineralization timescale is too long. The latter two possibilities are discussed in further detail in Section 4.4.1. Below 300m, the model shows better agreement with the observations. The observations show a maximum $\left[\mathrm{Fe}_{T}\right]$ at $\sim 1200 \mathrm{~m}$, which varies seasonally. The model maximum $\left[\mathrm{Fe}_{T}\right]$ is at a slightly shallower depth and does not predict $\left[\mathrm{Fe}_{T}\right]$ as high as observations indicate. This discrepancy can be attributed to the presence of the Loihi seamount, a local source of hydrothermal iron. At $3000 \mathrm{~m}$, the model predicts an $\left[\mathrm{Fe}_{T}\right]$ of $0.5 \mathrm{nM}$, while Boyle (unpublished) measured $0.45 \mathrm{nM}$.

The modeled profile in the North Pacific $\left(50^{\circ} \mathrm{N}, 145^{\circ} \mathrm{W}\right)$ matches the observations from Johnson et al. (1997) well (Figure 5-6). The $\mathrm{Fe}_{T}$ is drawn down at the surface and has a maximum $\left[\mathrm{Fe}_{T}\right]$ at $\sim 1000$ meters. At intermediate depths, the modeled $\mathrm{Fe}_{T}$ 


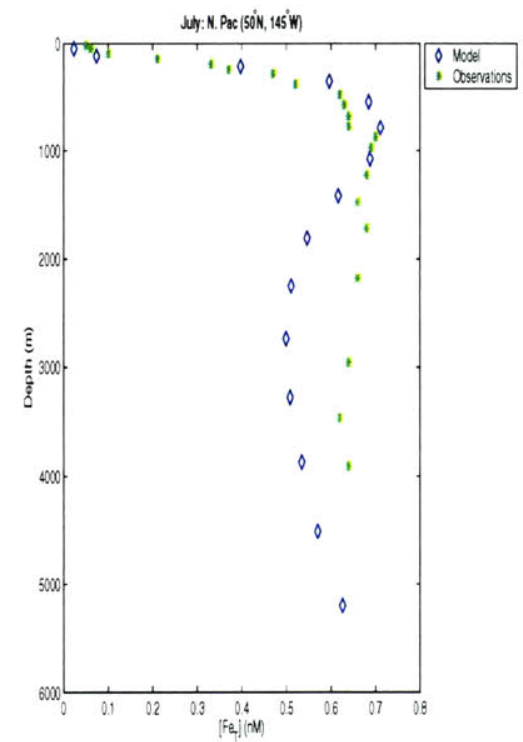

Figure 5-6: Modeled profile in the North Pacific at $50^{\circ} \mathrm{N}, 145^{\circ} \mathrm{W}$ (diamonds) for July compared to observations. Observational data $\left({ }^{*}\right)$ from Johnson et al. (1997).

is more strongly scavenged than the observations. Iron from the continental margins may add iron at depth in this region, possibly explaining why the modeled $\left[\mathrm{Fe}_{T}\right]$ is lower at intermediate depths. In the equatorial Pacific, the model completely draws down $\left[\mathrm{Fe}_{T}\right]$, also seen in the observations (Figure 5-7). The model has a maximum $\left[\mathrm{Fe}_{T}\right]$ at $1000 \mathrm{~m}$ due to remineralization, and decreases at intermediate depths due to scavenging. The $\left[\mathrm{Fe}_{T}\right]$ increases at depths greater than $3000 \mathrm{~m}$ because the scavenging rate decreases due to the decrease in particle density.

In Figure 5-8, I plot the modeled profile $\left[\mathrm{Fe}_{T}\right]$ (diamonds) at $56^{\circ} \mathrm{S}, 143^{\circ} \mathrm{E}$ in the Southern Ocean and compare it to measurements made by Sohrin et al. (2000). The model depletes Fe completely at the surface. Measurements by Sohrin et al. (2000) show excess Fe at the surface, but Coale et al. (2002) have shown Fe to be depleted in surface Southern Ocean waters. At intermediate depths (1000-2500m), the modeled concentration is slightly higher, but has a similar profile to the measurements. My model successfully predicts a lower $\left[\mathrm{Fe}_{T}\right]$ at $1000 \mathrm{~m}$ than is observed in the Pacific and Atlantic basins. Below $3000 \mathrm{~m}$, the model agrees well with observations. 


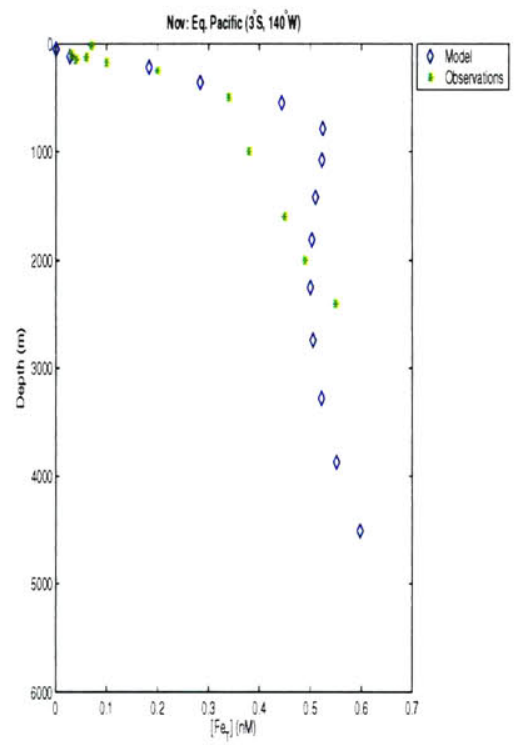

Figure 5-7: Modeled profile in the Equatorial Pacific at $3^{\circ} \mathrm{S}, 140^{\circ} \mathrm{W}$ (diamonds) compared to observations $\left({ }^{*}\right)$ in November. Observational data from Johnson et al. (1997).

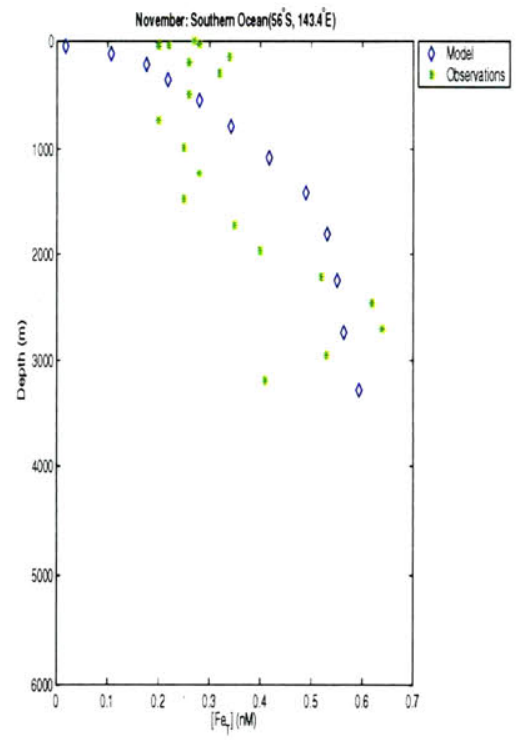

Figure 5-8: Modeled profile in the Southern Ocean at $56^{\circ} \mathrm{S}, 143^{\circ} \mathrm{E}$ (diamonds) compared to observations $\left({ }^{*}\right)$. Observational data from Sohrin et al. (2000). 
In summary, beneath the surface layer, the model agrees well with observed profiles for different regions of the ocean. At the surface, the model overestimates the excess $\left[\mathrm{Fe}_{T}\right]$ in high flux regions. In areas with lower aeolian input such as the Southern Ocean and the central Pacific, the model is able to drawdown $\left[\mathrm{Fe}_{T}\right]$ completely, while observations do show a low $\left[\mathrm{Fe}_{T}\right]$ at the surface. In the equatorial and North Pacific, both HNLC regions, the model achieves better agreement at the surface with the data. Processes missing from this model which might account for these discrepancies include a variable $\mathrm{Fe}: \mathrm{C}$ ratio, or a more complex parameterization of biological export that accounts for the varying needs of different class-size phytoplankton. Inclusion of these processes may improve the model's performance at the surface and are areas I hope to explore in the future.

\section{Surface Transects}

In the western North Atlantic, Boyle et al. (unpublished) collected surface samples along $45^{\circ} \mathrm{W}$ between $10^{\circ} \mathrm{N}$ and $35^{\circ} \mathrm{N}$ in January 2001 and then again in July 2001 to study interannual variability in surface $\left[\mathrm{Fe}_{T}\right]$. They found (Figure 5-9) little variation in the $\left[\mathrm{Fe}_{T}\right]$. In January, the observations show $\left[\mathrm{Fe}_{T}\right]=0.6 \mathrm{nM}$, while it is 0.55 $\mathrm{nM}$ in July at $10^{\circ} \mathrm{N}$. The model predicts a $\left[\mathrm{Fe}_{T}\right]=0.78 \mathrm{nM}$ in January (Figure 5-9) and $0.82 \mathrm{nM}$ in July at $10^{\circ} \mathrm{N}$. Although the model predicted $\left[\mathrm{Fe}_{T}\right]$ are higher than observations, the fact that $\left[\mathrm{Fe}_{T}\right]$ at the surface in January and July are comparable, is consistent with observations. Modeled $\left[\mathrm{Fe}_{T}\right]$ are much higher than observations due to the high aeolian flux forcing for this region. Of interest is the surface $\left[\mathrm{Fe}_{T}\right]$ between January and July (Figure 5-10). Model results suggest a strong seasonal cycle. Monthly measurements of surface $\mathrm{Fe}_{T}$ would confirm or refute this suggestion.

The observations and modeled results are somewhat surprising, since aeolian flux is low during January, but high in July (Figure 5-11). The dust flux estimates used in the model simulation are high for June through November, but drop significantly. I calculate a local residence time of 35 days for iron in surface waters at this location. 

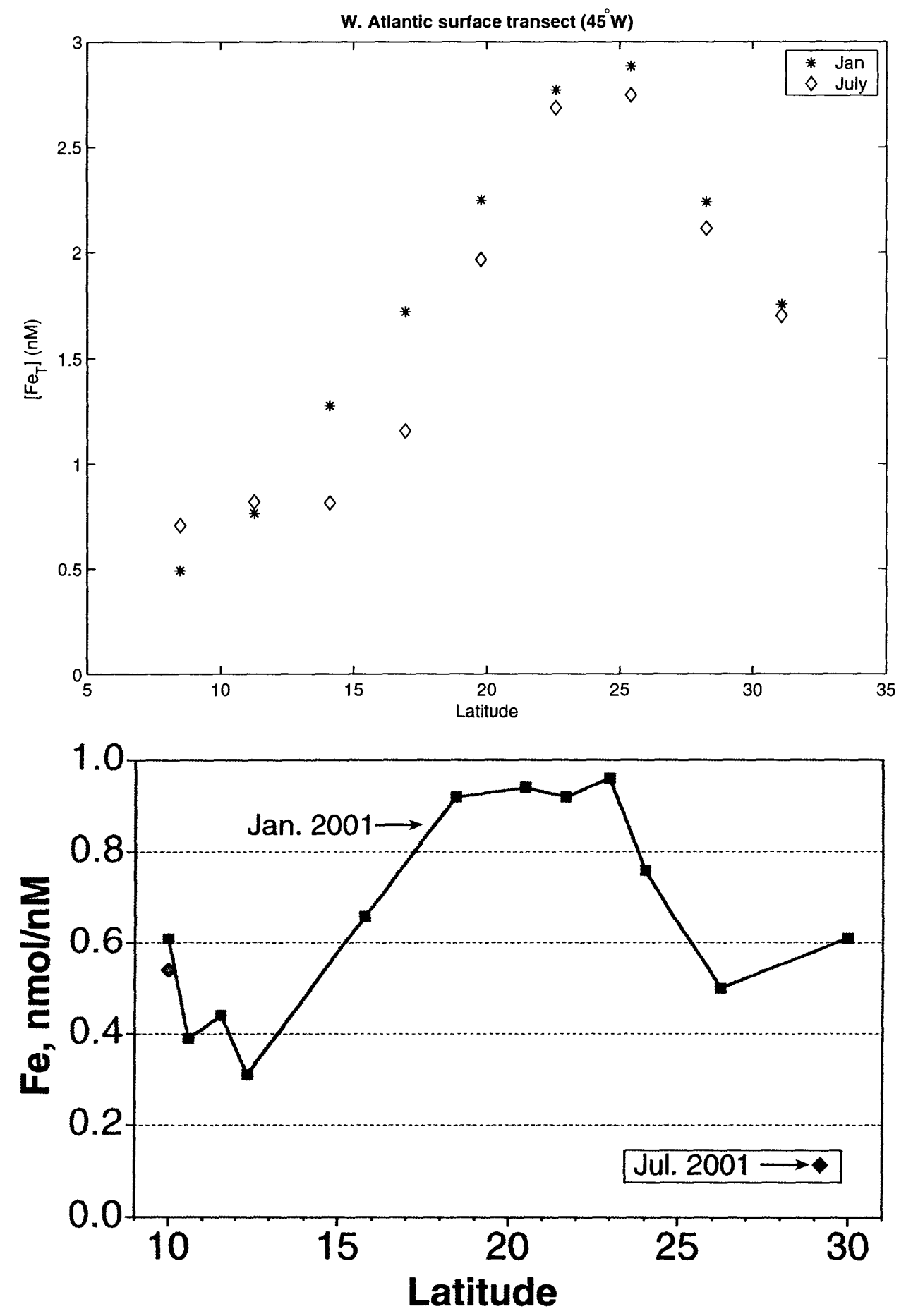

Figure 5-9: Surface transect of dissolved $[\mathrm{Fe}](<0.4 \mu \mathrm{m})$ at $45^{\circ} \mathrm{W}$ in January and July. The top panel are modeled $\left[\mathrm{Fe}_{T}\right]$. The lower panel are observations made by Boyle and coworkers (unpublished). Figure courtesy of E. Boyle. 


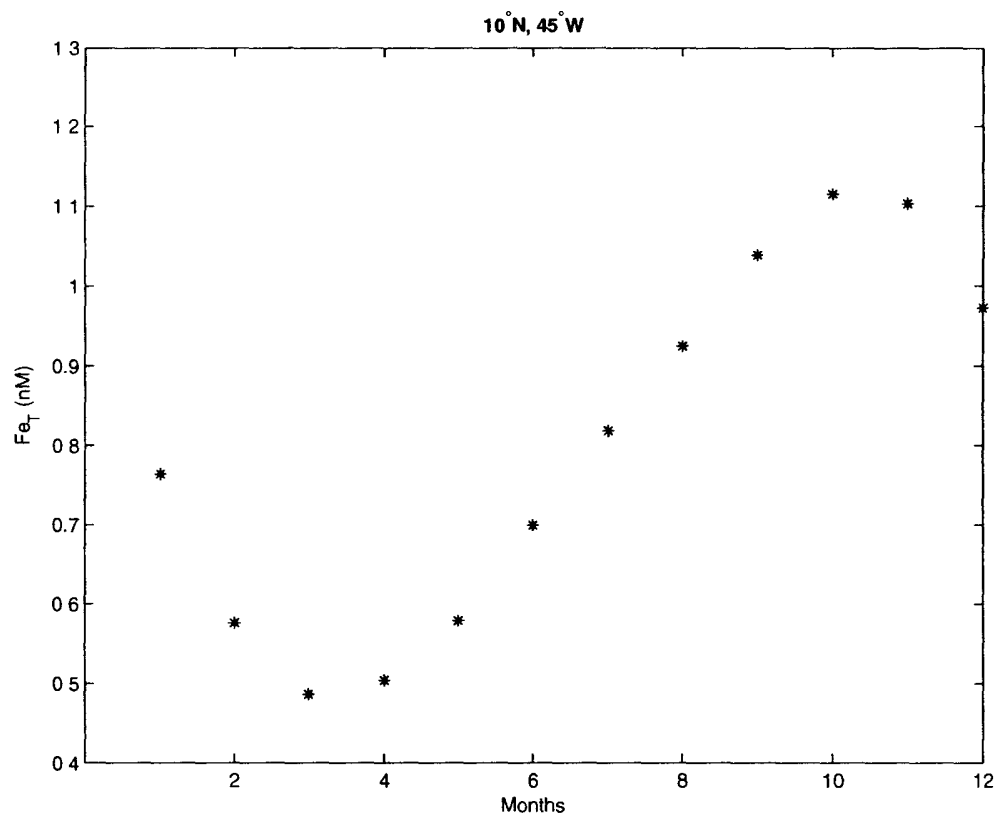

Figure 5-10: Monthly modeled surface $\left[\mathrm{Fe}_{T}\right]$ at $10^{\circ} \mathrm{N}, 45^{\circ} \mathrm{W}$.

This implies that the soluble Fe in the dust deposited in November still influences surface waters in January.

For station ALOHA, Boyle (unpublished) compiled seasonal surface $\left[\mathrm{Fe}_{T}\right]$ and found a sharp increase in surface $\left[\mathrm{Fe}_{T}\right]$ in April (Figure 5-12A). Although quantitatively the model predicts much lower surface $\left[\mathrm{Fe}_{T}\right]$ than observed (Figure 5-12B), the model is able to reproduce the seasonal cycle, which is controlled by the aeolian dust flux, with highest flux during the spring (Figure 5-13). The model also predicts high $\left[\mathrm{PO}_{4}\right]$ for station ALOHA, which is at odds with observations (Figure 4-6). This suggests the aeolian flux used to force the model is too low, creating a HNLC region where there is not one. Alternatively it could be related to 'nutrient trapping' or the long timescale for remineralization of DOP in the model. Both of these possibilities are discussed in greater detail in Section 4.4.1.

The model does a poor job of predicting the magnitude of $\left[\mathrm{Fe}_{T}\right]$ for the surface transects I compared my model to. In the Atlantic, the model values are higher than observed and in the Pacific, the model predicts lower $\left[\mathrm{Fe}_{T}\right]$ than observed. Improved 


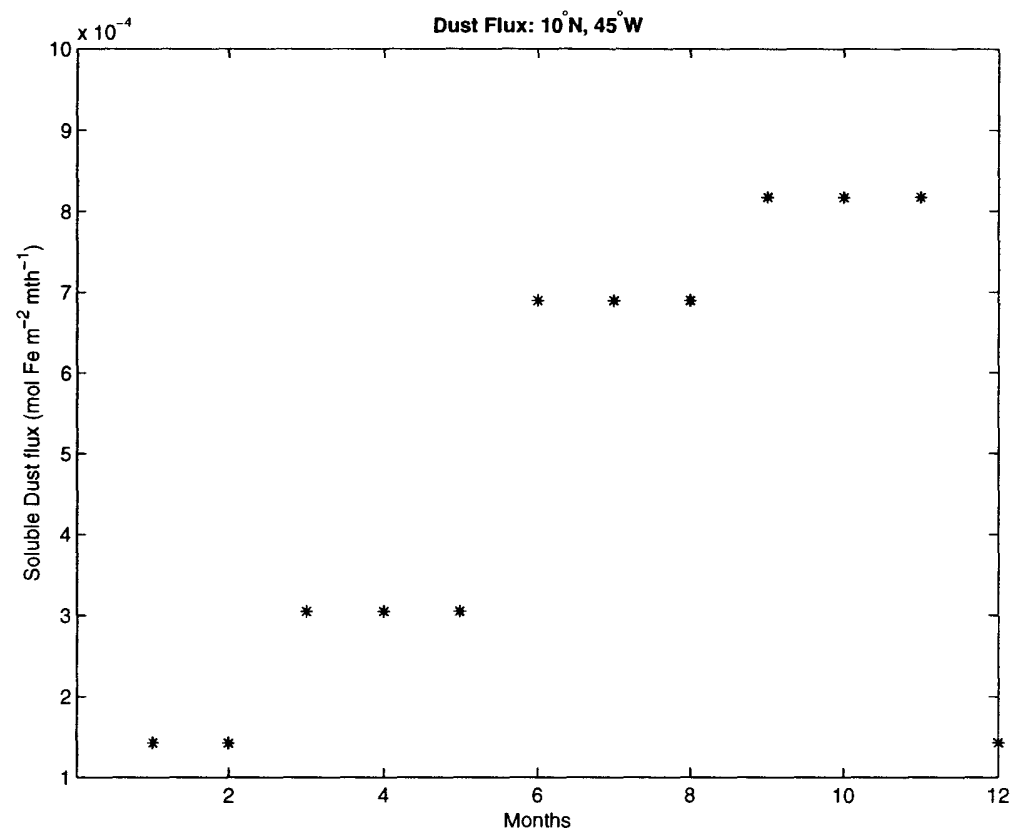

Figure 5-11: Monthly dust flux at $10^{\circ} \mathrm{N}, 45^{\circ} \mathrm{W}$ used in the model.

dust flux estimates and including surface processes such as precipitation and aggregation of Fe may improve model results. However, the aim of the model was to capture the cycling of $\mathrm{Fe}$ in the deep water, so it is not entirely surprising that the model can improve in the surface. The model is able to successfully mimic the seasonal cycle at Station ALOHA and suggests there is a strong seasonal surface signal in the western Atlantic also.

\subsection{Sensitivity to Aeolian Forcing}

Aeolian deposition is the primary source of iron into the global ocean and thus plays an important role in setting the ocean Fe distribution. Yet estimates of aeolian $\mathrm{Fe}$ deposition are poorly constrained due to the episodic nature of dust deposition. I test the sensitivity of the ocean iron distributions to the range of estimates in regional dust flux by forcing the model with a second set of aeolian flux forcing fields that was generated from an atmospheric dust transport model (Mahowald et al., 2003). 

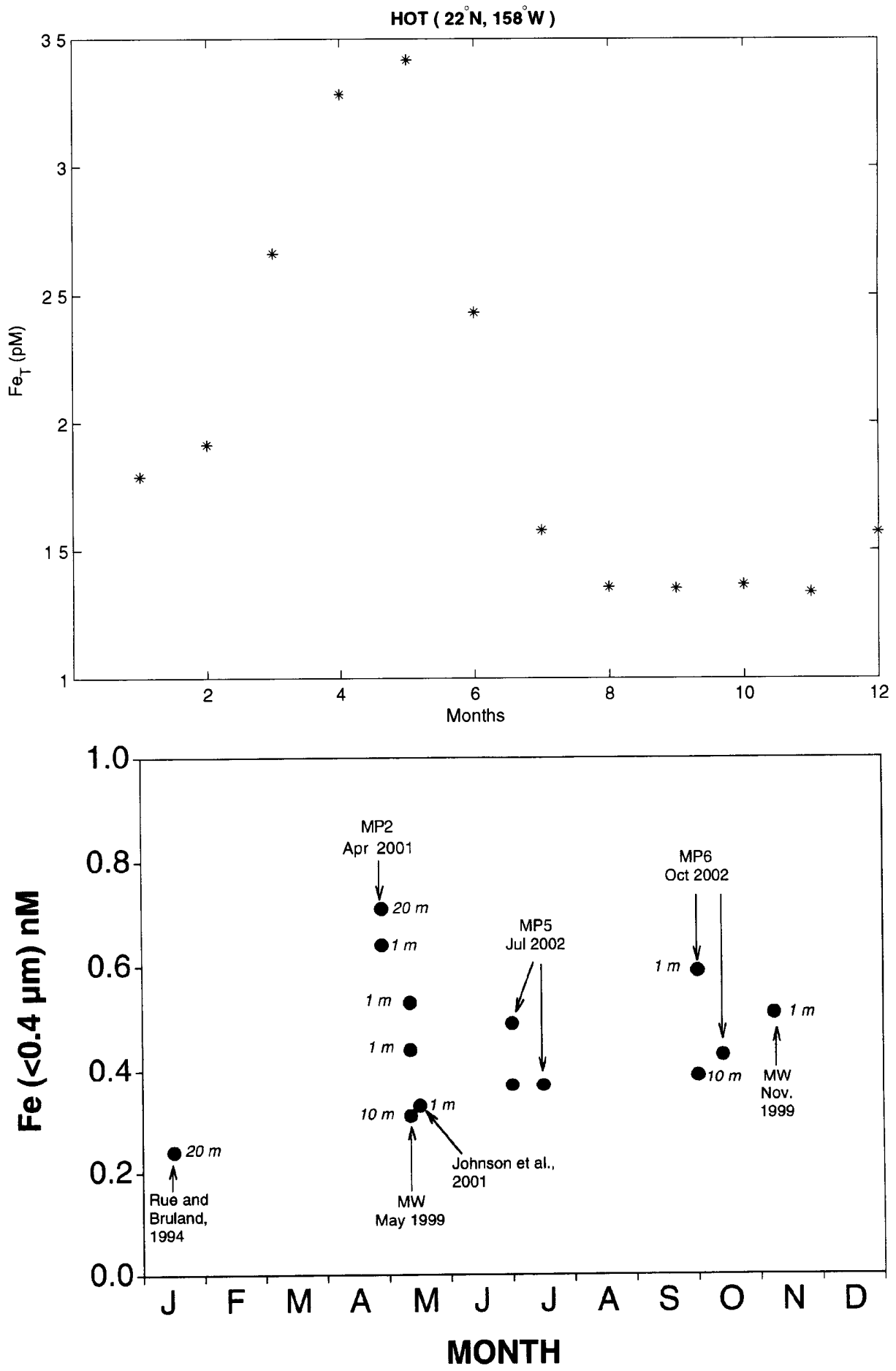

Figure 5-12: Monthly surface $\left[\mathrm{Fe}_{T}\right]$ at station ALOHA $\left(22^{\circ} \mathrm{N}, 158^{\circ} \mathrm{W}\right)$. The top panel are modeled $\left[\mathrm{Fe}_{T}\right]$. Note that units for modeled $\left[\mathrm{Fe}_{T}\right]$ are $\mathrm{pM}$. The lower panel shows observations compiled by Boyle (unpublished). Lower panel figure courtesy of E. Boyle. 


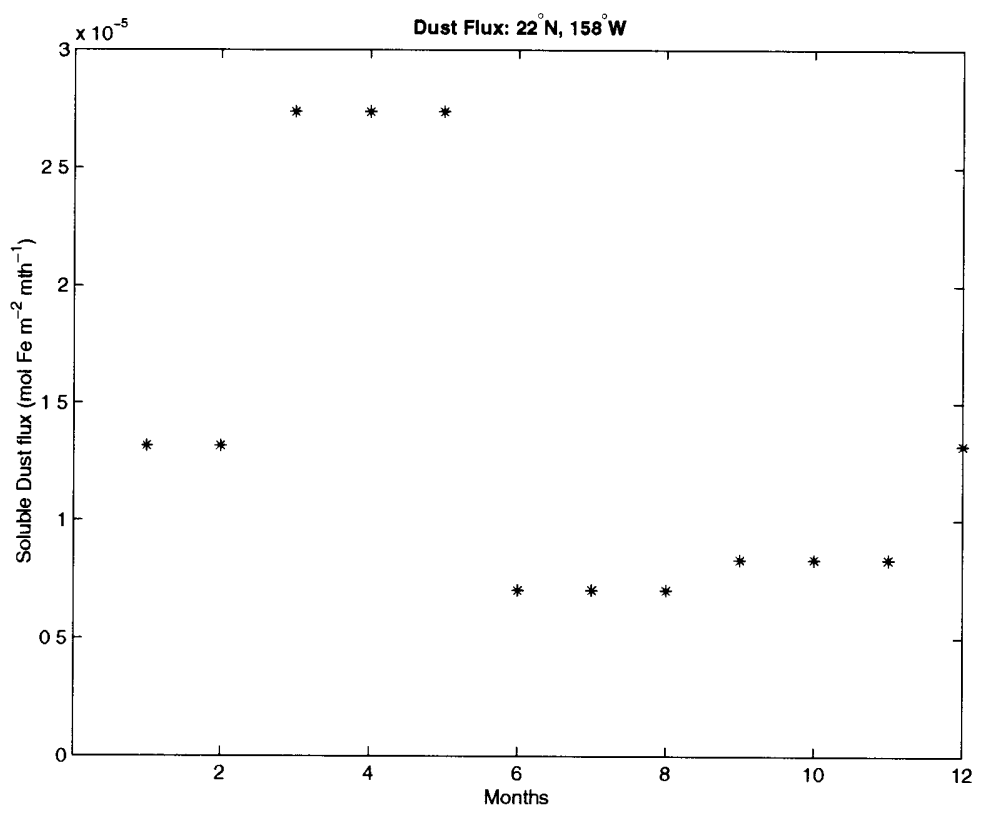

Figure 5-13: Monthly dust flux at Station ALOHA used in the model.

In this section, I describe the aeolian flux field and discuss the corresponding results of my model.

\section{Forcing Field}

Mahowald et al. (2003) generated daily global aeolian flux maps from a 22-year atmospheric model simulation. Figure 5-14 displays the seasonal global iron flux used in this sensitivity study. I assume 3.5 weight\% of dust is iron and $1 \%$ solubility. Similar to the Gao forcing field, aeolian iron deposition is highest in the Northern Atlantic. Deposition is also high in the Arabian Sea and the Northwestern Pacific, although relative to Gao et al. (2001) (see Figure 4-5), the Northwestern Pacific flux is weaker in the Mahowald et al. (2003) simulation. The most notable difference between the two aeolian flux forcing fields is the strength of deposition in the Southern Hemisphere. The Mahowald et al. (2003) simulation suggests much higher dust deposition in the Southern Hemisphere, especially off of the Australian coast and the northeastern coast of South America. 


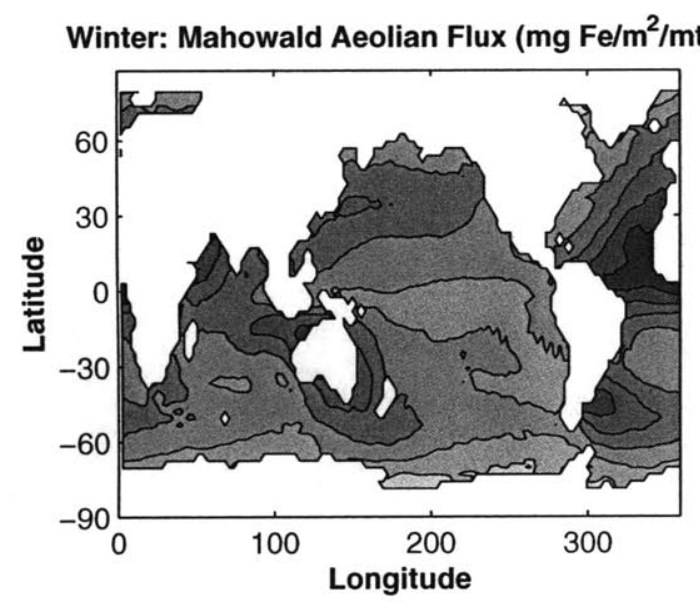

Summer: Mahowald Aeolian Flux ( $\mathrm{mg} \mathrm{Fe} / \mathrm{m}^{2} / \mathrm{mth}$ )

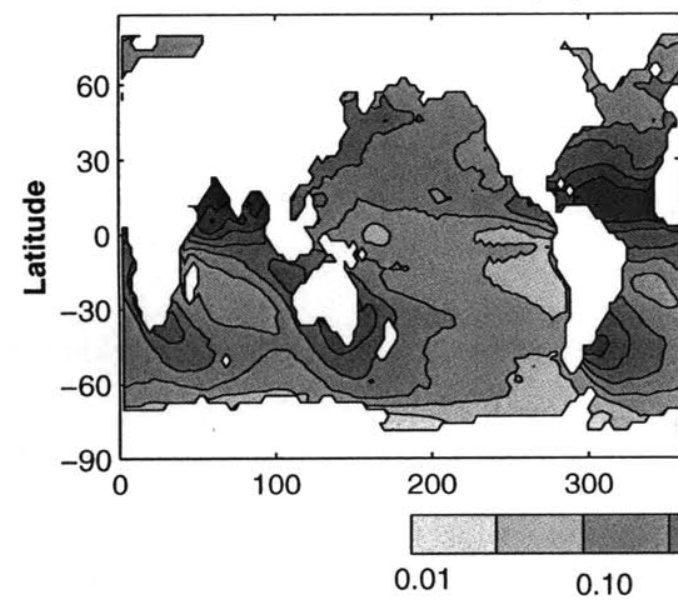

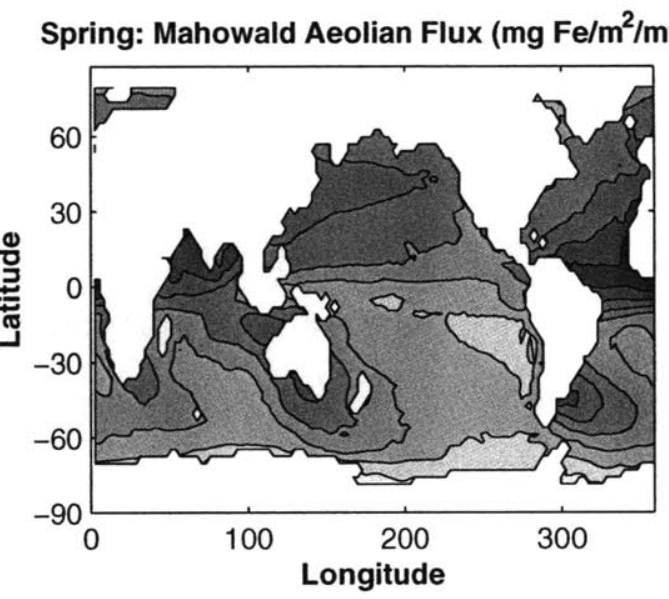

Fall: Mahowald Aeolian Flux (mg Fe/m $/ \mathrm{m}^{2} \mathrm{mth}$ )

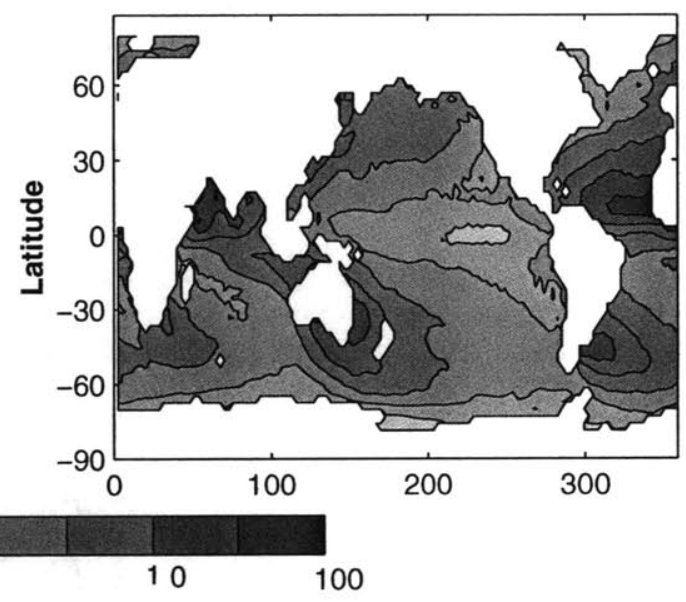

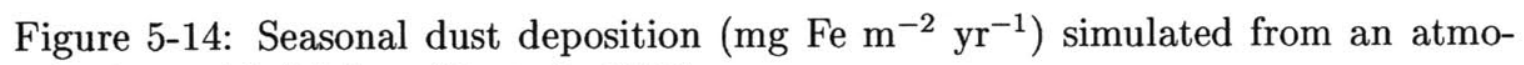
spheric model (Mahowald et al., 2003). 


\section{Results}

The Southern Ocean surface $\left[\mathrm{PO}_{4}\right]$ is lower (Figure 5-15) when the model is forced with the Mahowald et al. (2003) fields, attributable to the higher aeolian flux in the Southern Hemisphere, relative to the Gao et al. (2001) forcing.

At the surface, the Mahowald simulation is able to drawdown $\mathrm{Fe}_{T}$ throughout the Pacific basin and the Southern Ocean (Figure 5-16). The magnitude and extent of excess $\mathrm{Fe}_{T}$ are higher for the Mahowald simulation in the North Atlantic and the Indian Ocean, while the band of elevated surface $\left[\mathrm{Fe}_{T}\right]$ in the North Pacific produced by the Gao simulation is not present in the Mahowald results. Therefore, the $\left[\mathrm{PO}_{4}\right]$ is also higher in the surface North Pacific of the Mahowald simulation.

At $1000 \mathrm{~m}$, both simulations predict a decreasing $\left[\mathrm{Fe}_{T}\right]$ gradient from the North Pacific to the central Pacific, in broad agreement with the observations. The North Pacific $\left[\mathrm{Fe}_{T}\right]$ is higher in the Gao simulation because there is a stronger aeolian input coming from Asia than in the Mahowald simulation.

At 2500 meters, the solution to both simulations looks remarkably similar. Elevated $\mathrm{Fe}_{T}$ transported by the North Atlantic Deep Water is carried further in the Mahowald simulation, likely due to the higher aeolian input into this region in the Mahowald forcing field. Significantly, the variations in the two aeolian flux fields are not large enough to affect the model solution in the deep water $\left[\mathrm{Fe}_{T}\right]$. While qualitatively, the two model results are similar for the surface $\left[\mathrm{PO}_{4}\right]$ and $\left[\mathrm{Fe}_{T}\right]$ distributions, the magnitudes differ considerably. The Gao simulation predicts higher surface $\left[\mathrm{PO}_{4}\right]$ in the Southern Ocean, in better agreement with observations (although still lower than observations) than the Mahowald simulation. The Mahowald simulation results for surface $\left[\mathrm{PO}_{4}\right]$ in the equatorial and subtropical Pacific are closer to observations. The $\mathrm{PO}_{4}$ distribution resulting from Mahowald simulation in the Southern Hemisphere reflects the observed gradient between the subtropical and subpolar waters. The simulation is not able to differentiate these water masses by their $\left[\mathrm{PO}_{4}\right]$. Both simulations overestimate excess surface iron concentrations in the North Atlantic and 

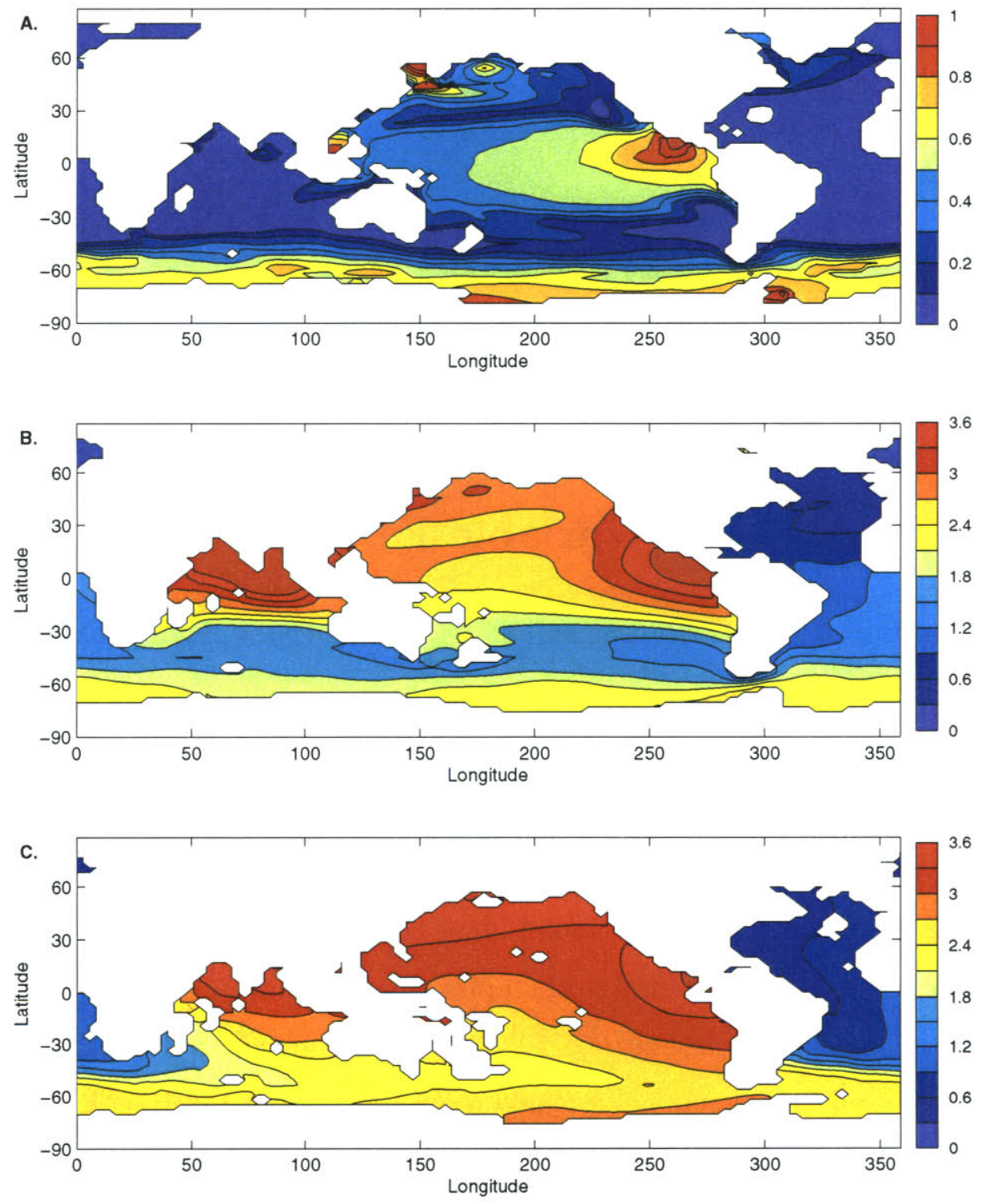

Figure 5-15: Modeled $\left[\mathrm{PO}_{4}\right](\mu \mathrm{M})$ using the dust forcing from Mahowald et al. (2003) at (A) surface, (B) $935 \mathrm{~m}$ and (C) $2495 \mathrm{~m}$. 
Indian Ocean, very likely reflecting the absence of processes that control $\left[\mathrm{Fe}_{T}\right]$ in surface waters.

It is important not to interpret either forcing field as better than the other. I could have tuned the solubility parameter $(\alpha)$ to improve the model output, but chose not to in order to understand the sensitivity of $\left[\mathrm{Fe}_{T}\right]$ to temporal and spatial differences in aeolian input. For example, decreasing $\alpha$, the solubility parameter, would improve the Southern Ocean surface $\left[\mathrm{PO}_{4}\right]$ in the Mahowald case, but it would also increase the surface $\mathrm{PO}_{4}$ throughout the surface waters of the model domain, making the model results look particularly unrealistic in the equatorial and subtropical Pacific waters.

\subsection{Sensitivity to Variable Fe:C Uptake Ratio}

In order to optimize growth, Hudson and Morel (1990) suggest phytoplankton growing in low Fe environments must increase their surface area:volume ratio or decrease their cellular iron requirement to optimize growth. Oceanic environments that are severely iron limited, such as the Southern Ocean, are dominated by small cells (Miller et al., 1991), supporting Hudson and Morel's (1990) conclusion with respect to cell size. Sunda and Huntsman (1995) found lower cellular iron requirements for oceanic phytoplankton compared to coastal phytoplankton, supporting Hudson and Morel's (1990) second conclusion. In Figure 5-17, I plot the results of Sunda and Huntsman's (1995) experiment for oceanic phytoplankton at ambient $\left[\mathrm{Fe}_{T}\right]<15 \mathrm{nM}$. The log-log plot shows a weak correlation of increasing $\mathrm{Fe}: \mathrm{C}$ with increasing $\left[\mathrm{Fe}_{T}\right]$. I fit a power law to the data:

$$
R=R_{0}[F e]^{n}
$$

where $\log \left(R_{0}\right)$ (the Y-intercept) equals 1.18 and $n$, the slope equals 0.44 . It is important to note that the lowest ambient $\left[\mathrm{Fe}_{T}\right]$ in Sunda and Huntsman's (1995) exper- 

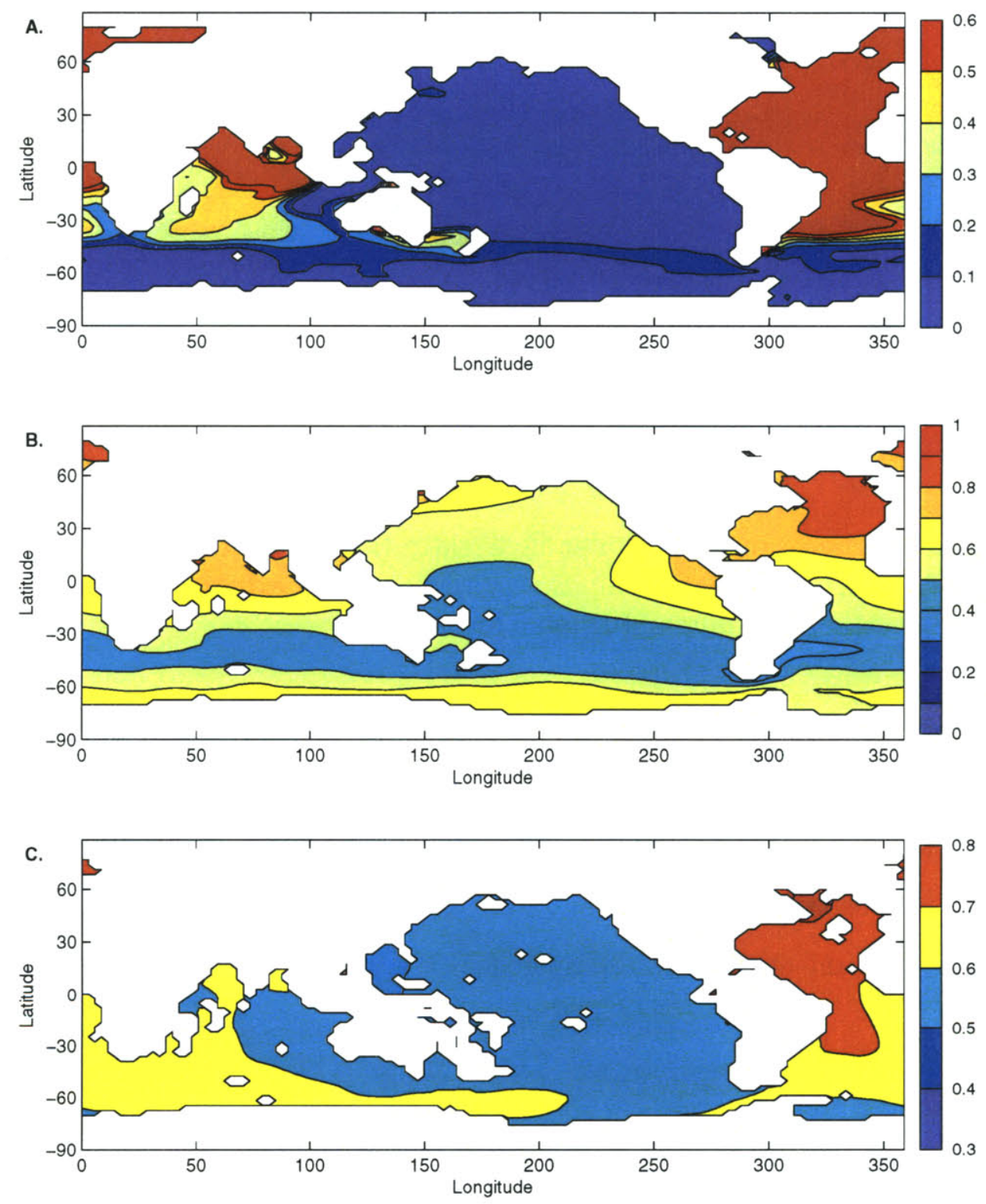

Figure 5-16: Modeled [ $\left.\mathrm{Fe}_{T}\right](\mathrm{nM})$ using the dust forcing from Mahowald et al. (2003) at (A) surface, (B) $935 \mathrm{~m}$ and (C) $2495 \mathrm{~m}$. 


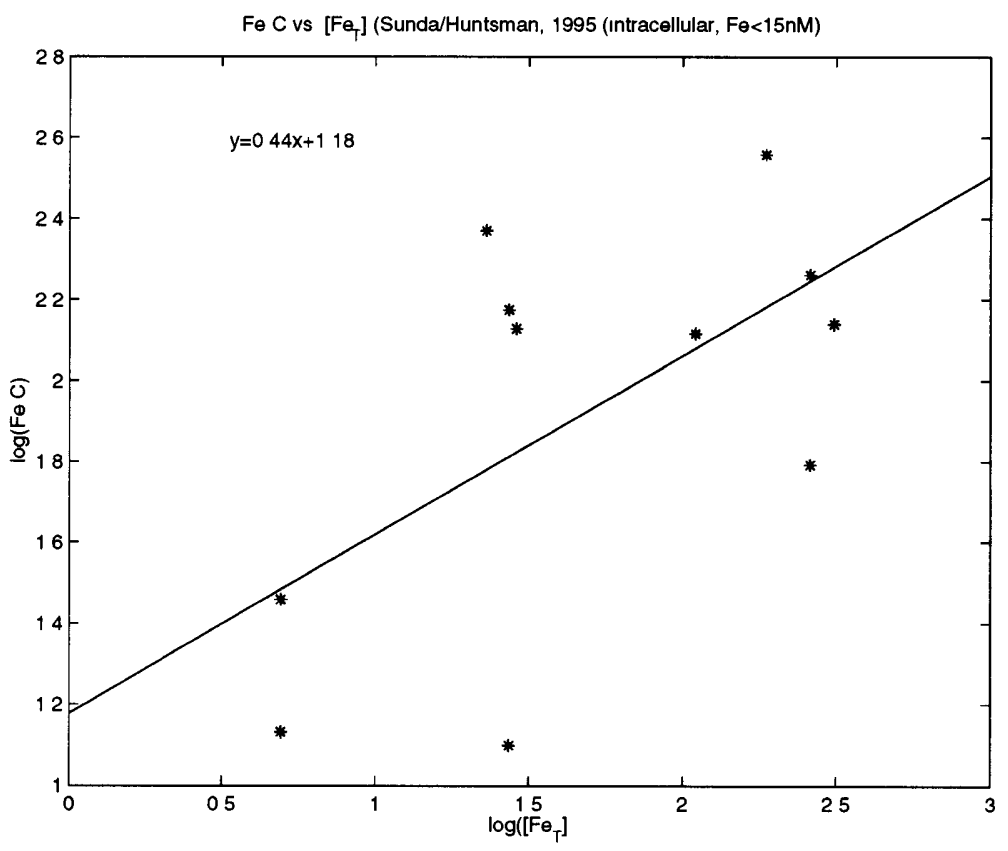

Figure 5-17: Variance in intracellular Fe:C ratio $\left(\log (\mathrm{Fe}: \mathrm{C})^{*} 10^{-6}\right)$ as a function of ambient $\left[\mathrm{Fe}_{T}\right](\mathrm{nM})$. The relationship is very weak and the experiment was conducted at high ambient $\left[\mathrm{Fe}_{T}\right]$ (Sunda and Huntsman, 1995).

iments were $2 \mathrm{nM}$. In the open ocean, rarely have $\left[\mathrm{Fe}_{T}\right]$ above $1 \mathrm{nM}$ been observed. Nevertheless, I impose this relationship in my model, allowing Fe:C ratio to vary based on the ambient $\left[\mathrm{Fe}_{T}\right]$. I assume phytoplankton reach a point where it is not possible to increase the Fe:C efficiency (arbitrarily set to $1^{*} 10^{-6} \mathrm{~mol} \mathrm{Fe}: \mathrm{mol} \mathrm{C}$ ). The $\mathrm{P}: \mathrm{C}$ ratio is constant $(117: 1)$. In the reference case, the $\mathrm{Fe}: \mathrm{C}$ ratio is $4^{*} 10^{-6} \mathrm{~mol} \mathrm{Fe}: 1$ mol C.

\section{Results}

In Figure 5-18, I plot the $\left[\mathrm{PO}_{4}\right]$ at the surface, $935 \mathrm{~m}$, and $2495 \mathrm{~m}$. By allowing the $\mathrm{Fe}: \mathrm{C}$ to decrease with decreasing surface $\left[\mathrm{Fe}_{T}\right]$ in accordance with Sunda and Huntsman's (1995) data, the Pacific switches from Fe limitation to $\mathrm{PO}_{4}$ limitation. While the model is still Fe limited in the Southern Ocean and the equatorial Pacific, the excess $\left[\mathrm{PO}_{4}\right]$ is much lower than observed. Due to higher export production, 
modeled $\left[\mathrm{PO}_{4}\right]$ is higher than observed at depth in the old Pacific waters.

Using a variable $\mathrm{Fe}: \mathrm{C}$ ratio has only a small effect on the Fe distribution (Figure 5-19). $\left[\mathrm{Fe}_{T}\right]$ is lower in the North Atlantic, but elevated for the rest of the surface ocean. In my reference case, I use an Fe:C ratio of $4^{*} 10^{-6}: 1$. Using the power law derived from Sunda and Huntsman's (1995) work, the Fe:C ratio is $4^{*} 10^{-6}$ only when $\left[\mathrm{Fe}_{T}\right]$ exceeds $2 \mathrm{nM}$. Modeled surface $\left[\mathrm{Fe}_{T}\right]$ only reaches such concentrations in the North Atlantic surface waters and the Indian Ocean. Thus, in the N. Atlantic and the Indian Ocean, the Fe:C ratio is higher in the variable Fe:C simulation relative to the constant Fe:C case. For the other areas of the ocean, the reverse is true. At depth, the structure is essentially unchanged, but the $\left[\mathrm{Fe}_{T}\right]$ is slightly lower at depth. This may be attributed to less $\mathrm{Fe}_{T}$ being biologically utilized at the surface and then subsequently exported at depth.

Simply using a variable Fe:C ratio in the model did not improve the model results. However, other free parameters could be tuned in concert. Simultaneously decreasing the solubility of the aeolian iron entering the ocean may have improved the model's response. Leaching studies of $\mathrm{Fe}$ from dust do suggest that less than 1\% (the solubility of dust in my model) of the Fe may be soluble (Jickells and Spokes, 2001; Spokes and Jickells, 1996 ). Different size class species may have different Fe:C ratios. Rather than parameterizing export production simply, an ecosystem model that accounts for the different requirements of various sized phytoplankton may be able to better predict surface $\left[\mathrm{Fe}_{T}\right]$ and $\left[\mathrm{PO}_{4}\right]$. While experimental evidence does suggest $\mathrm{Fe}: \mathrm{C}$ ratios are dependent on ambient surface water $\left[\mathrm{Fe}_{T}\right]$ (Sunda and Huntsman, 1995), the nature of this relationship is not clear.

\subsection{Chapter Summary}

I examine more closely the complexation case by comparing my model results to observed profiles and surface transects to assess the ability of the model to reproduce 

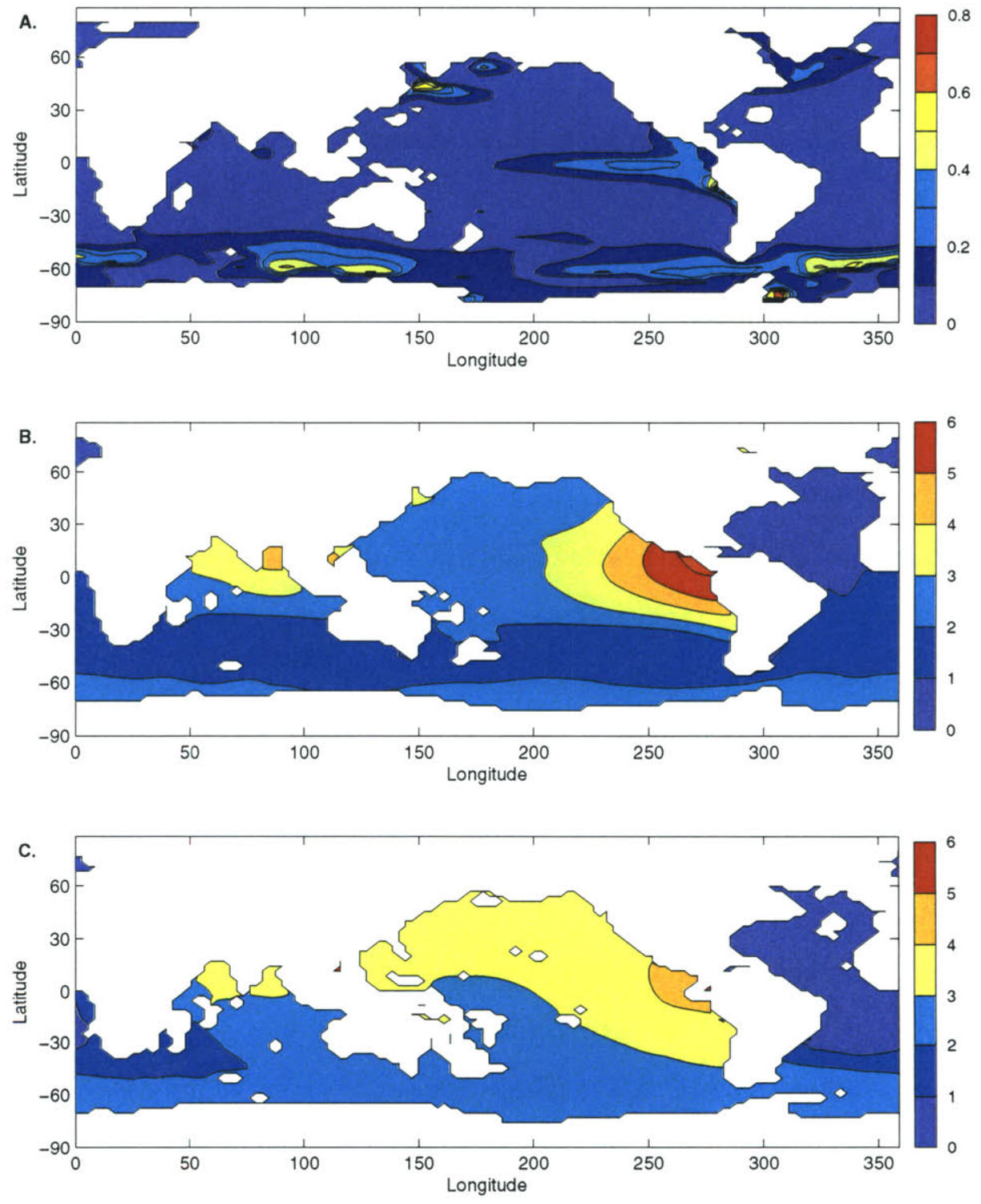

Figure 5-18: Modeled $\left[\mathrm{PO}_{4}\right](\mu \mathrm{M})$ using a variable Fe:P ratio based on the data from Sunda and Huntsman (1995) at (A) surface, (B) $935 \mathrm{~m}$ and (C) $2495 \mathrm{~m}$. 

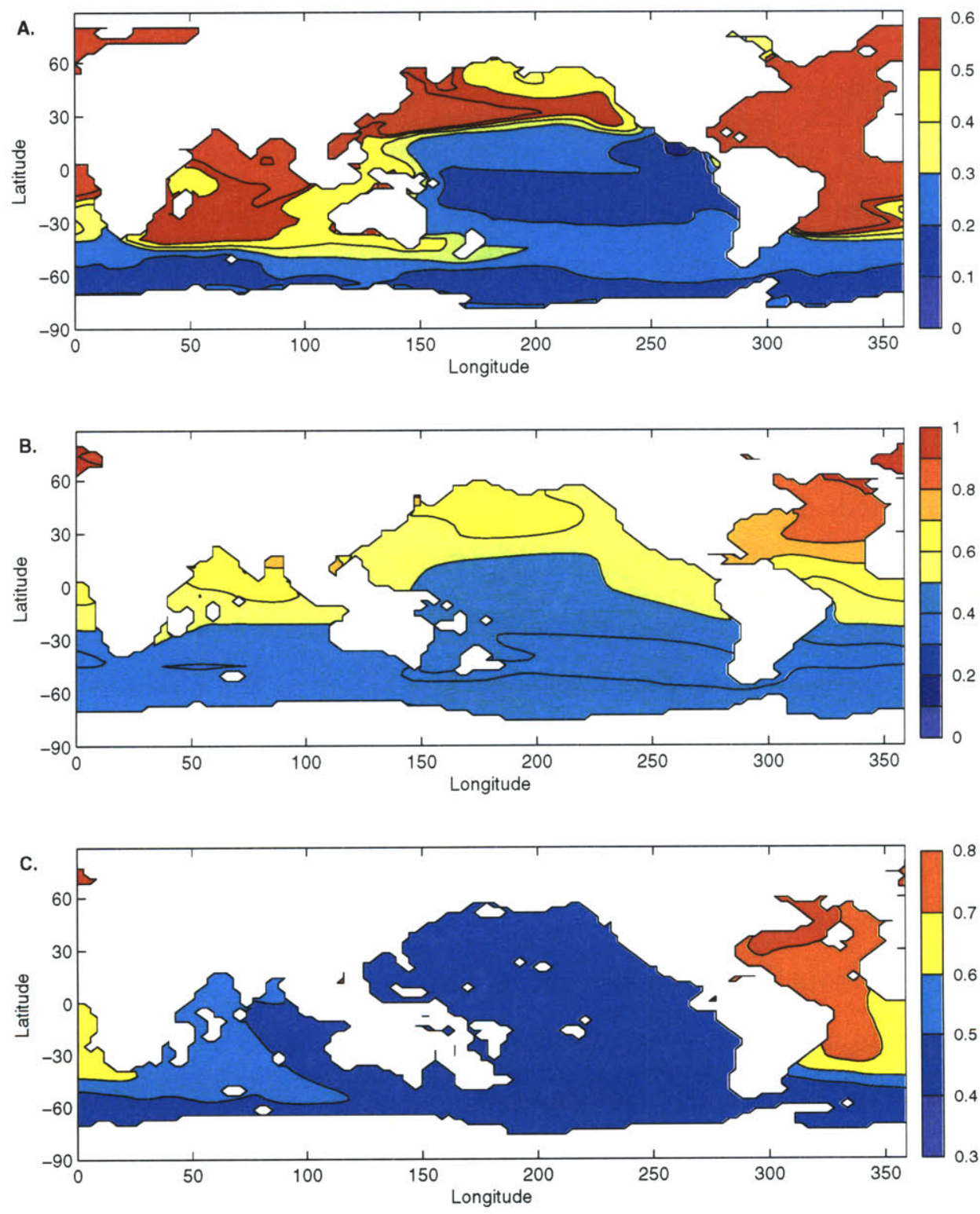

Figure 5-19: Modeled $\left[\mathrm{Fe}_{T}\right](\mathrm{nM})$ using a variable Fe:P ratio based on the data from Sunda and Huntsman (1995) at (A) surface, (B) $935 \mathrm{~m}$ and (C) $2495 \mathrm{~m}$. 
vertical gradients and seasonal variability. Below $300 \mathrm{~m}$, the model can successfully predict $\left[\mathrm{Fe}_{T}\right]$. At the surface, the model predicts seasonal variability in $\left[\mathrm{Fe}_{T}\right]$. It overestimates surface $\left[\mathrm{Fe}_{T}\right]$ in high aeolian flux regions such as the North Atlantic. This could be attributed to the absence of processes such as aggregation and subsequent sinking or precipitation that may serve as sinks for iron. The model also predicts iron limitation for the subtropical Pacific, not consistent with observations. The model may be underestimating the dust flux to this region, misrepresenting the dynamics of the region due to the coarse resolution of the grid, or trapping nutrients beneath the mixed layer as discussed in Section 4.4.1.

I define a tracer, $\mathrm{Fe}^{*}$ that quantifies the degree to which a water mass is iron limited. At all depths, the North Atlantic has a positive $\mathrm{Fe}^{*}$ value, indicating it is never iron limited. The excess iron at the surface due to aeolian transport is carried southward at depth by North Atlantic Deep Water. Except for surface waters between $25^{\circ} \mathrm{N}$ and $40^{\circ} \mathrm{N}, \mathrm{Fe}^{*}$ is negative throughout the Indo-Pacific basin. The positive $\mathrm{Fe}^{*}$ at the surface in the North Pacific can be attributed to the elevated aeolian flux coming from Asia. The deep North Pacific has the most negative Fe* values, reflecting the stripping out of Fe from these old waters. Southern Ocean waters are negative everywhere, reflecting the low aeolian input in the surface waters, and the dominance of scavenging over transport at depth.

Lastly, I calculate the residence time and estimate the contribution of $\mathrm{Fe}_{T}$ to the surface waters from upwelling and aeolian input. I estimate the residence time of $\mathrm{Fe}$ to be $\sim 285$ years, confirming that transport plays an important role in controlling deep water $\left[\mathrm{Fe}_{T}\right]$. Globally, upwelling accounts for $40 \%$ of 'new' iron reaching the euphotic zone. 


\section{Chapter 6}

\section{GCM simulation: Southern Ocean}

\section{Phosphate Sensitivity to Increased}

\section{Aeolian Dust Flux}

I force my complexation iron parameterization with estimated global dust fluxes from the Last Glacial Maximum (LGM) (Mahowald et al., 1999) to study the response of Southern Ocean surface $\left[\mathrm{PO}_{4}\right]$. In Chapter 3, I carried out the same simulation using the multi-box model. I repeat this simulation in the more sophisticated physical description of the general circulation model to investigate the intrabasinal response of $\mathrm{PO}_{4}$ in the Southern Ocean. Due to varying wind stresses and fluxes of salt and heat to the ocean, as well as extent of ice cover in the Southern Ocean, it is likely that the strength of upwelling and thermohaline circulation differed considerably during the LGM. I do not consider such changes here, but hope to explore the sensitivity of Southern Ocean surface $\mathrm{PO}_{4}$ drawdown to circulation changes in the future. The box model results provide me with an integrated answer and are not able to resolve variations spatially. In this chapter I present the results from the GCM simulation. I also discuss the importance of upwelling relative to aeolian flux as a source of new $\mathrm{Fe}_{T}$ to the euphotic zone and the distribution of $\mathrm{Fe}^{*}$. 


\subsection{Aeolian Forcing Field}

Mahowald et al. (1999) used linked terrestrial biosphere, dust source and atmospheric transport models to simulate the dust cycle in the atmosphere for the Last Glacial Maximum. Figure 6-1A shows the Fe forcing field used in the increased dust flux scenario (referred to as 'paleo' simulation) and compare it to the forcing field used for the 'modern' simulations (Figure 6-1B) . As in the 'modern' simulation, I assume $1 \%$ of aeolian $\mathrm{Fe}$ is soluble and 3.5 weight percent of aeolian dust is Fe. The model is forced seasonally. In comparison to the modern aeolian iron forcing field, the ocean global input is nine times higher for the 'paleo' simulation and 63 times higher in the Southern Ocean (Fig 6-1C). The increase in dust flux is within the range of increase that ice cores and sediments suggest (Petit et al., 1999; Rea, 1994), but at the high end of estimates. In the Northern Hemisphere, largest increases are (Figure 6-1C) in the North Pacific and North Atlantic. In the Southern Hemisphere, the dust flux is much stronger off of the eastern coasts of Australia and South America.

\subsection{Global Distributions}

In this section, I present surface $\mathrm{PO}_{4}$ and deepwater $\mathrm{Fe}_{T}$ distributions forcing the model with the 'paleo' dust fluxes and compare them to the solution using 'modern' dust fluxes. As in the increased dust flux simulation using the box model, the $\left[\mathrm{L}_{T}\right]$ is constant and set to $1 \mathrm{nM}$.

\subsubsection{Phosphate}

Surface phosphate drawdown is complete over large regions of the ocean, yet in the high nutrient, low chlorophyll regions of the ocean, there are pockets of excess $\left[\mathrm{PO}_{4}\right](\mathrm{Fig} 6-2 \mathrm{~A})$. Intermediate and deep water $\left[\mathrm{PO}_{4}\right]$ (Figure 6-2B,C) are higher than the model predicted for the 'modern' simulation, due to the export of $\mathrm{PO}_{4}$ biologically 

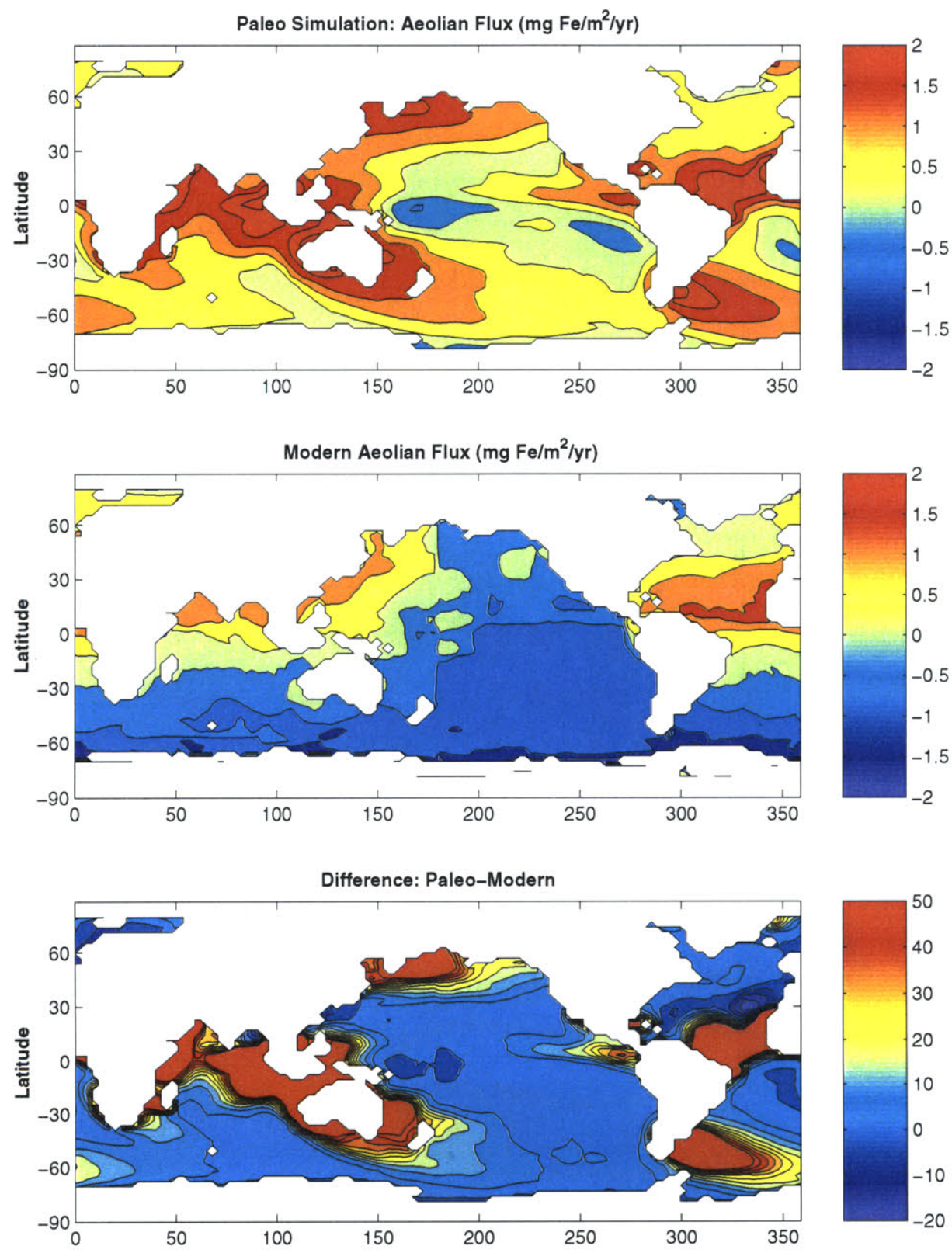

Figure 6-1: A) Aeolian Flux forcing for the increased dust flux simulation (Mahowald et al., 1999). B) The dust forcing used for the 'modern' simulations presented in Chapters 4 and 5 (log scale). C) The difference between between the 'paleo' and 'modern' forcing fields (absolute scale). 
utilized at the surface. This results in the redistribution of surface $\mathrm{PO}_{4}$ at depth.

\subsubsection{Iron}

Iron is completely drawn down only in the equatorial Pacific and the Southern Ocean (Figure 6-3A), two areas that are Fe limited today. Surface $\left[\mathrm{Fe}_{T}\right]$ is above $5 \mathrm{nM}$ in certain areas of the Indian Ocean and North Atlantic. Unless $\left[\mathrm{L}_{T}\right]$ increases as a function of ambient $\left[\mathrm{Fe}_{T}\right]$, the surface $\left[\mathrm{Fe}_{T}\right]$ exceeds solubility limits (Liu and Millero, 2002). As discussed in Chapter 4, processes that may be occurring which lower surface $\left[\mathrm{Fe}_{T}\right]$ are not included in the model.

At intermediate depth (Figure 6-3B), the deepwater $\left[\mathrm{Fe}_{T}\right]$ increases in all basins. The imposed $\left[\mathrm{L}_{T}\right]$ places an upper limit on deep water $\left[\mathrm{Fe}_{T}\right]$. Only in the North Atlantic, where dust input is highest does $\left[\mathrm{Fe}_{T}\right]$ reach $1 \mathrm{nM}$. In the North Pacific at 935 meters, $\left[\mathrm{Fe}_{T}\right]$ increases by $0.2 \mathrm{nM}$, while in the Southern Ocean, increases as high as $0.4 \mathrm{nM}$ are observed. North Atlantic Deep Water transports Fe into the Atlantic and Indian sectors of the Southern Ocean (Figure 6-3C). In the North Pacific, $\left[\mathrm{Fe}_{T}\right]$ only increases by $\sim 0.05 \mathrm{nM}$ relative to the 'modern' simulation. Since the deep waters of the North Pacific are the oldest, it has been subjected to scavenging longer than any other water mass.

\subsection{Southern Ocean Results}

Due to the Southern Ocean's potential ability to absorb $\mathrm{pCO}_{2}$, I examine more closely the effect of increased dust flux on surface Southern Ocean $\left[\mathrm{PO}_{4}\right]$. Specifically, I analyze the change in $\mathrm{Fe}^{*}$ and calculate the importance of upwelling relative to aeolian flux as a source of 'new' Fe to the euphotic zone. 

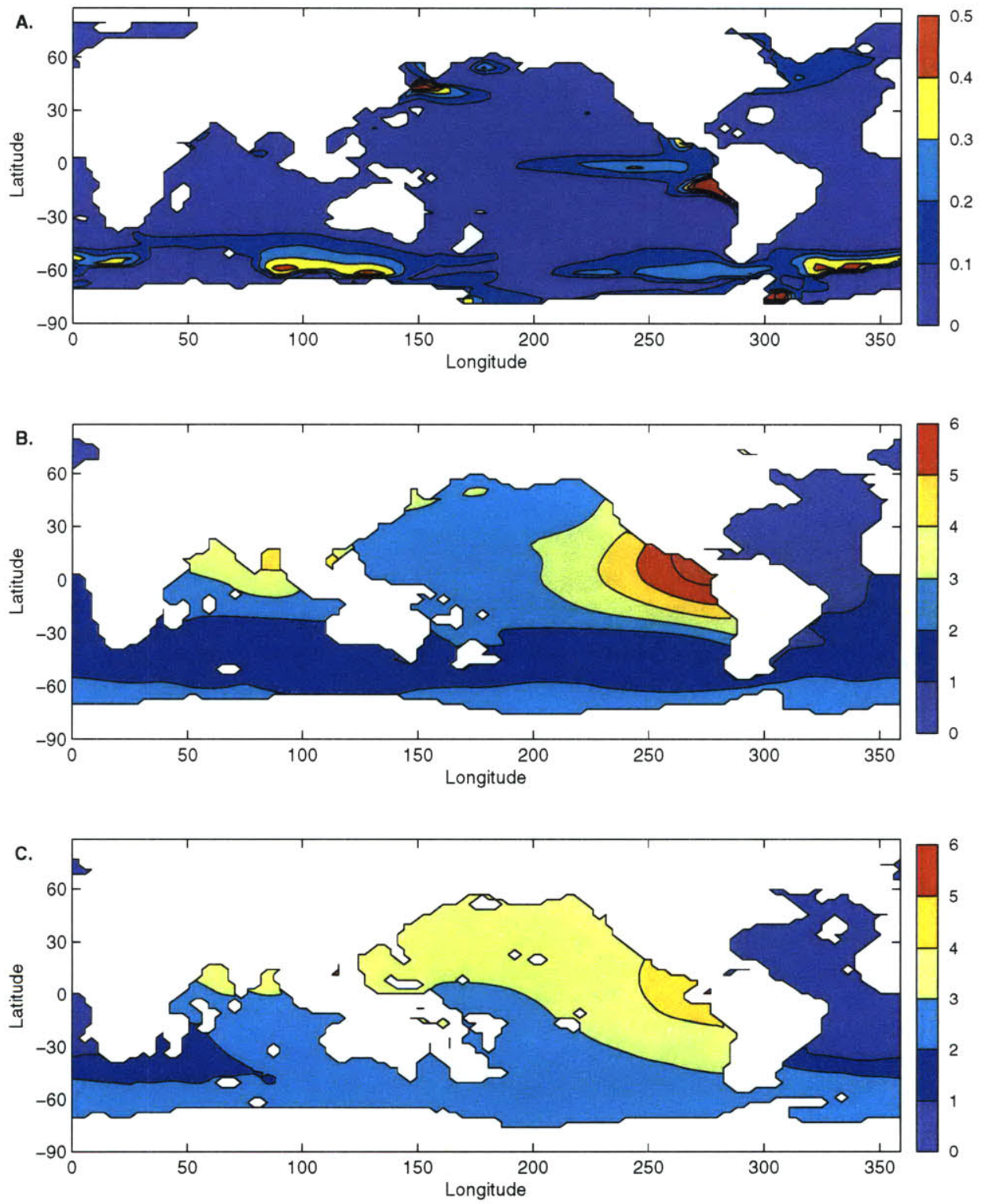

Figure 6-2: Modeled $\left[\mathrm{PO}_{4}\right]$ for the 'paleo' case at A) surface, B) $935 \mathrm{~m}$ and C) $2495 \mathrm{~m}$. 

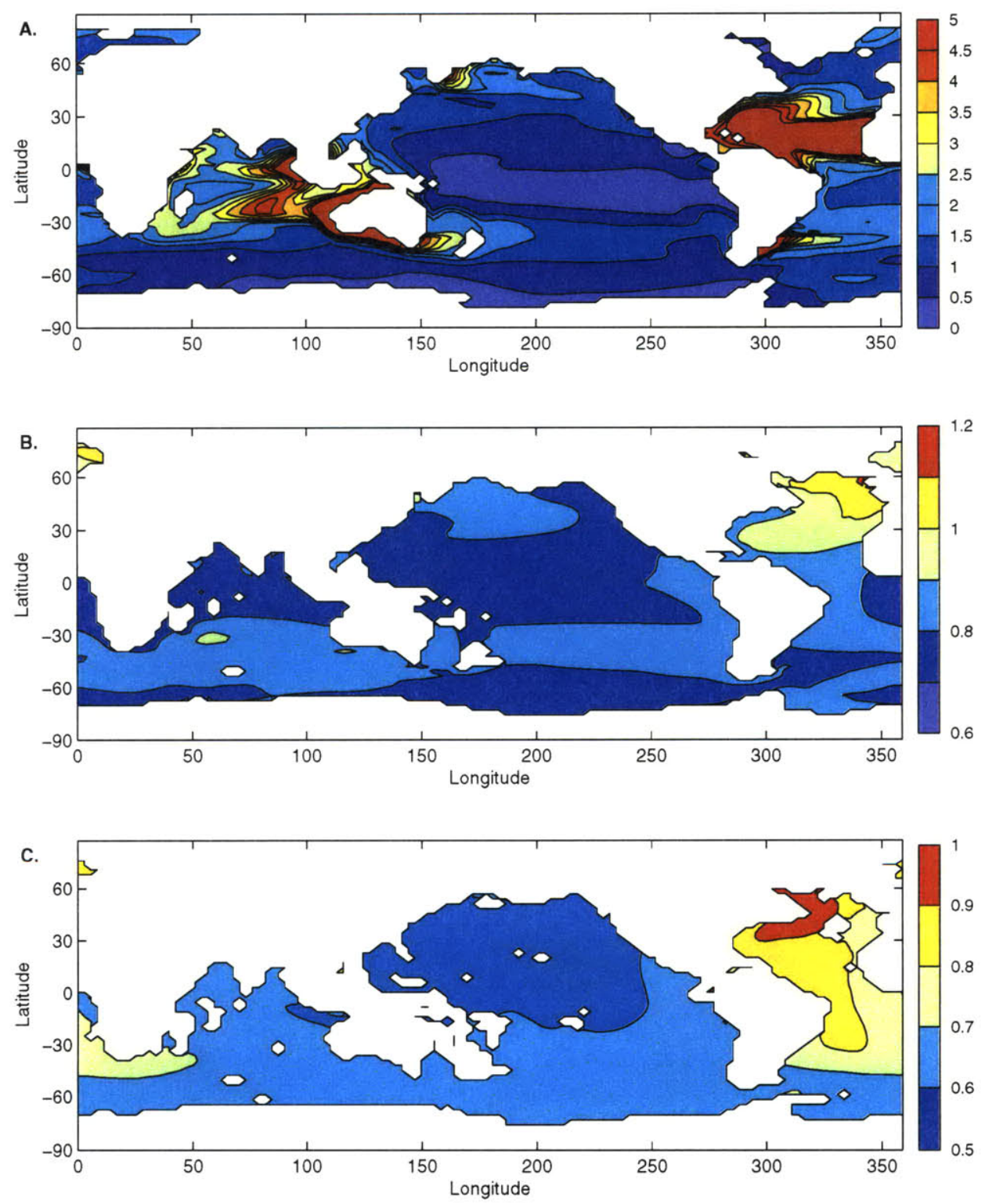

Figure 6-3: Modeled [ $\mathrm{Fe}_{T}$ ] for the 'paleo' case at A) surface, B) $935 \mathrm{~m}$ and C) $2495 \mathrm{~m}$. 


\subsubsection{Comparison of 'modern' and 'paleo' surface phosphate distribution}

The average Southern Ocean surface $\left[\mathrm{PO}_{4}\right]$ decreases from $\sim 0.6 \mu \mathrm{M}$ during the 'modern' simulation to $\sim 0.1 \mu \mathrm{M}$ for the 'paleo' simulation (Figure 6-4A, B). The box model results predicted a $\Delta \mathrm{PO}_{4}$ of $\sim 0.25 \mu \mathrm{M}$ (Figure 3-2C) with a 10 fold increase in global dust supply. In the box model simulation, dust flux was increased 10 fold in each basin, whereas in the GCM-paleo simulation, the increase in dust flux to the Southern Ocean is 63 times larger, while in the central Pacific dust flux only increased $\sim 3$ times. Additionally the physics in the box model are very idealized. Due to these differences, the box model and GCM results are not inconsistent.

Although $\mathrm{PO}_{4}$ is completely drawn down in portions of the Southern Ocean for the 'paleo' simulation, it is important to note in the 'modern' simulation that model surface $\left[\mathrm{PO}_{4}\right]$ is lower than observed. The observed average $\left[\mathrm{PO}_{4}\right]$ in the surface Southern Ocean is $\sim 2 \mu \mathrm{M}$, but the model only predicts an excess $\left[\mathrm{PO}_{4}\right]=0.6 \mu \mathrm{M}$. Thus, the results should not be interpreted in terms of the absolute $\left[\mathrm{PO}_{4}\right]$ for the paleo simulation, rather according to the $\Delta \mathrm{PO}_{4}$. Archer and Johnson (2000) use the Mahowald et al. (1999) 'paleo' dust forcing and find that surface $\mathrm{PO}_{4}$ only decreases $10^{12}$ moles in the surface, while my model predicts a $\sim 2.5$ times greater decrease in total surface $\mathrm{PO}_{4}$. The discrepancy relates to the large uncertainty in dust fluxes. Compared to the Gao et al. (2001) 'modern' dust flux, the Mahowald 'paleo' fluxes are 8.75 times higher averaged globally, whereas compared to the Mahowald et al. (1999) 'modern' fluxes, the Mahowald 'paleo' fluxes are only 1.75 times higher. On the other hand, Archer and Johnson (2000) carried out another simulation in which atmospheric dust flux was increased uniformly over the ocean surface. A four fold increase in dust flux resulted in the surface inventory of $\mathrm{PO}_{4}$ decreasing by $\sim 3 \mu \mathrm{M}$ and a decrease in $\mathrm{pCO}_{2}$ on the order of $20-30 \mathrm{ppm}$, closer in agreement with my results. 

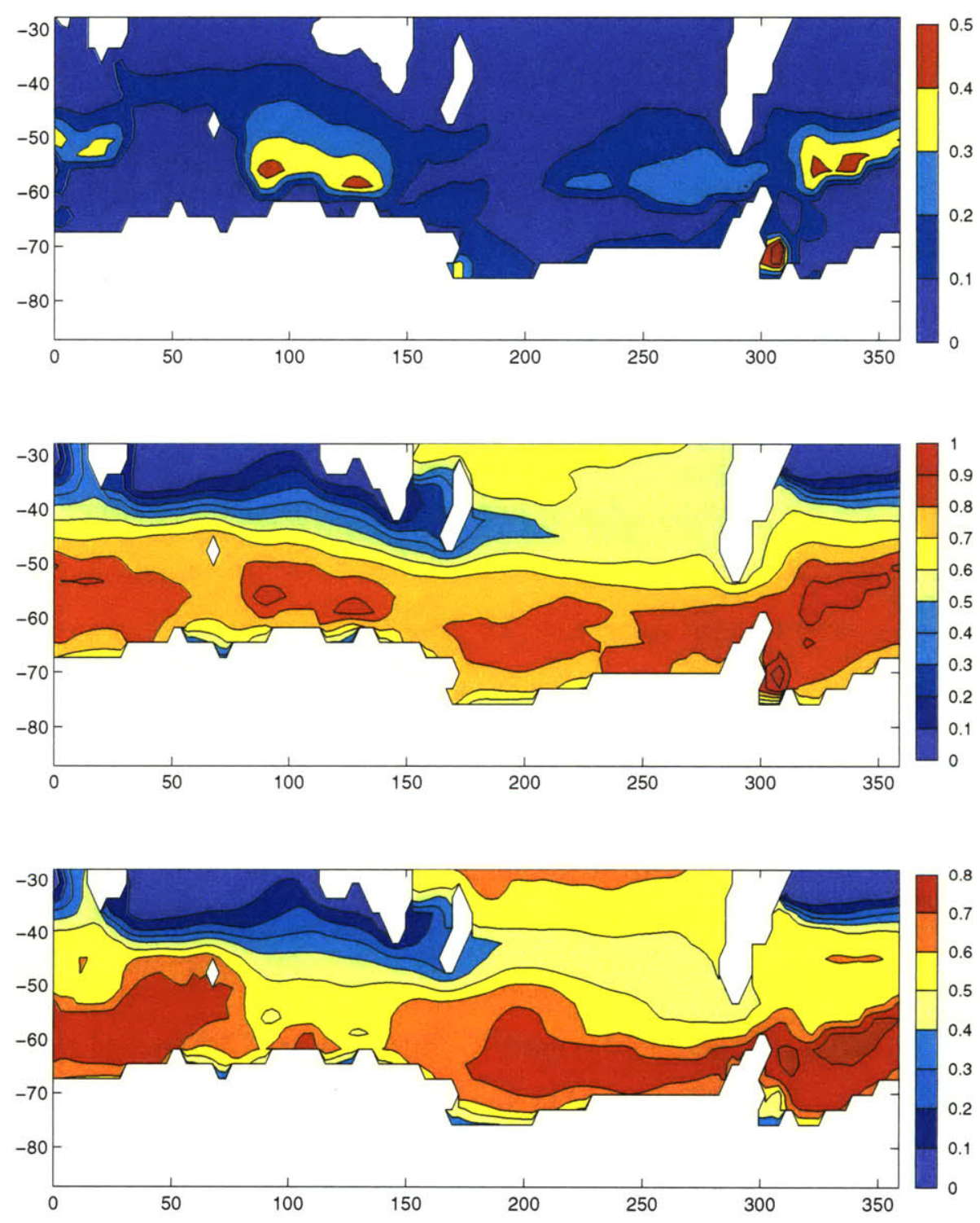

Figure 6-4: A comparison of $\left[\mathrm{PO}_{4}\right]$ in the Southern Ocean between the A) 'paleo' case and B) the 'modern' case. C) The difference in $\left[\mathrm{PO}_{4}\right]$ between the 'modern' and 'paleo' case. 


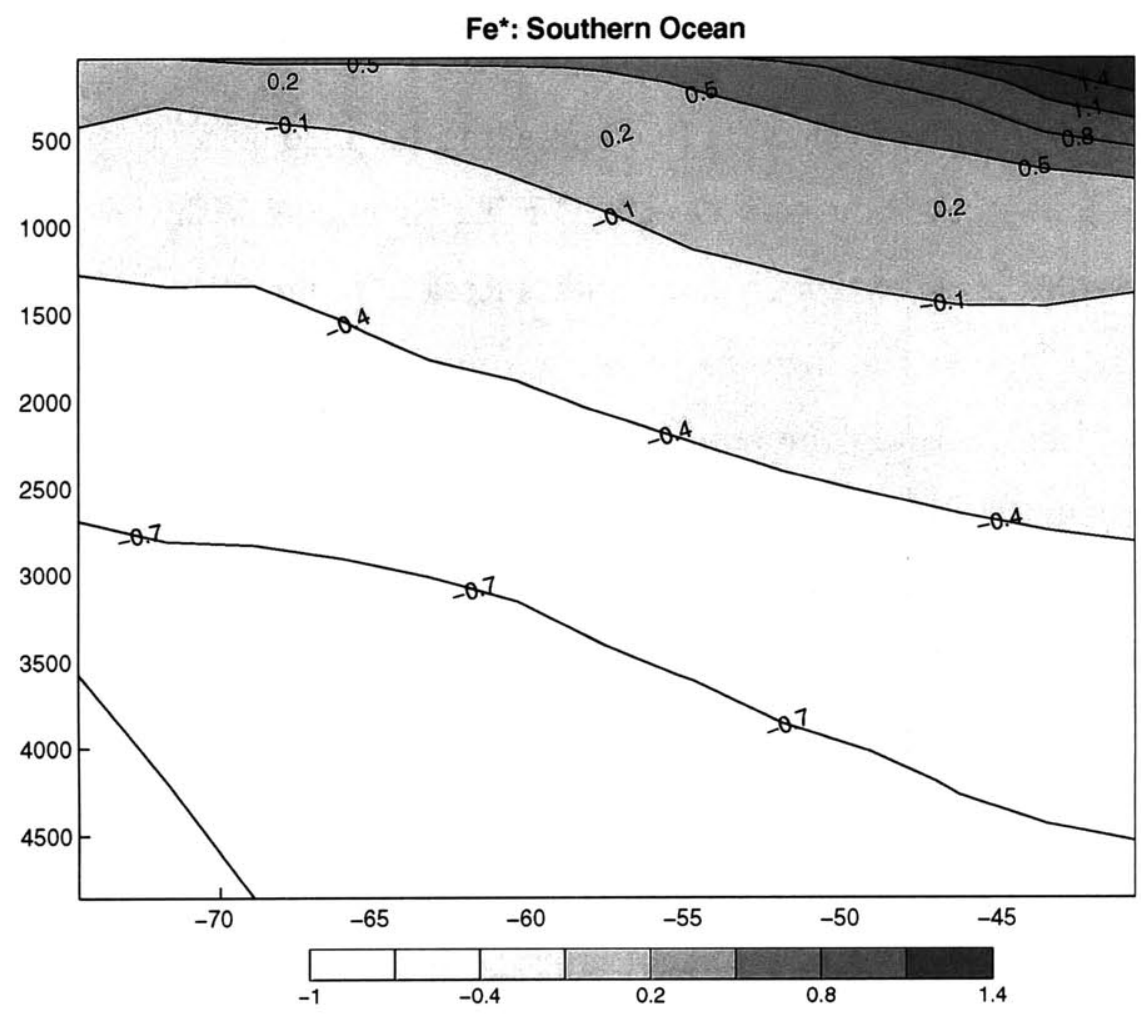

Figure 6-5: Zonally averaged Fe* in the Southern Ocean for the 'paleo' case.

\subsection{2 $\mathrm{Fe}^{*}$}

$\mathrm{Fe}^{*}$ changes considerably when the global dust flux is increased. In Figure 6-5, I plot the zonally averaged calculated $\mathrm{Fe}^{*}$ for the Southern Ocean. In the present day, $\mathrm{Fe}^{*}$ is negative throughout the Southern Ocean (Figure 5-3). Forcing the model with LGM aeolian flux forcing fields results in a positive $\mathrm{Fe}^{*}$ in the Southern Ocean surface waters, attributed to the increased aeolian input, as well as the upwelling of high $\mathrm{Fe}^{*}$ North Atlantic Deep Waters to form Antarctic Intermediate Waters. Although Fe* is positive everywhere in the surface, $\mathrm{PO}_{4}$ is not completely drawn down. This implies that light is also limiting productivity. Negative $\mathrm{Fe}^{*}$ values are found only in the Antarctic Bottom Waters. This shift from negative $\mathrm{Fe}^{*}$ waters to positive $\mathrm{Fe}^{*}$ waters throughout the Southern Ocean suggests that the balance between scavenging and transport has shifted in favor of transport. 


\subsubsection{Local Source of Iron to the Southern Ocean}

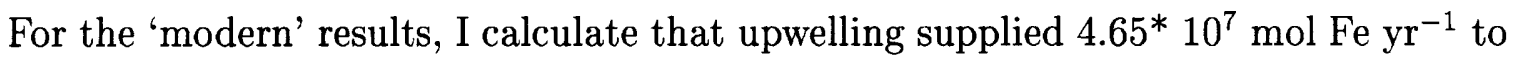
the euphotic zone in the Southern Ocean. Forcing the model with the 'paleo' aeolian iron fields results in an order of magnitude increase of upwelled iron reaching the euphotic zone. Due to the increase in aeolian flux though, upwelling only supplies $22 \%$ of 'new' iron reaching the euphotic zone, whereas in the 'modern' simulation, upwelling accounted for $47 \%$ of the iron reaching the euphotic zone. Evidence suggests (COHMAP Members, 1988) that during the LGM, the wind strength increased, which would result stronger patterns of upwelling and downwelling associated with Ekman processes, and hence communication between surface and deep waters. On the other hand, ice cover also increased, preventing waters from upwelling to the surface. My results do not take either of these effects into account. Using a two-dimensional model of the Southern Ocean developed by Taka Ito, I plan to explore the effects of such changes on $\mathrm{PO}_{4}$ drawdown. Nevertheless, my results suggest that increased dust flux changes the balance between upwelling and aeolian flux as sources of 'new' iron to the euphotic zone.

\subsection{Comment}

There has been considerable focus on seeding the Southern Ocean (Lam and Chisholm, 2002 ) with iron to absorb anthropogenic $\mathrm{CO}_{2}$, yet preliminary results from this work and others (Archer and Johnson, 2000; Lefévre and Watson, 1999;Watson et al., 2000 ) suggest that increased efficiency of the biological pump due to iron loading might account for only $25-40 \mathrm{ppm}$ of the $80 \mathrm{ppm}$ drawdown of glacial-interglacial change. This would result in the sequestration of $\sim 100$ gigatons of carbon, equivalent to only 10-15 years of current anthropogenic $\mathrm{CO}_{2}$ emissions. 


\section{Chapter 7}

\section{Conclusions}

This study focused on understanding the controls of deep water iron distribution in order to assess the decoupling of iron and phosphorus in the ocean interior and implications for upwelling as a source of new 'iron' to the euphotic zone. In the beginning of the thesis, I present three candidate parameterizations of deep ocean iron cycling. All three parameterizations are able to reproduce the observed deep water iron gradients in the context of an idealized six box model. Using a 3-D ocean general circulation model, which has a more sophisticated representation of physics, identifies some differences. The model supports the notion that the binding of Fe to an organic ligand is able to counteract the loss of $\mathrm{Fe}$ due to scavenging, allowing $\left[\mathrm{Fe}_{T}\right]$ to exceed solubility limits (Liu and Millero, 2002) and broadly captures a number of significant observable details including deep water iron gradients, and excess ligand concentrations.

I define a tracer, $\mathrm{Fe}^{*}$ that indicates the degree to which a water mass is iron limited relative to $\mathrm{PO}_{4}$. Due to the high aeolian flux and sinking of North Atlantic Deep Water, the Atlantic basin has a positive $\mathrm{Fe}^{*}$ value at all depths, indicating it is never Fe limited. HNLC areas are also regions of upwelling, so deep water Fe is an important source to the euphotic zone. In the HNLC areas, $\mathrm{Fe}^{*}$ is negative below the euphotic zone, reflecting the dominance of scavenging over transport at depth 
which leads to the decoupling between $\mathrm{Fe}$ and $\mathrm{PO}_{4}$. At the surface in $\mathrm{HNLC}$ regions, the aeolian $\mathrm{Fe}$ flux is not large enough to compensate for the upwelled negative $\mathrm{Fe}^{*}$ waters.

I estimate that the global ocean residence time of iron is $\sim 285$ years. Such a long residence time confirms that transport plays an important role in controlling deep water $\left[\mathrm{Fe}_{T}\right]$ and explains why modeled deep water $\left[\mathrm{Fe}_{T}\right]$ in the Southern Ocean is higher than can be supported by the aeolian flux to the region.

There is much interest in assessing the importance of upwelling as a source of 'new' iron to the euphotic zone. Having developed a model that is broadly consistent with the limited observations of deep water Fe observations, I am able to estimate the contribution of iron by upwelling to the euphotic zone. I find that in the model $40 \%$ of 'new' iron is supplied to the surface waters by upwelling in good agreement with Fung et al. (2000), but low compared to Archer and Johnson (2000). This discrepancy may be explained by the higher than observed deep water $\left[\mathrm{Fe}_{T}\right]$ Archer and Johnson's (2000) model predicts for the Pacific basin and the Southern Ocean.

Due to the potential ability of iron to change the efficiency of the carbon pump in the remote Southern Ocean, I study the response of Southern Ocean surface $\mathrm{PO}_{4}$ to increased aeolian dust flux. My box model results suggest that a global ten fold increase in dust flux can support a $\mathrm{PO}_{4}$ drawdown of $\sim 0.25 \mu \mathrm{M}$, while the GCM results suggests a $\mathrm{PO}_{4}$ drawdown of $0.5 \mu \mathrm{M}$ in the Southern Ocean. Given the approximation and uncertainties in each model, this difference is perhaps not surprising. The resolution of vertical structure in the GCM may be a significant difference. The interpretation of these results with regards to $\mathrm{pCO}_{2}$ drawdown should be made with caution, due to uncertainties to parameters such as wind strength, extent of ice cover and the response of ligand production to increased aeolian iron input. 


\subsection{Next Steps}

\subsubsection{Research Recommendations from a Modeling Perspec- tive}

While the complexation-scavenging parameterization of iron is able to capture the observed deep water gradients, comparisons with surface iron observations show that the model does a poor job of predicting surface $\left[\mathrm{Fe}_{T}\right]$. These results suggest that colloidal chemistry and precipitation may be added to the model. Research efforts aimed at studying the formation characterization, and cycling of Fe colloids would be immensely helpful.

The aeolian flux of iron is poorly constrained. Global monitoring stations and developing the capability to place iron sensors on buoys in remote waters would aid in better quantifying the magnitude and periodicity of aeolian iron input. In addition, the chemistry of aeolian iron in clouds and its solubility in marine surface waters is poorly constrained. A better understanding of these processes would be useful for such models.

Sunda and Huntsman (1995) suggest that marine phytoplankton adjust their Fe requirements based on ambient iron concentrations. Since the exact nature of this relationship is not known, it is very difficult to parameterize this effect, as seen in the sensitivity study in Chapter 4. Culture work aimed at quantifying Fe:C uptake ratios as a function of ambient $\left[\mathrm{Fe}_{T}\right]$ that are within the range observed in the surface ocean would help in this regard.

The source(s), $\operatorname{sink}(\mathrm{s})$ and chemical characterization of Fe-binding ligands are not well known, resulting in the parameterization of ligand chemistry with an imposed, finite $\left[\mathrm{L}_{T}\right]$. Experimental work aimed at studying the ligand cycle would provide information to parameterize ligand chemistry in a more mechanistic manner than is presently done.

There is a pressing need for more iron measurements, especially in the deep wa- 


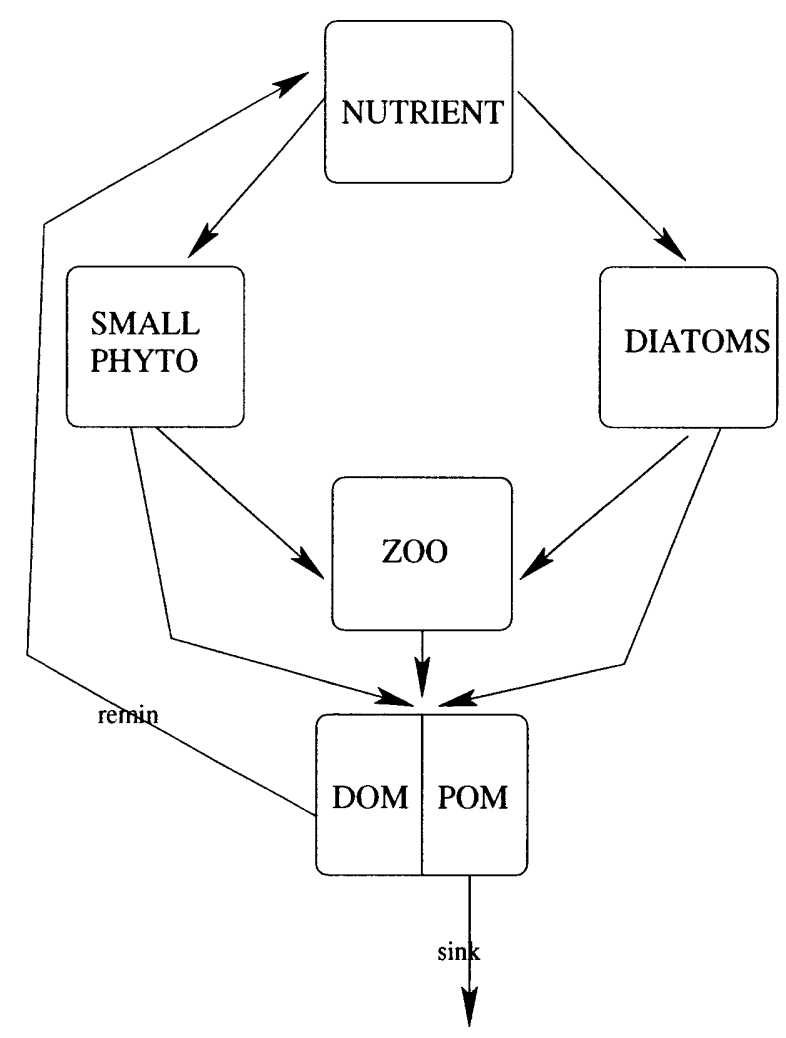

Figure 7-1: Schematic diagram of ecosystem model. Figure courtesy of S. Dutkiewicz.

ters. As shown in Chapter 1, there are only a handful of measurements at depths greater than $2500 \mathrm{~m}$, making it very difficult to constrain the model at depths. Based on model results, I suggest measurements are needed in the Southern Hemisphere, particularly in the Southern Ocean and the southern Indo-Pacific basin. My model results (Chapter 5) suggest that iron has a seasonal cycle at the surface. Time-series of surface measurements at both high and low flux regions would be useful in this regard.

\subsubsection{On-going Work}

The model does a poor job of predicting surface $\left[\mathrm{Fe}_{T}\right]$ in high dust flux regions such as the North Atlantic. I am working to improve the model's performance in such regions by including solubility limits of iron and processes in surface waters that may 
serve as a sink for iron in surface waters, such as colloid formation and aggregation of iron.

Replacing the simplified export parameterization with an explicit ecosystem model would distinguish the varying Fe requirements of different sized phytoplankton. In addition, recent work has shown that iron limitation increases Si:N uptake ratios (Hutchins and Bruland, 1998; Takeda, 1998). Accounting for such a response may improve the model's ability to predict modern surface $\left[\mathrm{PO}_{4}\right]$ and would have implications for an increased dust flux scenario. Currently, Stephanie Dutkiewicz, Mick Follows and I are coupling a simple ecosystem model with the iron model presented in this thesis. The ecosystem model consists of three nutrient pools: nitrogen, silica, and iron, as well as two phytoplankton size classes to account for the differing physiological requirements (Figure 7-1). The model successfully captures primary productivity (Figure 7-2). We plan to continue developing these models and perform sensitivity tests to explore implications of global change.

Given the importance of the Southern Ocean with regards to climate change, more work needs to be done in this area to better understand its role in absorbing $\mathrm{CO}_{2}$. As discussed in the preceding paragraphs, improving the surface macronutrient and iron concentrations during the modern will help in determining the Southern Ocean's role in past/future $\mathrm{CO}_{2}$ absorption. Furthermore, a better understanding of dynamics in this region is also necessary. Due to the importance of diatoms in the Southern Ocean, it is also important to couple iron and silica cycles. To better constrain the Southern Ocean results, I am working with Taka Ito, who has developed a dynamical model of the Southern Ocean, to study tracer transport. We are also coupling the ocean model to a simple atmospheric model to make projections regarding $\mathrm{pCO}_{2}$ drawdown. 

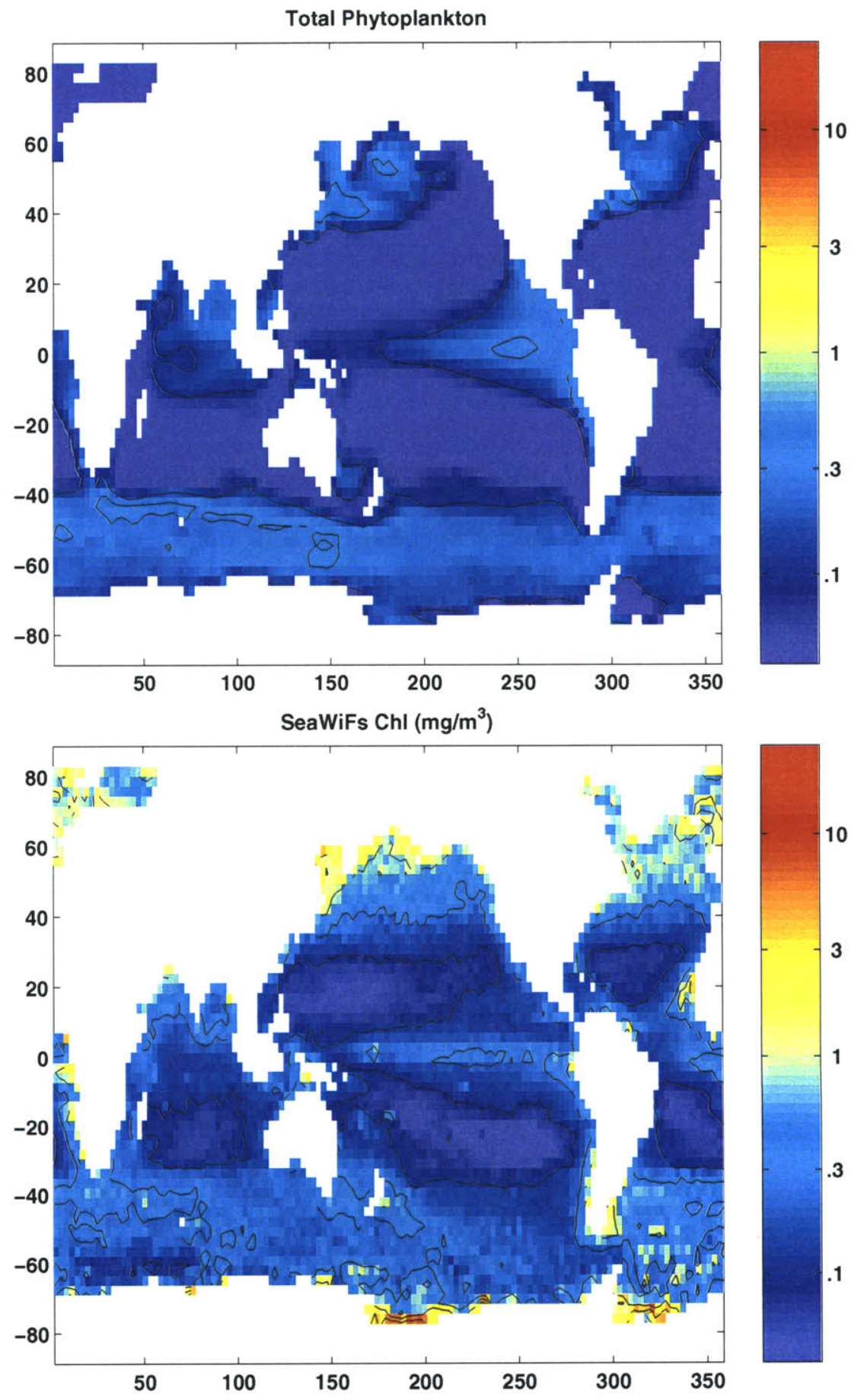

Figure 7-2: Comparison of modeled chlorophyll (top panel) with chlorophyll calculated from SeaWiFs. Figures courtesy of S. Dutkiewicz. 


\subsection{Final Comments}

The purpose of this thesis was to further the understanding of iron cycling, an element known to limit biological productivity in upwelling regions of the global ocean. The results of this thesis, in agreement with other models, suggests that a ten fold increase in global dust flux could drawdown as much as $0.5 \mu \mathrm{M} \mathrm{PO}_{4}$ in the Southern Ocean, approximately $1 / 3$ of the excess $\left[\mathrm{PO}_{4}\right]$, clearly not the only process affecting $\mathrm{pCO}_{2}$. Working on modeling the iron cycle has made it very clear to me that the ocean nutrient cycle is extremely complex and there are many open questions regarding our understanding of the system. Trying to tinker with the cycling of iron to mitigate increased $\mathrm{pCO}_{2}$ may lead to many unintended consequences. As Rachel Carson, the noted marine scientist and environmentalist stated, "the 'control of nature' is a phrase conceived in arrogance, born of the Neanderthal age of biology and the convenience of man." Rather, "the more clearly we can focus our attention on the wonders and realities of the universe about us, the less taste we shall have for destruction." 


\section{References}

Adcroft, A., C. Hill and J. Marshall, 1997: Representation of topography by shaved cells in a height coordinate ocean model, Mon. Wea. Rev., 125, 2293-2315.

Anderson, D., and F. Morel, 1978: Copper sensitivity of Gonyaulax tamarensis, Limnol. Oceangr., 23, 283-295.

Archer, D., G. Eshel, A. Winguth, W. Broecker, R. Pierrehumbert, M. Tobis and R. Jacob, 2000: Atmospheric $\mathrm{pCO}_{2}$ sensitivity to the biological pump of the ocean, Global Biogeochem. Cycles, 14, 1219-1230.

Archer, D., and K. Johnson, 2000: A model of the iron cycle in the ocean, Global Biogeochem. Cycles, 14, 269-279.

Armstrong, R., 1999: An optimization-based model of iron-light-ammonium colimitation of nitrate uptake and phytoplankton growth, Limnol. Oceanogr., 44, 1436-1446.

Aumont, O., J. Orr, P. Monfray, G. Madec and E. Maier-Reimer, 1999: Nutrient trapping in the equatorial Pacific: The ocean circulation solution, Global Biogeochem. Cycles, 13, $351-369$.

Bacon, M., and R. Anderson, 1982: Distribution of Thorium isotopes between dissolved and particulate forms in the deep sea, $J$ Geophys. Res., 87, 2045-2056.

Boyd, P., A. Watson, C. Law and et al., 2000: A mesoscale phytoplankton bloom in the polar Southern Ocean stimulated by iron fertilization, Nature, 407, 695-702.

Boye, M., C. van den Berg, J. de Jong, H. Leach, P. Croot and H. de Baar, 2001: Organic complexation of iron in the Southern Ocean, Deep-Sea Res. I, 48, 1477-1497.

Boyle, E., 1997: What controls dissolved iron concentrations in the world ocean? - a comment, Mar. Chem., 57, 163-167.

Broecker, W., J. Lynch-Stieglitz, D. Archer, M. Hoffmann, E. Maier-Reimer, O. Marchal, T. Stocker and N. Gruber, 1999: How strong is the Harvardton-Bear constraint?, Global Biogeochem. Cycles, 13, 817-820.

Broecker, W., and T. Peng, 1986: Carbon cycle: 1985 glacial to interglacial changes in the operation of the global carbon cycle, Radiocarbon, 28, 309-327.

Broecker, W., and T. Peng, 1987: The role of $\mathrm{CaCO}_{3}$ compensation in the glacial to inter- 
glacial atmospheric $\mathrm{CO}_{2}$ change, Global Biogeochem. Cycles, 1, 15-29.

Bruland, K. W., K. J. Orians and J. P. Cowen, 1994: Reactive trace metals in the stratified central North Pacific, Geochem. Cosmochim. Acta, 58, 3171-3182.

Christian, J., M. Verschell, R. Murtugudde, A. Busalacchi and C. McClain, 2002: Biogeochemical modelling of the tropical Pacific Ocean II: Iron biogeochemistry, Deep-Sea Res. II, 49, 545-565.

Coale, K., K. Johnson, K. Buesseler and S. Group, 2002: SOFeX: Southern Ocean Iron Experiments. Overview and Experimental Design, $A G U$ Abstract.

Coale, K., S. Fitzwater, R. Gordon, K. Johnson and R. Barber, 1996: Control of community growth and export production by upwelled iron in the equatorial Pacific Ocean, Nature, 379, 621-624.

Cochran, J., K.Buesseler, M. Bacon and H. Livingston, 1993: Thorium isotopes as indicators of particle dynamics in the upper ocean: Results from the JGOFS North Atlantic Bloom Experiment, Deep-Sea Res. I, 40, 1569-1595.

Conkright, M., S. Levitus and T. Boyer, 1994: NOAA Atlas Series, chapter World Ocean Atlas 1994, Volume 1 : Nutrients, U.S. Department of Commerce.

de Baar, H. J., J. T. de Jong, R. F. Nolting, K. R. Timmermans, M. A. van Leeuwe, U. Bathmann, M. R. van der Loeff and J. Sildam, 1999: Low dissolved Fe and the absence of diatom blooms in remote Pacific waters of the Southern Ocean, Mar. Chem., 66, 1-34. de Jong, J., J. den Das, U. Bathmann, M. Stoll, G. Kattner, R. Nolting and H. de Baar, 1998: Dissolved iron at subnanomolar levels in the Southern Ocean as determined by ship-board analysis, Anal. Chim. Acta, 377, 113-124.

Duce, R., and N. Tindale, 1991: Atmospheric transport of iron and its deposition in the ocean, Limnol. Oceanogr., 36, 1715-1726.

Dutay, J., J. Bullister, S. Doney and O. Members, 2002: Evaluation of ocean model ventilation with CFC-11: comparison of 13 global ocean models, Ocean Modelling, 4, 89-120.

Dutkiewicz, S., M. Follows, J. Marshall and W. Gregg, 2001: Interannual variability of phytoplankton abundances in the North Atlantic, Deep-Sea Res. II, 48, 2,323-2,344.

Fitzwater, S., K. Coale, R. Gordon, K. Johnson and M. Ondrusek, 1996: Iron deficiency and phytoplankton growth in the equatorial Pacific, Deep-Sea Res. II, 43, 995-1015. 
Follows, M., T. Ito and J. Marotzke, 2002: The wind-driven subtropical gyres and atmospheric $\mathrm{pCO}_{2}$, Global Biogeochem. Cycles, 16, 1113.

Francois, R., M. Altabet, E. Yu, D. Sigman, M. Bacon, M. Frank, G. Bohrmann, G. Bareille and L. Labeyrie, 1997: Contribution of Southern Ocean surface-water stratification to low atmospheric $\mathrm{CO}_{2}$ concentrations during the last glacial period, Nature, 389, 929-935.

Fridlind, A., and M. Jacobsen, 2000: A study of gas-aerosol equilibrium and aerosol pH in the remote marine boundary layer during the First Aerosol Characterization Experiment (ACE 1), J. Geophys. Res., 105, 17325-17340.

Fung, I., S. Meyn, I. Tegen, S. Doney, J. John and J. Bishop, 2000: Iron supply and fixation in the upper ocean, Global Biogeochem. Cycles, 14, 281-295.

Gao, Y., Y. Kaufman, D. Tanre, D. Kolber and P. Falkowski, 2001: Seasonal distribution of Aeolian iron fluxes to the global ocean, Geophys. Res. Lett., 28, 29-32.

Gent, P., and J. McWilliams, 1990: Isopycnal mixing in ocean circulation models, J. Phys. Oceanogr., 22, 626-651.

Gledhill, M., and C. VandenBerg, 1994: Determination of complexation of iron (III) with natural organic complexing ligands in seawater using cathodic stripping voltammetry, Mar. Chem., 47, 41-54.

Gledhill, M., C. VandenBerg, R. Nolting and K. Timmermans, 1998: Variability in the speciation of iron in the northern North Sea, Mar. Chem., 59, 283-300.

Gruber, N., and J. Sarmiento, 1997: Global patterns of marine nitrogen fixation and denitrification, Global Biogeochem. Cycles, 11, 235-266.

Honeyman, B., L. Balistrieri and J. Murray, 1988: Oceanic trace metal scavenging and the importance of particle concentration, Deep-Sea Res. I, 35, 227-246.

Honeyman, B., and P. Santschi, 1989: A Brownian-pumping model for trace metal scavenging: evidence from Th isotopes, J. Mar. Res., 47, 951-992.

Hudson, R., and F. Morel, 1990: Iron transport in marine phytoplankton:kinetics of medium and cellular coordination reactions, Limnol. Oceanogr., 35, 1002-1020.

Hutchins, D., and K. Bruland, 1998: Iron-limited diatom growth and Si:N uptake ratios in a coastal upwelling regime, Nature, 393, 561-564.

Jickells, T., and L. Spokes, 2001: The Biogeochemistry of Iron in Seawater, chapter Atmo- 
spheric Iron Inputs to the Oceans, pp. 85-121, SCOR/IUPAC Series, J. Wiley.

Johnson, K., R. Gordon and K. Coale, 1997: What controls dissolved iron concentrations in the world ocean?, Mar. Chem., 57, 137-161.

Karsten, R., H. Jones and J. Marshall, 2002: The role of eddy transfer in setting the stratification and transport of a Circumpolar Current, J. Phys. Oceangr., 32, 39-54.

Karsten, R., and J. Marshall, 2002: Constructing the residual circulation of the ACC from observations, J. Phys. Oceangr., 32, 3315-3327.

Keeling, R., and M. Visbeck, 2001: Antarctic stratification and glacial $\mathrm{CO}_{2}$, Nature, 412, $605-606$.

Kumar, N., R. Anderson, R. Mortlock, P. Froelich, P. Kubik, B. Dittrich-Hannen and M. Suter, 1995: Increased biological productivity and export production in the glacial Southern Ocean, Nature, 378, 675-680.

Lam, P., and S. Chisholm, 2002: Iron Fertilization of the Oceans: Reconciling Commercial Claims with Published Models, White Paper., pp. 1-5.

Lefévre, N., and A. J. Watson, 1999: Modeling the geochemical cycle of iron in the oceans and its impact on atmospheric $\mathrm{CO}_{2}$ concentrations, Global Biogeochem. Cycles, 13, 727736.

Leonard, C., C. McClain, R. Murtugudde, E. Hofmann and J. L.W. Harding, 1999: An ironbased ecosystem model of the central equatorial Pacific, J.Geophys. Res., 104, 1325-1341.

Levitus, S., and T. Boyer, 1994: NOAA Atlas Series, chapter World Ocean Atlas 1994, Volume 4 : Temperature, U.S. Department of Commerce.

Levitus, S., R. Burgett and T. Boyer, 1994: NOAA Atlas Series, chapter World Ocean Atlas 1994, Volume 1 : Salinity, U.S. Department of Commerce.

Liu, X., and F. Millero, 2002: The solubility of iron in seawater, Mar. Chem., 77, 43-54.

Macrellis, H., C. Trick, E. Rue, G. Smith and K. Bruland, 2001: Collection and detection of natural iron-binding ligands from seawater, Mar. Chem., 76, 175-187.

Mahowald, N., K. Kohfeld, M. Hansson, Y. Balkanski, S. Harrison, I. Prentice, M. Schulz and H. Rodhe, 1999: Dust sources and deposition during the last glacial maximum and current climate: A comparison of model results with paleodata from ice cores and marine sediments, J.Geophys. Res., 104, 15895-15916. 
Mahowald, N., C. Luo, J. del Corral and C. Zender, 2003: Interannual variability in atmospheric mineral aerosols from a 22-year model simulation and observational data, $J$. Geophys. Res., in press.

Marshall, J., A. Adcroft, C. Hill, L. Perelman and C. Heisey, 1997a: A finite-volume, incompressible Navier Stoke model for studies of the ocean on parallel computers, $J$. Geophys. Res., 102, 5753-5766.

Marshall, J., C. Hill, L. Perelman and A. Adcroft, 1997b: Hydrostatic, quasi-hydrostatic, and nonhydrostatic ocean modeling, J. Geophys. Res., 102, 5733-5752.

Marshall, J., H. Jones, R. Karsten and R. Wardle, 2002: Can eddies set ocean stratification?, J. Phys. Oceanogr., 32, 26-38.

Martin, J., 1990: Glacial-Interglacial $\mathrm{CO}_{2}$ change: The iron hypothesis, Paleo., 5, 1-13.

Martin, J., G. Knauer, D. Karl and W. Broenkow, 1987: Iron deficiency and phytoplankton growth in the equatorial Pacific, Deep-Sea Res. II, 34, 267-285.

Martin, J., K. Coale, K. Johnson and et al., 1994: Testing the iron hypothesis in ecosystems of the equatorial Pacific Ocean, Nature, 371, 123-129.

McKinley, G., M. Follows and J. Marshall, 2000: Interannual variability of oxygen fluxes in the North Atlantic, Geophys. Res. Lett., 27, 2933-2936.

Measures, C., and S. Vink, 2001: Dissolved Fe in the upper waters of the Pacific sector of the Southern Ocean, Deep-Sea Res. I, 48, 3913-3941.

Members, C., 1988: Climatic changes of the last 18,000 years: Observations and model simulations, Science, 241, 1043-1052.

Miller, C., B. Frost, P. Wheeler, M. Landry, N. Welschmeyer and T. Powell, 1991: Ecological dynamics in the subarctic Pacific, a possibly iron- limited ecosystem, Limnol. Oceanogr., 36, 1600-1615.

Moore, K., S. Doney, D. Glover and I. Fung, 2002: Iron cycling and nutrient-limitation patterns in surface waters of the World Ocean, Deep-Sea Res. II, 49, 463-507.

Najjar, R., J. Sarmiento and J. Toggweiler, 1992: Downward transport and fate of organic matter in the ocean: simulations with a general circulation model, Global Biogeochem. Cycles, 6, 45-76.

Nishioka, J., S. Takeda, C. Wong and W. Johnson, 2001: Size-fractionated iron concen- 
trations in the northeast Pacific Ocean: distribution of soluble and small colloidal iron, Mar. Chem., 74, 157-179.

Nolting, R., L. Gerringa, M. Swagerman, K. Timmermans and H. de Baar, 1998: Fe (III) speciation in the high nutrient, low chlorophyll Pacific region of the Southern Ocean, Mar. Chem., 62, 335-352.

North, G., R. Cahalan and J. Coakley, 1981: Energy balance climate models, Rev. of Geophys. and Space Phys., 19, 91-121.

Obata, H., H. Karatani and E. Nakayama, 1993: Automated determination of iron in seawater by chelating resin concentration and chemiluminescence detection, Anal. Chem., 65, 1524-1528.

Orr, J., 2002: Global Ocean Storage of Anthropogenic Carbon: Final Report, pp. 1-129, EC Environment and Climate Programme,.

Paltridge, G., and C. Platt, 1976: Radiative Processes in Meteorology and Climatology, Elsevier, Amsterdam.

Petit, J., R. Rouzel, D. Raynaud and et al., 1999: Climate and atmospheric history of the past 420,000 years from the Vostok ice core, Antarctica, Nature, 399, 429-436.

Powell, R., and J. Donat, 2001: Organic complexation and speciation of iron in the South and Equatorial Atlantic, Deep-Sea Res. II, 48, 2877-2893.

Price, N., L. Anderson and F. Morel, 1994: The equatorial Pacific Ocean: Grazer-controlled phytoplankton populations in an iron-limited ecosystem, Limnol. Oceanogr., 39, 520-534.

Rea, D., 1994: The paleoclimatic record provided by eolian deposition in the deep sea: the geologic history of wind, Rev. of Geophys., 32, 159-195.

Rue, E., and K. Bruland, 1995: Complexation of iron(III) by natural organic ligands in the Central North Pacific as determined by a new competitive ligand equilibration/adsorptive cathodic stripping voltammetric method, Mar. Chem., 50, 117-138.

Rue, E., and K. Bruland, 1997: The role of organic complexation on ambient iron chemistry in the equatorial Pacific ocean and the response of a mesoscale iron addition experiment, Limnol. Oceanogr., 42, 901-910.

Sarmiento, J., and J. Orr, 1991: Three-dimensional simulations of the impact of Southern Ocean nutrient depletion on atmospheric $\mathrm{CO}_{2}$ and ocean chemistry, Limnol. Oceanogr., 
36(1928-1950).

Sedwick, P., G. DiTullio and D. Mackey, 2000: Iron and manganese in the Ross Sea, Antarctica: Seasonal iron limitation in Antarctic shelf waters, JGR, 105, 11,321-11,336.

Siefert, R., A. Johansen and M. Hoffmann, 1999: Chemical characterization of ambient aerosol collected during the southwest monsoon and inter-monsoon seasons over the Arabian Sea: Labile-Fe(II) and other trace metals, J. Geophys. Res., 104, 3511-3526.

Sloyan, B., and S. Rintoul, 2001: Circulation, renewal, and modification of Antarctic mode and intermediate water, J. Phys. Oceangr., 31, 1005-1030.

Sohrin, Y., S. Iwamoto, M. Matsui, H. Obata, E. Nakayama, K. Suzuki, N. Handa and M. Ishii, 2000: The distribution of Fe in the Australian sector of the Southern Ocean, Deep-Sea Res. I, 47, 55-84.

Spokes, L., and T. Jickells, 1996: Factors controlling the solubility of aerosol trace metals in the atmosphere and on mixing into seawater, Aquat. Geochem., 1, 355-374.

Sunda, W., and S. Huntsman, 1995: Iron uptake and growth limitation in oceanic and coastal phytoplankton, Mar. Chem., 50, 189-206.

Takeda, S., 1998: Influence of iron availability on nutrient consumption ratio of diatoms in oceanic waters, Nature, 393, 774-777.

Takeda, S., A. Kamatani and K. Kawanobe, 1995: Effects of nitrogen and iron enrichments on phytoplantkon communities in the northwestern Indian Ocean, Mar. Chem., 50, 229241.

Tegen, I., and I. Fung, 1995: Contribution to the atmospheric mineral aerosol load from land surface modification, J. Geophys. Res., 100, 18707-18726.

van den Berg, C., 1995: Evidence for organic complexation of iron in seawater, Mar. Chem., 50, 139-157.

Watson, A., D. Bakker, A. Ridgwell, P. Boyd and C. Law, 2000: Effect of Iron Supply on Southern Ocean $\mathrm{CO}_{2}$ uptake and implications for glacial atmospheric $\mathrm{Co}_{2}$, Nature, 407, 730-733.

Wells, M., N. Zorkin and A. Lewis, 1983: The role of colloid chemistry in providing a source of iron to phytoplankton, J. Mar. Res., 41, 731-746.

Willey, J., R. Kieber, K. Williams, J. Crozier, S. Skrabal and G. Avery, 2000: Temporal 
variability of iron speciation in coastal rainwater, J. Atmos. Chem., 37, 185-205.

Witter, A., D. Hutchins, A. Butler and G. Luther, 2000: Determination of conditional stability constants and kinetic constants for strong model Fe-binding ligands in seawater, Mar. Chem., 69, 1-17.

Witter, A., and G. Luther, 1998: Variation in Fe(III)-organic complexation with depth in the Northwestern Atlantic Ocean as determined using a kinetic approach, Mar. Chem., 62, 241-248.

Wu, J., E. Boyle, W. Sunda and L. Wen, 2001: Soluble and colloidal iron in the oligotrophic North Atlantic and North Pacific, Science, 293, 847-849.

Wu, J., and G. Luther, 1994: Size-fractionated iron concentrations in the water column of the western North Atlantic Ocean, Limnol. Oceanogr., 39, 1119-1129.

Wu, J., and G. Luther, 1995: Complexation of Fe(III) by natural organic ligands in the Northwest Atlantic Ocean by a competitive ligand equilibration method and kinetic approach, Mar. Chem., 50, 159-177.

Yamanaka, Y., and E. Tajika, 1997: Role of dissolved organic matter in the marine biogeochemical cycle: Studies using an ocean biogeochemical general circulation-model, Global Biogeochem. Cycles, 4, 599-612. 